Uma abordagem para interoperabilização de dados de acelerômetros em aplicações interativas

\author{
Jorge Rodrigues Carvalho
}





\title{
Uma abordagem para interoperabilização de dados de acelerômetros em aplicações interativas
}

\author{
Jorge Rodrigues Carvalho
}

Orientador: Prof. Dr. Rudinei Goularte

Dissertação apresentada ao Instituto de Ciências Matemáticas e de Computação - ICMC-USP, como parte dos requisitos para obtenção do título de Mestre em Ciências - Ciências de Computação e Matemática Computacional. VERSÃO REVISADA

\author{
USP - São Carlos \\ Maio/2013
}


Ficha catalográfica elaborada pela Biblioteca Prof. Achille Bassi e Seção Técnica de Informática, ICMC/USP, com os dados fornecidos pelo(a) autor(a)

C331 Carvalho, Jorge Rodrigues

C331a Uma abordagem para interoperabilização de dados de acelerômetros em aplicações interativas / Jorge Rodrigues Carvalho; orientador Rudinei Goularte. -São Carlos, 2013.

$70 \mathrm{p}$.

Dissertação (Mestrado - Programa de Pós-Graduação em Ciências de Computação e Matemática Computacional) -- Instituto de Ciências Matemáticas e de Computação, Universidade de São Paulo, 2013.

1. Engenharia de Documentos. 2. Acelerômetros. 3. Reconhecimento Gestual. I. Goularte, Rudinei, orient. II. Título. 
"I have never let my schooling interfere with my education." Mark Twain "Knowledge is learning something every day. Wisdom is letting go of something every day." Provérbio Zen 



\section{Agradecimentos}

Apenas gostaria de agradecer à Vida, o Universo e Tudo Mais. 


maneiras menos intrusivas (gestos, voz e escrita baseada em tinta eletrônica, por exemplo). Com o aumento da popularidade de dispositivos equipados com sensores de aceleração, os desenvolvedores agora dispõem de um novo dispositivo que pode ser utilizado para prover interação entre usuários e diferentes aplicações, como por exemplo as que se encontram presentes em ambientes de TV interativos. Assim, aplicações que fazem uso de acelerômetros vêm sendo desenvolvidas para situações específicas, e suas implementações e formatos de dados manipulados são dependentes do domínio para o qual foram projetados. Este trabalho apresenta um modelo para a formalização do modo como esses dados podem ser manipulados, por meio de uma abordagem genérica e extensível. Além disso, o modelo permite a descrição de regras para agregação de valor a estes dados por meio da adição de significados. Isto é obtido com a proposta de uma arquitetura em camadas que possibilita a estruturação e compartilhamento desses dados de modo flexível. Três protótipos foram implementados na linguagem de programação Java, fazendo-se uso dessa arquitetura e de uma API desenvolvida para facilitar o uso do modelo. Essas implementações demonstram a viabilidade do modelo proposto como solução para a questão da interoperabilidade nos cenários ilustrados, e para a extensibilidade dos dados, nos casos em que uma mudança de requisitos faz-se necessária.

Palavras Chaves: Engenharia de Documentos, Acelerômetros, Reconhecimento Gestual 


port user interaction with applications in less intrusive ways (gestures, voice and writing based on electronic ink, for instance). With the increasing popularity of accelerometers, developers now have another tool that can be used to provide interaction between users and different applications, such as interactive TV environments. However, applications that make use of accelerometers are currently being developed for specific situations, and their implementations and handled documents are also dependent on the domain for which they were designed. This work aims to propose a model to formalize how the accelerometer data may be handled in a generic way. In addition, the model enables the description of rules to aggregate value to these data through the addition of meanings. This is done by proposing a layered architecture to structure and share data in a flexible way. Three prototypes were implemented in the Java programming language, making use of this architecture and an API designed to facilitate the model implementation. These prototypes demonstrate the feasibility of the model proposed as a solution to the issue of interoperability in the scenarios illustrated, and the problem of data extensibility, whenever a change of requirements poses necessary.

Keywords: Document Engineering, Accelerometers, Gesture Recognition 

$\begin{array}{lr}\text { Agradecimentos } & 7\end{array}$

$\begin{array}{ll}\text { Resumo } & 9\end{array}$

Abstract $\quad$ i

1 Introdução 1

1.1 Trabalhos Relacionados . . . . . . . . . . . . . . . . . . . . . 3

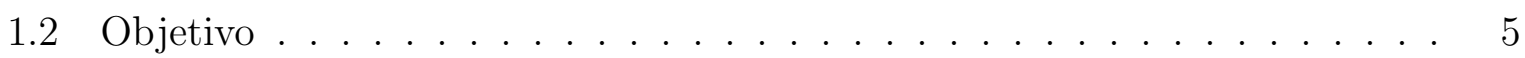

1.3 Estrutura do Texto . . . . . . . . . . . . . . . . . 6

2 Conceitos Relacionados $\quad 7$

2.1 Computação Ubíqua e Interfaces Naturais . . . . . . . . . . . . . . . . 7

2.1.1 Interfaces Naturais . . . . . . . . . . . . . . . . . . . . . 10

2.2 Documentos XML e Padrões W3C . . . . . . . . . . . . . . . . . 13

2.2.1 W3C XML Schemas . . . . . . . . . . . . . . 15

2.2.1.1 Espaços de Nomes e a Tag Schema . . . . . . . . . . . . 16

2.2.1.2 Declaração de Elementos . . . . . . . . . . . . . . . . . . . 17

2.2.1.3 Declaração de Atributos . . . . . . . . . . . . . . . . . . . 17

2.2.1.4 Definição de Tipos . . . . . . . . . . . . . . . . . . . . 18

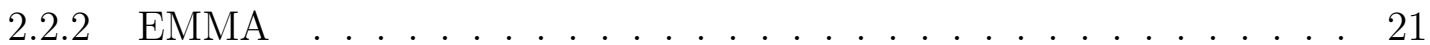

2.3 Considerações Finais . . . . . . . . . . . . . . . . . . . . . . . 25

3 Arquitetura e Modelo Propostos 27

3.1 Arquitetura . . . . . . . . . . . . . . . . . . 27

3.1.1 Abstração de Acelerômetros . . . . . . . . . . . . . . . . . . . . 29

3.1 .2 Reconhecimento Gestual . . . . . . . . . . . . . . . . 31

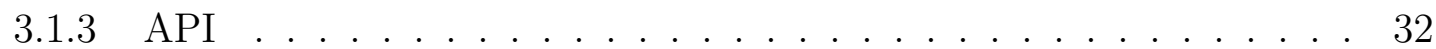

3.2 Modelo . . . . . . . . . . . . . . . . . . . . . 33

3.2 .1 O Elemento 'data' . . . . . . . . . . . . . . . 35

3.2 .2 O Elemento 'meaning' . . . . . . . . . . . . . . . . 37

3.2 .3 Modelo Auxiliar . . . . . . . . . . . . . . . . . . . . . 39

3.3 MeaningsAPI .......................... 41 
3.3.1 Documento Gerado e Integração com EMMA . . . . . . . . . . . . . 44

3.4 Considerações Finais . . . . . . . . . . . . . . . . . . . . . 46

4 Cenários e Exemplos de Uso $\quad 47$

4.1 Troca de Área de Trabalho . . . . . . . . . . . . . . . . . . . . 47

4.2 Genius . . . . . . . . . . . . . . . . . . . . 53

4.3 Porta-Retratos . . . . . . . . . . . . . . . . 56

4.4 Considerações Finais . . . . . . . . . . . . . . . . . . . . 60

5 Conclusão $\quad 61$

5.1 Resultados Obtidos . . . . . . . . . . . . . . . . . . . . 62

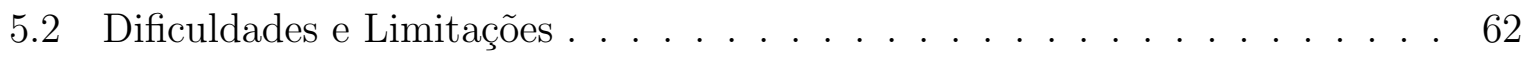

5.3 Trabalhos Futuros . . . . . . . . . . . . . . . . . . 63

$\begin{array}{ll}\text { Referências } & 64\end{array}$ 


\section{Lista de Figuras}

2.1 Dispositivos de computação ubíqua por escala de tamanho: um (a) tab (inch-scale), um (b) tablet PC (foot-scale), uma (c) lousa eletrônica e um (d) mimio (Cattelan et al., 2003) . . . . . . . . . . . . . . . . 8

2.2 Evolução das interfaces com o usuário. Adaptado de (De los Reyes, 2009) . 10

2.3 Navegação em mapa por meio da OUI Gummi, da Sony (Schwesig et al., 2004) . . . . . . . . . . . . . . . . . . . 13

3.1 Arquitetura proposta . . . . . . . . . . . . . . . . . . . . 28

3.2 Dados brutos de aceleração nos eixos X, Y e Z de um acelerômetro . . . . 29

3.3 Eixos do acelerômetro . . . . . . . . . . . . . . . . . . . 30

3.4 Diagrama de classes UML para o relacionamento entre modelos . . . . . . 33

3.5 Diagrama de Classes UML para o relacionamento entre classes da API MeaningsAPI . . . . . . . . . . . . . . . . . 43

4.1 Disposição padrão das áreas de trabalho no sistema operacional Ubuntu 12.04 LTS . . . . . . . . . . . . . . . . . . . . . . . . 4 48

4.2 Resultado do processo de transição da área de trabalho . . . . . . . . . . . 49

4.3 Diagrama representando todos os componentes de uma aplicação que faça uso da API MeaningsAPI . . . . . . . . . . . . . . . . . . 51

4.4 Usuário executando reconhecimento gestual . . . . . . . . . . . . . 53

4.5 Genius, originalmente "Simon" na versão americana . . . . . . . . . . . . . 54

4.6 Genius sendo executado normalmente com o botão vermelho aceso (esquerda). Uma mensagem indicando um erro na sequencia inserida (direita) 55

4.7 Tela de abertura da aplicação Porta-Retratos . . . . . . . . . . . . . . . . . 59

4.8 Tela principal da aplicação Porta-Retratos . . . . . . . . . . . . . . . . 59 



\section{Lista de Listagens}

2.1 Exemplo de documento XML . . . . . . . . . . . . . . . . . . . . . . . 14

2.2 Estrutura do Esquema XML . . . . . . . . . . . . . . . . . . . . . . 15

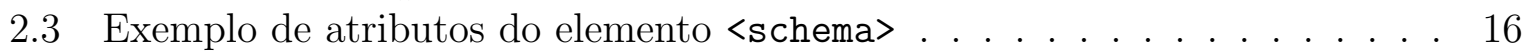

2.4 Exemplo de definição de um elemento . . . . . . . . . . . . . . . . . . . . . 17

2.5 Exemplo de definição e declaração de um atributo . . . . . . . . . . . . . . 18

2.6 Exemplo de instanciação de um atributo . . . . . . . . . . . . . . 18

2.7 Exemplo de tipo simples com conjunto específico de valores . . . . . . . . . 18

2.8 Exemplo de definição de elemento complexo . . . . . . . . . . . . . . . 20

2.9 Exemplo de instânciação de elemento complexo . . . . . . . . . . . . . . . 20

2.10 Exemplo de declaração e definição de elemento e tipo abstrato . . . . . . . 20

2.11 Exemplo de instanciação de elemento com tipo abstrato . . . . . . . . . . . 21

2.12 Exemplo de documento EMMA . . . . . . . . . . . . . . . . 22

3.1 Trecho de código exemplificando o uso do método accelerationReceived 30

3.2 Trecho de código exemplificando o uso do método gestureReceived . . . . 32

3.3 Declaração do elementos "data" e "meaning" . . . . . . . . . . . . . . . . 34

3.4 Definição do tipo complexo sensorDataType . . . . . . . . . . . . . . 35

3.5 Definição dos tipos simples accelerationValueType e gravityType . . . . . . 36

3.6 Definição dos tipos complexo meaningType . . . . . . . . . . . . . . . . 37

3.7 Definição do tipo complexo contentType . . . . . . . . . . . . . . . 38

3.8 Definição do tipo concreto directions Type baseado no tipo abstrato meaningType . . . . . . . . . . . . . . . . . . . 39

3.9 Definição do tipo concreto shapesType baseado no tipo abstrato meaningType 41

3.10 Atributos da classe Meaning . . . . . . . . . . . . . . . . . . . 43

3.11 Exemplo de um documento de instância . . . . . . . . . . . . . . . . . 44

4.1 Trecho de código ilustrando o uso do método createGesture . . . . . . . . . 50

4.2 Trecho de código com dois casos de combinações de teclas. Para para case 0 a combinação CTRL+ALT+LEFT é simulada. Para case 1 é simulado CTRL+ALT+RIGHT . . . . . . . . . . . . . . . . . . 52

4.3 Definição do tipo personalizado simonType . . . . . . . . . . . . . . 55

4.4 Documento HTML responsável pela execução do Porta-Retratos . . . . . . 56

4.5 Definição do tipo personalizado showcaseType . . . . . . . . . . . . . 57 



\section{Lista de Siglas}

AMR - Adaptive Multi-Rate

ANN - Artificial Neural Networks

API - Application Programming Interface

C\&A - Captura e Acesso

CAPPA - Context-Aware Peer-to-Peer Architecture

CAPPAS - Context-Aware Peer-to-Peer Architecture Service

CLI - Command Line Interfaces

DOM - Document Object Model

DTD - Document Type Definition

DTW - Dynamic Time Warping

EMMA - Extensible MultiModal Annotation markup language

GPS - Global Positioning System

GUI - Graphical User Interfaces

HID - Human Interface Device

HMM - Hidden Markov Models

HTML - HyperText Markup Language

HTTP - HyperText Transfer Protocol

JAWT - Java APIs for Bluetooth Wireless Technology

JSR-82 - Java Specification Request $n^{\circ}$ 82

Lariisa - Laboratoire Réseaux Intelligence Intégration Santé Aplication 
LTS - Long-Term Support

MIME - Multipurpose Internet Mail Extensions

NCL - Nested Context Language

NUI - Natural User Interfaces

OUI - Organic User Interfaces

PC - Personal Computer

PHP - PHP: Hypertext Preprocessor

POJO - Plain Old Java Objects

RA - Realidade Aumentada

SBTVD - Sistema Brasileiro de Televisão Digital

TUI - Tangible User Interfaces

TVDI - Televisão Digital Interativa

UML - Unified Modeling Language

URI - Uniform Resource Identifier

W3C - World Wide Web Consortium

XML - Extensible Markup Language

XSLT - eXtensible Stylesheet Language for Transformation 


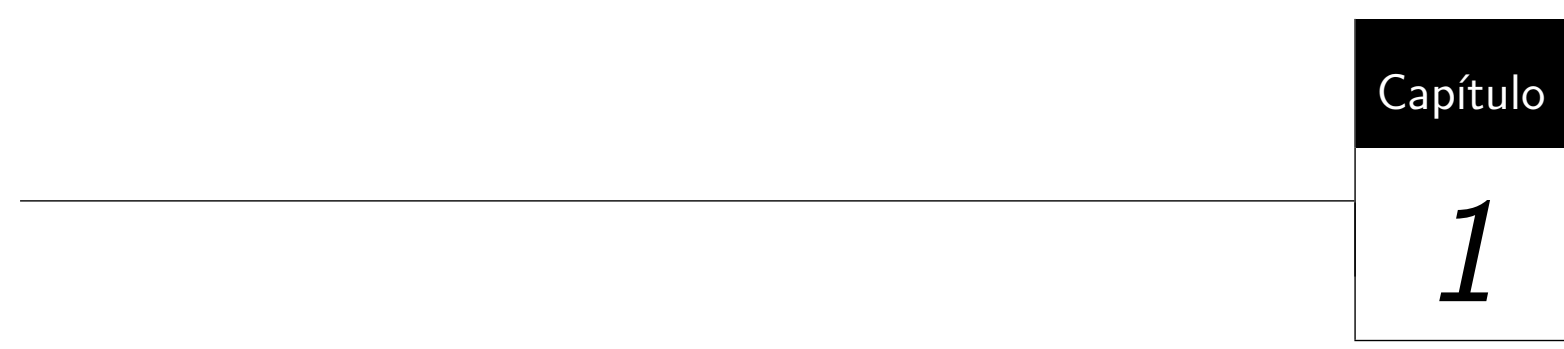

\section{Introdução}

A proliferação de aplicações multimídia interativas é uma realidade em nosso cotidiano. A evolução da área de Tecnologia da Informação permitiu a criação de promissoras tecnologias, novos meios de interação e formatos de documentos e protocolos, culminando com o desenvolvimento de aplicações capazes de produzir e lidar com o conteúdo digital que circula atualmente na Internet, em sua maioria, explorando inovações em interavidade. Um exemplo disso é o repositório de vídeos on-line do Google, o Youtube ${ }^{1}$, que permite que vídeos possam ser anotados com textos, links para outros vídeos ou páginas na Internet, legendas e até mesmo pequenos trechos de outros vídeos de maneira sobreposta.

No entanto, à medida que novos tipos de mídia são agregados e manipulados conjuntamente, níveis de complexidade também são adicionados. Tais aplicações interativas, já comuns em nosso cotidiano, em sua maioria ainda fazem uso do antigo paradigma monitor-teclado-mouse. Contudo, nota-se que gradualmente novos modos de interação vêm sendo investigados e desenvolvidos tanto pela indústria quanto pelo meio acadêmico, possibilitando novas maneiras de manipular este crescente conjunto de informações, que demanda métodos mais intuitivos que facilitem as tarefas dos usuários.

O antigo paradigma monitor-teclado-mouse, há muito utilizado pelo mercado, gradualmente cede seu lugar às interfaces naturais. Por exemplo, em um ambiente doméstico provido de um aparelho televisor, é comum o principal dispositivo de entrada ser um controle remoto. Devido às características diversas que um controle remoto e um tecla-

\footnotetext{
${ }^{1}$ http://www.youtube.com/ - Acessado em 11/fev/2013
} 
do/mouse de computador pessoal apresentam entre si, mecanismos e aplicações que possibilitem a interação com cada dispositivo são inevitavelmente diferentes. No entanto, de modo similar aos tradicionais ambientes computacionais, interfaces naturais também podem ser utilizadas para interagir com dispositivos televisores, bem como outros aparelhos, domésticos ou não. Antes limitada aos mainframes e posteriormente aos computadores pessoais, atualmente a computação está presente em diversos dispositivos e nos auxilia na execução de muitas de nossas tarefas diárias. Essa pervasividade da computação é descrita por Weiser (Weiser, 1999) ao lançar as bases para a Computação Ubíqua, definida como a computação que se mescla ao cotidiano, tão intrinsecamente a ponto de desaparecer e não ser mais conscientemente notada. O antigo paradigma vai contra a esta característica, ao exigir o uso de dispositivos de entrada específicos, que em nada são parecidos com os instrumentos que utilizamos para executar nossas tarefas cotidianas. Assim, um novo modo de interagir faz-se necessário.

A pesquisa em interfaces naturais investiga o uso de dispositivos não-tradicionais de modo a permitir a interação dos usuários de um modo menos intrusivo, tornando a interação homem-máquina semelhante às interações feitas pelas pessoas em suas tarefas cotidianas (Abowd e Mynatt, 2000).

A literatura reporta várias modalidades de interfaces naturais com o usuário, como voz, escrita e baseadas em caneta - ou combinações entre elas, como no caso das interfaces multimodais (Oviatt, 2007). Com a queda nos preços e consequente popularização de dispositivos de entrada equipados com sensores, como acelerômetros, os desenvolvedores agora podem implementar várias opções de interação com suas aplicações. Sensores de aceleração se tornaram muito populares nos últimos anos, e podem ser encontrados em automóveis (Hernandez, 2005), aparelhos domésticos (Pan et al., 2010), dispositivos portáteis (Khan et al., 2010) (por exemplo, smartphones) e, mais recentemente, em consoles para jogos como o Nintendo $\mathrm{Wii}^{2}$. Prevê-se que no futuro a maioria dos dispositivos de entrada serão equipados com sensores de movimentos, e serão operados por combinações de comandos associados a gestos. Estes últimos sendo identificados a partir de sinais emitidos por sensores, como acelerômetros.

Essencialmente, acelerômetros transmitem o valor numérico absoluto da aceleração exercida em um ou mais eixos, por um certo movimento durante um determinado tempo (Ravi et al., 2005). Esses valores podem ser utilizados de maneira direta (por exemplo, a partir de um certo valor alguma ação pode ser executada) ou indireta (por exemplo, a variação da aceleração durante um determinado tempo pode ser utilizada para definir um gesto), por meio do uso de técnicas específicas, como algoritmos de reconhecimento de padrões (Bishop, 2006). No entanto, pode-se observar que aplicações disponíveis no

\footnotetext{
${ }^{2}$ http://www.nintendo.com/wii. Acessado em 28/jan/2013
} 
mercado e reportadas na literatura (Kela et al., 2006; Kim et al., 2004; Pan et al., 2010), que fazem uso de acelerômetros, são projetadas para situações específicas e, além disso, a maneira como elas são implementadas e como manipulam os seus formatos de documentos é dependente do domínio para o qual elas foram projetadas.

Um estudo mais aprofundado da literatura (Aoki et al., 2010; Chang et al., 2009; Gurrin et al., 2010; Mugellini et al., 2009; Oliveira et al., 2009) demonstra uma falta de abordagens particulamente projetadas para encapsular os dados dos acelerômetros de modo a torná-los facilmente acessíveis para diferentes aplicações, ou seja, interoperáveis. A interoperabilidade é um fator importante para o sucesso de uma nova tecnologia (DiMario, 2006). Eventualmente haverá dados que precisarão ser transferidos entre diferentes aplicações. Simplesmente capturar e disponibilizar os dados brutos dos acelerômetros não é o bastante, pois eles por si só não têm significado útil; faz-se necessário um mecanismo que os transforme em informação útil para as aplicações, estruturando-as juntamente com significados de modo a agregar valor e prover a interoperabilidade. Até onde a literatura reporta, não existe um método aberto e estruturado que possibilite a interoperabilidade dos dados de acelerômetros associados com descritores de significados, como pode ser observado na Seção 1.1.

\subsection{Trabalhos Relacionados}

Vários estudos que fazem uso, direta ou indiretamente, de dados de acelerômetros podem ser encontrados na literatura. Na área de interfaces naturais, Gurrin et al. (Gurrin et al., 2010) propõem uma aplicação para interagir naturalmente com extensos bancos de dados multimídia por meio de gestos. Eles concentram seus estudos na análise comparativa de técnicas de interação e fazem uso de acelerômetros para executar o reconhecimento gestual. No entanto, não especificam como os dados dos acelerômetros são tratados, nem que mudanças seriam necessárias para adaptar a aplicação para outros ambientes, com dispositivos diversos.

A ferramenta WiiNote (Mugellini et al., 2009) possibilita a criação de anotações em imagens com tinta eletrônica. Todavia, o sistema não faz uso de reconhecimento gestual, apenas os dados brutos do sensor são utilizados, de um modo específico, que apenas serve para os propósito da aplicação. Objetivando executar o reconhecimento gestual, o trabalho de Schlömer et. al. (Schlömer et al., 2008) propõe uma API que trata os dados brutos dos acelerômetros de maneira a permitir a utilização de vários tipos de sensores, disponibilizando os resultados de modo orientado a eventos. Porém, ela não disponibiliza nenhum mecanismo que adicione significado a estes gestos. Este problema é discutido por Aoki et al. (Aoki et al., 2010), ao propor um método de inserção de texto com dados 
obtidos por acelerômetros por meio de reconhecimento gestual, objetivando prover uma maneira mais fácil e confortável de inserir texto em TVs Digitais Interativas (TVDI) por meio de controles remotos. No entanto, neste caso, os significados são implementados de um modo não flexível, pois não há a possibilidade de se alterar ou estender estes significados. Ainda na área de pesquisa em TVDI, Chang et al. (Chang et al., 2009) faz uso dos dados brutos obtidos por acelerômetros anexados a controles remotos, ao propor uma nova maneira de identificar usuários baseado somente no modo como os mesmo manipulam o dispositivo.

O Grupo de Trabalho em Geolocalização ${ }^{3}$ do Consórcio World Wide Web (W3C) recentemente lançou um esboço (Block e Popescu, 2011) descrevendo um trabalho em andamento que objetiva prover um meio padronizado para representar dados de movimento e orientação de dispositivos por meio da definição de eventos DOM (Document Object Model - Modelo de Objetos de Documentos). Embora isto simplifique o modo como os dados são representados, neste caso ainda não é tratado o problema de adicionar significados aos dados obtidos.

$\mathrm{Na}$ área da medicina, Oliveira et al. (Oliveira et al., 2009) implementam um protótipo que permite o monitoramento e suporte de pacientes em convalescença, ou que ainda estão sendo afetados por doenças, e que necessitam de intensa supervisão médica, por meio de dados obtidos por vários sensores equipados na casa do paciente, como acelerômetros, Sistema de Posicionamento Global (GPS ${ }^{4}$ ), termômetros, etc., utilizados para obter informações de contexto do paciente, a fim de auxiliar o diagnóstico feito por agentes de saúde.

Mais recentemente, grandes empresas como Sony e Microsoft vêm lançando produtos que possibilitam modos de interação inovadores, como pode ser observado no novo PlayStation Vita ${ }^{5}$ e no Kinect para o Xbox $360^{6}$. O primeiro combina dados de aceleração e de multi-toque para melhorar a experiência em seus jogos, já o segundo dispõe de funcionalidades baseadas em visão computacional que o permite ser utilizado não somente em um ambiente de jogos, mas em muitas outras aplicações. Ainda que diversos detalhes relativos à implementação destas ferramentas não sejam disponibilizados para o público em geral devido a razões comerciais, existem iniciativas nesse sentido, como a da Microsoft que lançou sua própria API de desenvolvimento para o Kinect ${ }^{7}$.

Nos trabalhos e estudos citados, é possível perceber um elevado grau de especificidade na maneira com que suas características são definidas. Os dados obtidos por vários tipos de

\footnotetext{
${ }^{3}$ Geolocation Working Group - http://www.w3.org/2008/geolocation/. Acessado em 24/jan/2013

${ }^{4}$ Global Positioning System

${ }^{5}$ http://us.playstation.com/psvita/ - Acessado em 25/jan/2013

${ }^{6}$ http://www.xbox.com/en-US/kinect - Acessado em 25/jan/2013

${ }^{7}$ http://www.microsoft.com/en-us/kinectforwindows/develop/ - Acessado em 25/jan/2013
} 
dispositivos, em particular os acelerômetros, são utilizados para os mais diversos fins, desde o reconhecimento gestual até a ativação de rotinas pré-estabelecidas. No entanto, nenhum destes estudos inclui detalhes mais específicos no que diz respeito a suas implementações, por exemplo as abordagens utilizadas na criação e no compartilhamento de documentos, ou como os significados relacionados com ações específicas são definidos. Tais usos e rotinas variam de trabalho para trabalho, de acordo com o problema e respectivo contexto sendo tratado, bem como a experiência dos pesquisadores envolvidos. Tal cenário dificulta a obtenção da interoperabilidade, visto que os dados produzidos por uma aplicação apenas são úteis para a aplicação em si, sendo necessária uma adaptação para que estes possam ser utilizados para outros fins.

Aplicações desenvolvidas de acordo com uma arquitetura específica, com um modelo de dados adaptado exclusivamente para o problema sendo tratado, correm o risco de perderem em interoperabilidade e, dependendo do modo como foram especificadas, também no quesito extensibilidade (DiMario, 2006). Ao se fazer uso de padrões abertos, criados e postos à prova pela comunidade, como os da W3C, aumenta-se a chance de que outros desenvolvedores compreendam o que foi feito e possam estender a aplicação, criando novos módulos e adicionando novas funcionalidades. Uma arquitetura modular, com interfaces bem definidas de acordo com boas práticas de projeto e implementação (Jones, 2000), possibilita um baixo acoplamento entre os diversos componentes da aplicação, facilitando assim o acréscimo destas novas funcionalidades. Já modelos de dados fechados e específicos, muito dificultam a comunicação entre aplicações (Chin et al., 2011), haja vista que os documentos utilizados dessa maneira devem passar por algum processo de tradução para que possam ser utilizados fora da implementação em questão.

\subsection{Objetivo}

Este trabalho tem por objetivo desenvolver uma abordagem para o tratamento de dados de acelerômetros, permitindo que os mesmos sejam manipulados e intercambiados por diversas aplicações. Isto é feito por meio da proposta de uma arquitetura em camadas que define um modelo de aquisição de dados de acelerômetros com baixo acoplamento, e um formato de dados estruturado e extensível com descritores de significados, representando os dados de tal modo que a informação seja interoperável. Com base nesse modelo, uma API foi projetada para permitir o acesso a esses dados, bem como prover os mesmos de modo estruturado e interoperável às aplicações que os solicitem. 


\subsection{Estrutura do Texto}

Este trabalho está organizado em cinco capítulos. Este capítulo introduziu a área de pesquisa, apresentando as lacunas na literatura que motivaram a realização deste trabalho. O Capítulo 2 apresenta os principais conceitos relacionados: Computação Ubíqua (grande área em que se situa este trabalho), de maneira especial tratando da sub-área de Interfaces Naturais; padrões abertos criados pela comunidade e recomendados pela W3C, utilizados como base para a abordagem desenvolvida neste trabalho. No Capítulo 3 o modelo de dados propriamente dito é descrito, juntamente com seus usos e a arquitetura em que se insere. O Capítulo 4 contém a descrição das ferramentas e bibliotecas utilizadas pelos protótipos que fazem uso desta abordagem, bem como uma descrição sucinta dos mesmos e da maneira como eles fazem uso das contribuições deste trabalho. O Capítulo 5 apresenta as contribuições, bem como as conclusões a que se chegou com este projeto. Por fim, são listadas as referências bibliográficas utilizadas ao longo deste documento. 


\section{Conceitos Relacionados}

\subsection{Computação Ubíqua e Interfaces Naturais}

Segundo Marc Weiser (Weiser, 1999), criador do termo Computação Ubíqua, uma aplicação é considerada ubíqua quando é utilizada de modo transparente pelo usuário, por estar embutida (onipresentemente) no ambiente. Ele destaca que as tecnologias mais profundas são aquelas que desaparecem da percepção do usuário, devido à naturalidade da interação das pessoas com essas tecnologias. Weiser vislumbrou que, no futuro, computadores habitariam os mais triviais objetos: etiquetas de roupas, xícaras de café, interruptores de luz, canetas, etc., de modo invisível para o usuário. Com base nesta visão, Weiser chegou a propor uma classificação para esses novos dispositivos, com base em seu tamanho, desde os pequenos e pessoais (inch-scale), passando pelos de médio porte (foot-scale), até os grandes e de uso coletivo (yard-scale). De fato, esta visão de Weiser se concretizou, e atualmente dispomos de dispositivos em todas estas categorias de tamanho (Figura 2.1) permeando os nossos ambientes de trabalho e atividades cotidianas.

Outro aspecto desta visão, está no surgimento de novas aplicações que agreguem valor a estas novas infraestruturas de dispositivos. Assim, de acordo Abowd e Mynatt (Abowd e Mynatt, 2000), o desenvolvimento destas aplicações está diretamente associado a três temas: Captura e Acesso de informações, Ciência de Contexto e Interfaces Naturais.

Truong et. al. (Truong et al., 2001) definem captura e acesso (C\&A) como a tarefa de preservar o registro de alguma experiência ao vivo e então permitir que a mesma possa ser 


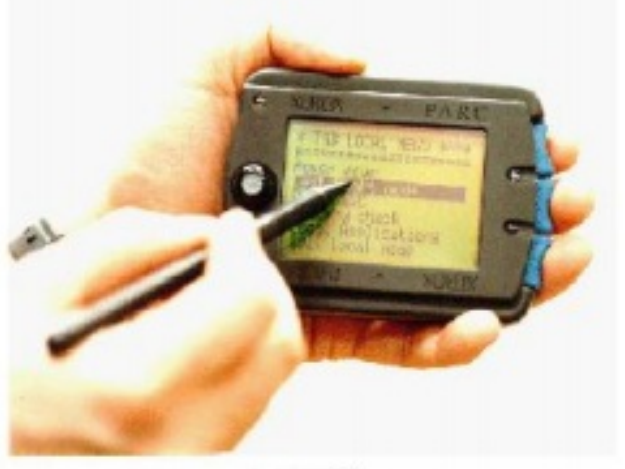

(a) $\mathrm{Tab}$

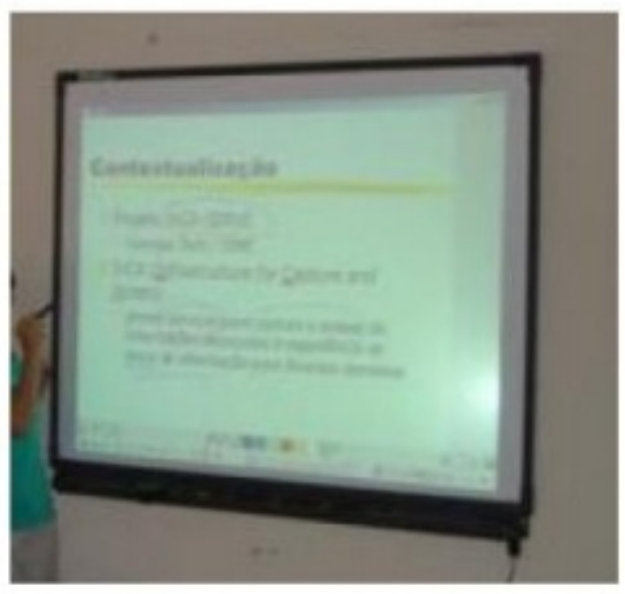

(c) Lousa eletrônica

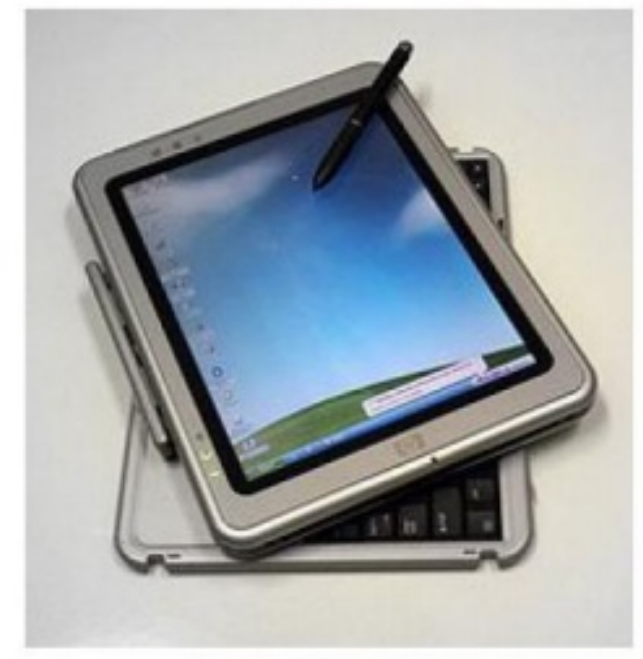

(b) Tablet PC

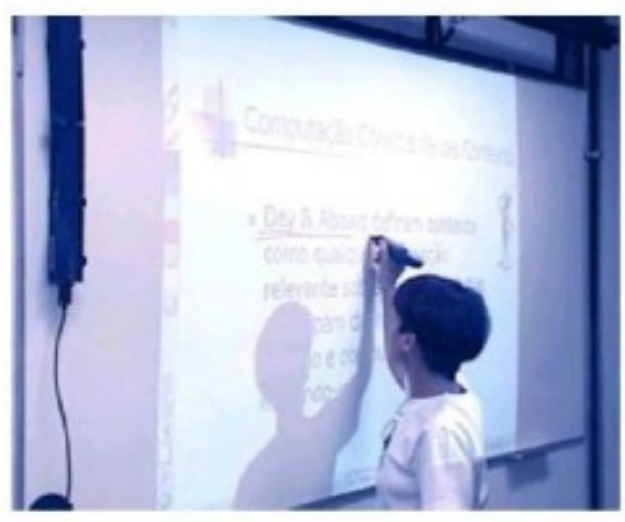

(d) Mimio

Figura 2.1: Dispositivos de computação ubíqua por escala de tamanho: um (a) tab (inch-scale), um (b) tablet PC (foot-scale), uma (c) lousa eletrônica e um (d) mimio (Cattelan et al., 2003)

revista em algum ponto no futuro. Segundo Abowd (Abowd e Mynatt, 2000), por captura e acesso, depreende-se a captura automatizada das experiências dos usuários para permitir o acesso flexível e universal a elas posteriormente. Captura ocorre quando uma entidade (por exemplo um sensor ou mesmo um programa de computador) gera um artefato com informações sobre o que aconteceu durante a execução de uma atividade. Acesso é o ato de revisitar um artefato capturado decorrido um certo intervalo de tempo, tempo este que pode variar de alguns milissegundos a anos, a contar da data da captura. Como exemplos de trabalhos na área de C\&A podem-se citar o iClass (Cattelan et al., 2003), um sistema de captura e acesso de vídeos, áudios e anotações em lousas eletrônicas que é, em termos de estruturação de software, uma evolução do textiteClass (Abowd, 1999) desenvolvido no Georgia Tech (Georgia Institute of Technology), e visa substituí-lo. Objetivando o registro e posterior disponibilização das informações geradas durante uma aula, o acesso a estes 
dados é feito por meio de um documento dinamicamente gerado por meio de scripts $\mathrm{PHP}^{1}$ em um navegador Web. Assim, as anotações e observações feitas pelo professor em uma determinada aula podem ser acessadas como uma sessão única a qualquer tempo por alunos e demais interessados, facilitando assim o processo de aprendizagem. Outro exemplo, também relacionado com interfaces naturais, é o sistema InkSeine (Hinckley et al., 2007), que provê uma maneira rápida de coletar e anotar conteúdo de múltiplos documentos, e permite o uso de tinta eletrônica. Por meio de aplicações de C\&A, atividades simples do dia a dia podem ser registradas e analisadas, visando possibilitar posteriores tomadas de decisão, relacionadas com a maneira ou a eficiência com que são desempenhadas.

Aplicações de computação ubíqua também podem ser cientes ao contexto, adaptando seu comportamento com base em informações obtidas a partir do ambiente físico e computacional (Abowd e Mynatt, 2000). Dey (Dey, 2001) define Sistema Ciente de Contexto como um sistema que faz uso do contexto de modo a prover informações relevantes e/ou serviços para o usuário, com a relevância diretamente relacionada com a tarefa a ser desempenhada. As informações de contexto mais comuns são a localização e a identidade do usuário, porém muitas outras informações poderiam ser utilizadas, tais como informações sobre outras pessoas envolvidas, a atividade sendo realizada, informações de tempo e as intenções do usuário. Um dos primeiros trabalhos em ciência de contexto foi o Active Badge (Want et al., 1992), que permitia a localização de pessoas usando crachás especiais por meio de sensores espalhados pelo ambiente. Outros exemplos são o protótipo CAPPAS (CAPPA Service) baseado no modelo CAPPA (Context-Aware Peer-to-Peer Architecture) proposto por Fagá (Fagá Jr et al., 2009) para a troca de informações de contexto e anotações de usuários em vídeos por meio de redes peer-to-peer e o projeto Lariisa (Laboratoire Réseaux Intelligence Intégration Santé Aplication) (Gonçalves et al., 2010), um modelo de suporte à tomada de decisão para sistemas públicos de saúde, que faz uso de informações de contexto obtidas em casas equipadas com set-top boxes que disponham do middleware Ginga. Os desafios da incorporação de mais informações de contexto, da representação de contextos e da combinação de sensores e reconhecimentos de atividades para informações de contexto mais complexas são abordadas por Abowd e Mynatt (Abowd e Mynatt, 2000).

Ainda segundo Abowd e Mynatt (Abowd e Mynatt, 2000), interfaces naturais são desejáveis de maneira a possibilitar diversos modos de interação com sistemas computacionais, permitindo assim que modos comuns de expressão e gestos implícitos do nosso cotidiano tornem-se comandos de entrada para os mais variados sistemas. Por explorar novos paradigmas de interação, esta linha acaba apresentando diversos trabalhos inovadores, que podem ser agrupados de acordo com o tipo de interação de que fazem uso, como

\footnotetext{
${ }^{1}$ Acrônimo recursivo para PHP: Hypertext Preprocessor
} 
escrita por meio de tinta eletrônica, voz e gestos. Exemplos representativos incluem: o trabalho de Schilit (Schilit et al., 1998) que trata da utilização da escrita manual como meio de interação em lousas e similares; o trabalho de Ishii e Ullmer (Ishii e Ullmer, 1997), criadores do conceito de interfaces tangíveis, que utiliza objetos do mundo real com o objetivo de manipular artefatos virtuais; e o trabalho de Hauptmann ("Hauptmann, 1995), que faz uso de reconhecimento de voz em bibliotecas de vídeos digitais. Na Seção 2.1.1, as interfaces naturais serão discutidas com mais detalhes.

\subsubsection{Interfaces Naturais}

Abowd e Mynatt (Abowd e Mynatt, 2000) mencionam que a interação física entre os seres humanos e computadores será cada vez mais diversa do atual paradigma teclado/mouse/monitor e mais parecida com a forma com que nós interagimos com o mundo físico. As interfaces naturais surgem como resultado dessa tendência.

Essas novas interfaces merecem crédito por permitirem rápido aprendizado, facilidade de uso e suporte a tarefas como autoria de desenhos, sem grandes alterações na estrutura das mesmas (Abowd e Mynatt, 2000). Os autores ainda observam que alguns insucessos de interfaces que utilizam, por exemplo, fala e tinta como entrada, se devem à não robustez com que os erros, comuns nessas interfaces, são tratados e à dificuldade de construí-las. Para facilitar o desenvolvimento de interfaces naturais é preciso que esses tipos de entradas possam ser tratados de forma simples, assim como o mouse e teclado são atualmente.

Existem diversas maneiras de se definir interfaces naturais. Embora não seja um conceito fácil de se definir, tais interfaces são fáceis de se distinguir ao se deparar com elas. A forma mais fácil é por meio da comparação com outros tipos de interfaces, como as interfaces gráficas com o usuário (GUI's ou Graphical User Interfaces) e as interfaces por linha de comando (CLI's ou Command Line Interfaces).
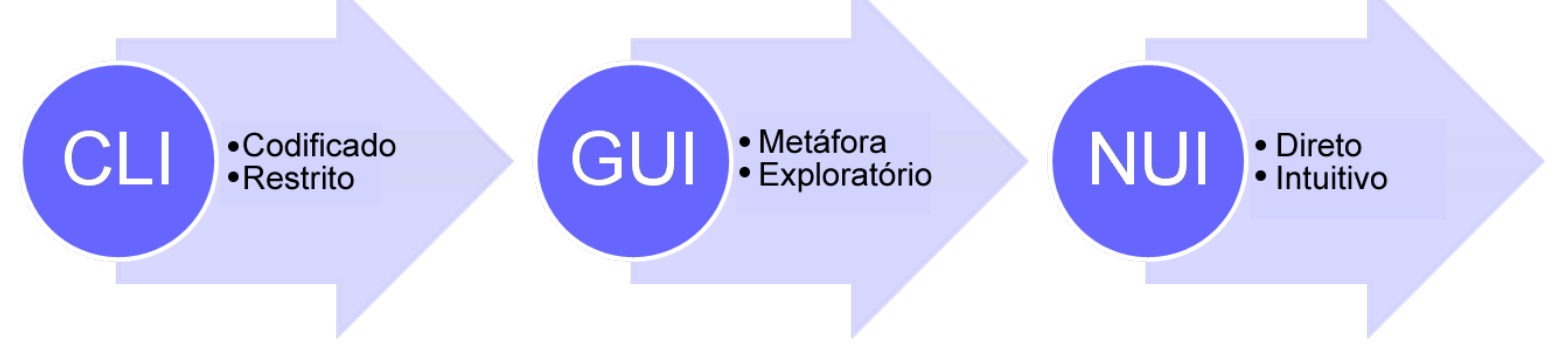

Figura 2.2: Evolução das interfaces com o usuário. Adaptado de (De los Reyes, 2009)

Em seu livro, Blake (Blake, 2011) propõe uma possível definição, ao dizer que as interfaces naturais são interfaces com o usuário projetadas para fazer uso de comportamentos naturais dos seres humanos a fim de interagir diretamente com o conteúdo. Tal definição implica em três aspectos relevantes que merecem ser destacados (Blake, 2011). 
Interfaces naturais são projetadas. Por projetadas, entende-se que as interfaces naturais necessitam de planejamento específico e de cuidadosas considerações, antes de sua implementação. Atenção especial deve ser dispensada a fim de garantir que a interação seja apropriada, satisfazendo as necessidades dos usuários, do conteúdo e do contexto.

Interfaces naturais fazem uso de comportamentos humanos. Tal proposição implica que a principal maneira com que os seres humanos interagem com as interfaces naturais é por meio de comportamentos naturais como toques, gestos e fala, bem como outras inúmeras formas de se expressar que temos praticado durante anos, nas quais somos particulamente experientes.

Interfaces naturais interagem diretamente com o conteúdo. Aqui temos que o foco das interações deve ser sobre o conteúdo e na direta manipulação do mesmo. Isso não significa que a interface não pode conter controles como botões e checkboxes quando necessário. Significa que os controles devem ser secundários ao conteúdo, e a manipulação direta deste conteúdo deve ser o método primário de interação.

Por ser uma linha ampla de pesquisa, vários trabalhos são publicados a cada ano, aplicados aos mais diversos contextos. Nesses trabalhos, são exploradas modos de interação por meio de gestos, voz e escrita baseada em caneta e tinta eletrônica - ou ainda, por meio de instrumentos mais familiares aos usuários, como o controle remoto da TV (Bulterman et al., 2006; Cesar et al., 2007; Ferscha et al., 2008). Atualmente, formas de integração entre diversas maneiras de interagir têm sido exploradas (Mugellini et al., 2009), dando origem ao conceito de interfaces multimodais (Oviatt, 2007). Schlömer (Schlömer et al., 2008), como base de seu sistema multimodal de navegação multímida, implementou um sistema de reconhecimento de gestos baseado nos acelerômetros presentes no Wiimote ${ }^{2}$, controle do Nintendo $\mathrm{Wii}^{3}$, que dentre outras possibilidades, permite a navegação por uma coleção de fotos em um aparelho de TV por meio de movimentos simples feitos com a mão. Em seu artigo, Lee (Lee, 2008) demonstra diversos usos possíves para o Wiimote, desde o rastreamento de vários objetos simultaneamente até realidade aumentada, passando pelo esquema de uma lousa eletrônica de baixo custo.

Do ponto de vista da indústria, apenas a possibilidade de uma interação mais natural tem sido o cerne da proposta e a razão do sucesso de vários produtos, especialmente na área de entretenimento, como pode ser observado no console da Nintendo, o Wii, que permite a interação com os jogos por meio de gestos reconhecidos por acelerômetros e sensores infra-vermelho. Ainda na área de entretenimento, a Microsoft desenvolveu para seu console Xbox 360 o Kinect ${ }^{4}$, um sensor de movimento que permite aos usuários

\footnotetext{
${ }^{2}$ http://www.nintendo.com/wii/console/controllers. Acessado em 18/nov/2012

${ }^{3} \mathrm{http}: / /$ www.nintendo.com/wii. Acessado em 18/nov/2012

${ }^{4}$ http://www.xbox.com/en-US/kinect. Acessado em 18/nov/2012
} 
interagirem com os jogos sem fazer uso de controles ou joysticks, da maneira mais natural possível, apenas com movimentos do próprio corpo.

À parte os avanços recentes mostrados pela indústria, que para o meio científico nada mais são do que a implementação de conceitos há muito estudados, atualmente as pesquisas em Interfaces Naturais tendem a explorar e viabilizar inovadores modos de interação, como interfaces baseadas em Realidade Aumentada, Interfaces Tangíveis e Interfaces Orgânicas.

Um sistema de Realidade Aumentada (RA) tem por objetivo criar a sensação de que objetos virtuais estão presentes no mundo real, por meio de software que combina elementos reais e virtuais, permitindo também a sua manipulação. Dentre as várias definições existentes na literatura, a que se mostra como mais aceita é a de Azuma (Azuma e Baillot, 2001), que diz que a RA é um sistema que suplementa o mundo real com objetos virtuais gerados por computador, parecendo coexistir no mesmo espaço e apresentando as seguintes propriedades:

- Combinar objetos reais e virtuais no ambiente real.

- Executar interativamente em tempo real.

- Alinhar objetos reais e virtuais entre si.

- Aplicar-se a todos os sentidos, incluindo visão, audição, tato, força e olfato.

Por outro lado, as Interfaces de Usuário Tangíveis ( Tangible User Interfaces - TUI) vão no sentido oposto, ou seja, permitem o uso de objetos virtuais por meio da manipulação de objetos reais. Nas TUIs, os usuários manipulam objetos físicos, ferramentas, superfícies ou espaços para interagir com as aplicações (Antle e Wise, 2013). A forma como os usuários manipulam os objetos reais é natural e intuitiva e cada objeto físico real é mapeado de modo a corresponder a um objeto virtual. Já em sistemas de RA, os objetos físicos são mapeados usando-se uma função um-para-um com operações sobre objetos virtuais. Com as TUIs, representação física permite que os usuários segurem e manipulem diretamente objetos, servindo de mecanismo de controle para a computação interna e a informação digital, criando a ilusão da interação tangível por meio de feedback dinâmico.

As Interfaces de Usuário Orgânicas (Organic User Interfaces - OUI), segundo Holman e Vertegaal (Holman e Vertegaal, 2008), são interfaces de computador que fazem uso de um display não-planar como dispositivo de saída primário, bem como dispositivo de entrada. Quando flexível, OUIs têm a habilidade de se tornar informação em um display a partir de deformação, seja por manipulação ou atuação. Os seus gráficos fluídos baseados em física são moldados por meio de multitouch e gestos bimanuais. Um exemplo de OUI pode ser observado na Figura 2.3. 


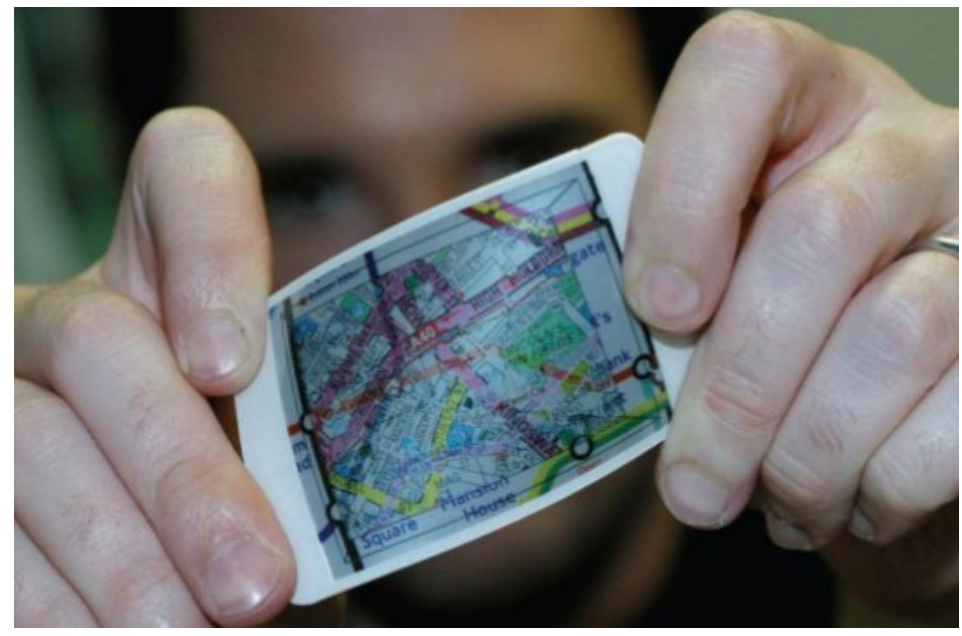

Figura 2.3: Navegação em mapa por meio da OUI Gummi, da Sony (Schwesig et al., 2004)

O objeto que representa a saída de informações para o usuário também representa o meio de entrada de informações do usuário, em uma forma que represente a sua função e que se altere para servir ao seu devido contexto. A forma com que essas interfaces se adaptam aos seus contextos de uso proporciona rápida compreensão, ergonomia e consequente satisfação do usuário, inspirando o seu uso de forma criativa, e não apenas com fins produtivos.

\subsection{Documentos XML e Padrões W3C}

A linguagem de marcação extensível (do inglês Extensible Markup Language - XML) (Bray et al., 1997) descreve uma classe de objetos de dados chamados documentos XML e parcialmente descreve o comportamento dos programas de computador que os processam. A XML foi desenvolvida como uma especificação pelo W3C para ser um conjunto padrão de regras que descrevessem os documentos em um formato que fosse legível tanto por máquinas quanto por seres humanos.

Formalmente, um documento XML é uma sequência de caracteres Unicode ${ }^{5}$, contendo caracteres de dados e informações de marcação explicitamente separados. Dessa maneira, os caracteres que compõem um documento XML podem ser divididos entre marcação e dados. Essencialmente, todo caractere que não é marcação constitui caractere de dados do documento. Por outro lado, strings que constituem marcação geralmente são precedidos pelo caractere < e terminam com o caractere >, sendo denominados tags. São três os tipos de tags, a saber: tags de início (por exemplo <titulo>), tags de fim (por exemplo

\footnotetext{
${ }^{5} \mathrm{http} / / /$ www.unicode.org/. Acessado em 12/fev/2013
} 
</titulo>) e tags de elemento vazio (por exemplo <foto localdafoto="pao.jpg"/>), como observado na Listagem 2.1.

Listagem 2.1: Exemplo de documento XML

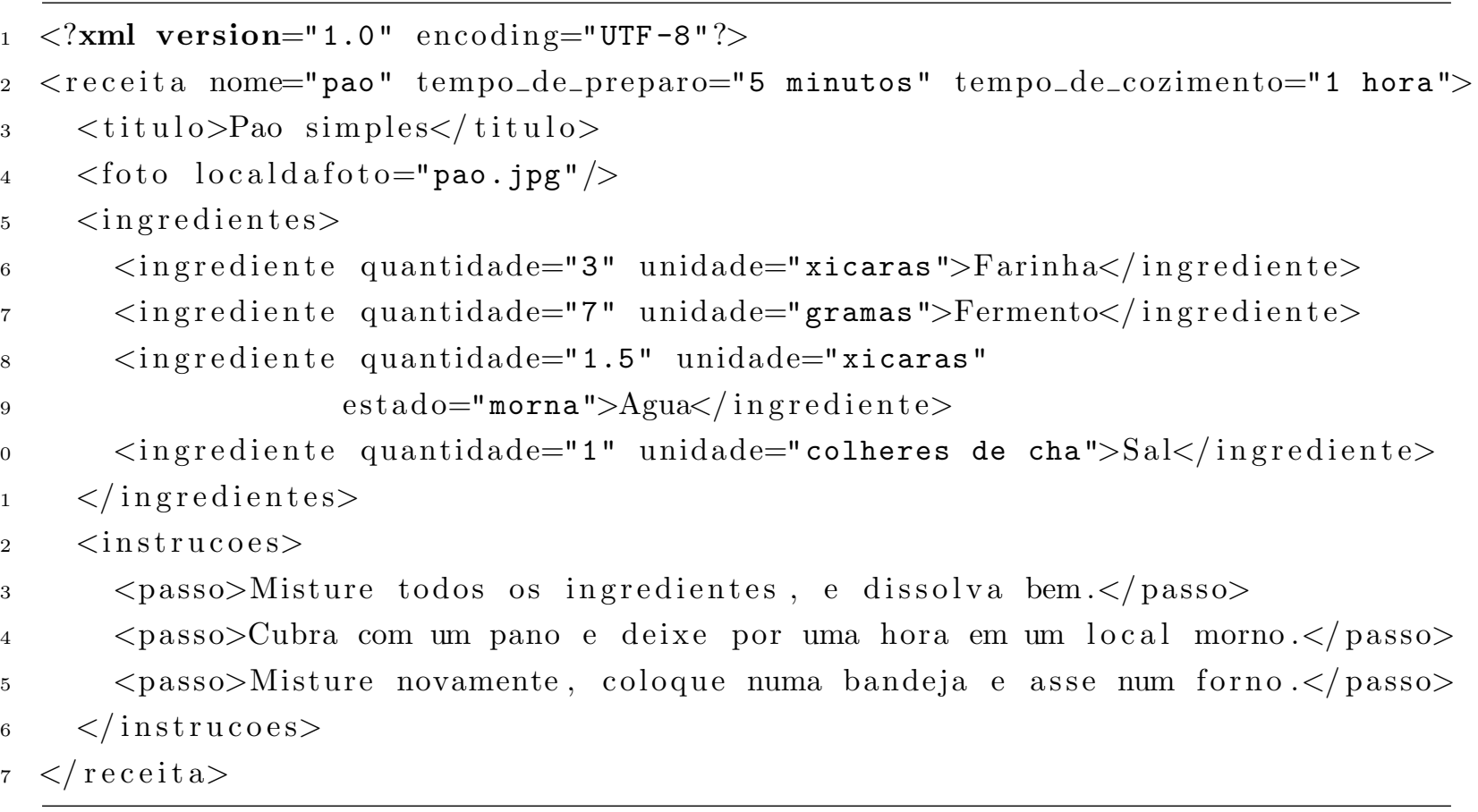

Um elemento é um componente lógico do documento XML, que pode começar com uma tag de início e terminar com sua correspondente tag de fim, ou ser composto apenas por uma tag de elemento vazio. Os caracteres encerrados pelas tags de início e fim, caso existam, são chamados de conteúdo do elemento, e podem compreender marcações, bem como outros elementos, que por sua vez são conhecidos como elementos filho. Como exemplos de elementos na Listagem 2.1 podem-se citar <titulo>Pao simples</titulo> e a tag de elemento vazio <foto localdafoto="pao.jpg"/>. Cada elemento tem um tipo, identificado por um nome, e pode ter um conjunto de especificações de atributos associados.

Um atributo é um par (nome, valor) presente na tag de início do elemento ou em sua tag de elemento vazio, em ambos os casos logo após seu nome. Na Listagem 2.1 o elemento ingrediente tem dois atributos, quantidade e unidade. Outro exemplo seria o elemento foto, onde o nome do atributo é localdafoto e o seu valor é pao.jpg.

Documentos XML podem, e devem, começar com uma declaração XML, como pode-se observar na primeira linha da Listagem 2.1. Processadores XML, ao executarem a leitura do documento podem repassar estas instruções de processamento para a aplicação, informando a versão da especificação XML e a codificação dos caracteres utilizados no documento. Se diz que um documento XML é bem formado quando literalmente é iniciado por essa instrução de processamento, e também possui um elemento raíz que encerra 
todos os demais, sem desrespeitar a estrutura de aninhamento (hierarquia) de elementos. Além disso, nomes de elementos devem começar com letra ou com _ (underscore); o restante pode incluir letras, dígitos, hífens ou o caracter _, mas nunca o caracter de espaço. Atributos não podem aparecer mais de uma vez no mesmo elemento e, por fim, deve-se notar que a linguagem XML é case sensitive, ou seja, há a diferenciação entre maiúsculas e minúsculas.

Por estas características, e pela grande aceitação do padrão por parte dos desenvolvedores, a XML tornou-se a grande aliada das aplicações que necessitam de formatos de dados que possam ser extensíveis e interoperáveis. No entanto, é necessário impor restrições sobre a estrutura de um documento, de modo a validar sua sintaxe e evitar a ocorrência de tags incorretas e permitir o processamento preciso de certos programas, como os processadores da linguagem extensível de folhas de estilo para transformações (eXtensible Stylesheet Language for Transformation - XSLT). Estas são providas por outra especificação da W3C, os XML Schemas.

\subsubsection{W3C XML Schemas}

Um W3C XML Schema, chamado neste trabalho de Esquema XML, é um documento escrito em XML que faz uso de um conjunto especial de elementos para definir a estrutura de outro documento XML (W3C, 2004a). Ou seja, por meio dos esquemas, um documento XML pode definir e validar um outro documento XML, além dos limites semânticos definidos pelo próprio XML. Um Esquema XML em particular tem a estrutura geral ilustrada na Listagem 2.2.

Listagem 2.2: Estrutura do Esquema XML

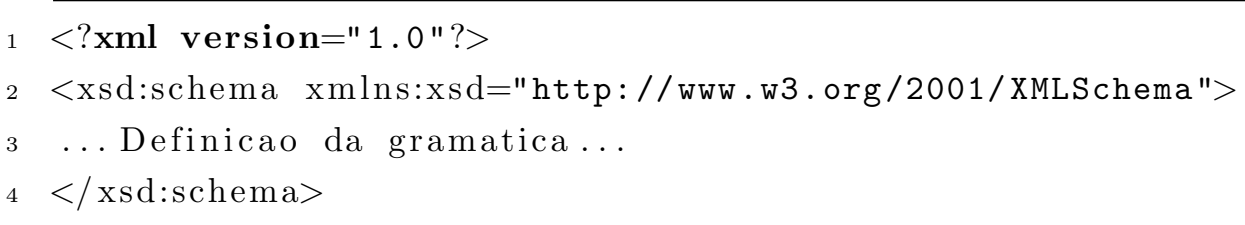

O elemento raiz do documento é representado pela tag 〈xsd:schema〉, que especifica por meio do atributo xmlns que as tags utilizadas neste documento são definidas por um padrão específico da W3C. Por padrão, um Esquema XML possui a extensão .xsd.

O Esquema XML (W3C, 2004a) foi especificado pela W3C com o objetivo de prover uma alternativa a Definição de Tipo de Documento XML (XML Document Type Definition - DTD ${ }^{6}$ ), que desse suporte a espaços de nomes (namespaces), facilitasse o projeto de vocabulários abertos e extensíveis, e atendesse às necessidades das aplicações orientadas a dados, que demandavam um sistema de tipagem de dados mais rico e flexível.

\footnotetext{
${ }^{6}$ http://www.w3.org/TR/2004/REC-xml11-20040204/\#sec-prolog-dtd - Acessado em 03/Fev/2013
} 
Esquema XML é uma linguagem de esquema com tipagem forte, que elimina qualquer tipo de não-determinismo da marcação, de modo a assegurar que não exista nenhuma ambiguidade na determinação dos tipos dos dados e que a validação possa ser executada por uma máquina de estados finitos. Foi a primeira linguagem de definição de esquemas a receber o status de recomendação, sendo reconhecida como padrão pela W3C em Maio de 2001. Desde Outubro de 2004 encontra-se na versão 1.1, quando passou por diversas correções e atingiu o status de recomendação novamente em Abril de 2012.

Tendo em vista os objetivos deste trabalho, a seguir são descritas as características dos Esquemas XML de maior importância para o modelo discutido no Capítulo 3.

\subsubsection{Espaços de Nomes e a Tag Schema}

Esquemas XML são organizados por espaços de nomes. O espaço de nomes XML(W3C, 2004a) fornece um método simples para referenciar descritores e esquemas de descrição, a partir de múltiplos esquemas diferentes, para que eles possam ser reusados para criar novos esquemas. Qualificadores de espaço de nomes associam elementos e atributos com um espaço de nomes particular identificado por um Identificador Uniforme de Recursos (Uniform Resource Identifier - URI). Cada definição de esquema deve começar com um preâmbulo para que seja possível identificar o espaço de nomes corrente.

Desse modo, um esquema também pode incluir outros esquemas com definições adicionais para o mesmo espaço de nomes e/ou pode importar um novo esquema com a definição de um espaço de nomes diferente. Este último recurso é utilizado neste trabalho para definir tipos específicos para a aplicação do usuário, conforme discutido na seção 3.2.3. Todos os componentes definidos pelo esquema fazem parte de um espaço de nomes alvo, definido como uma propriedade do próprio esquema por meio do elemento XML <schema> que inclui os seguintes atributos (ilustrados na Listagem 2.3):

- xmlns: um URI para o espaço de nomes do Esquema XML (XML Schema Namespace).

- targetNamespace: o URI pelo qual o esquema corrente é identificado.

- xmlns: referências a esquemas externos.

Listagem 2.3: Exemplo de atributos do elemento <schema>

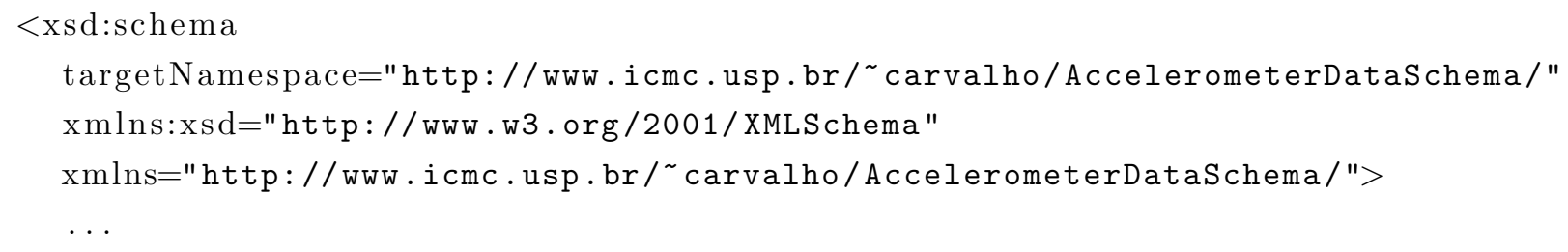




\subsubsection{Declaração de Elementos}

A declaração de elementos (W3C, 2004a) habilita a ocorrência, em instâncias de documentos, de elementos com nomes e tipos específicos. A declaração de um elemento especifica a definição de tipo para um elemento do esquema ou explicitamente ou por referência, pode especificar o número de ocorrências mínima e máxima (minOccurs e maxOccurs, respectivamente) e informação padrão (através do atributo default). Por exemplo, a declaração de elemento na Listagem 2.4 associa o nome "País" ao tipo (previamente definido) códigoPaís, especifica que o valor padrão para o elemento <País> é "br" e que o elemento $<$ País> pode ocorrer zero ou mais vezes.

Listagem 2.4: Exemplo de definição de um elemento

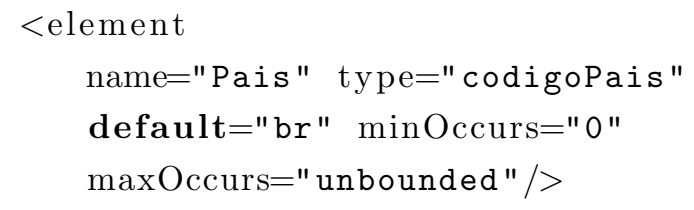

\subsubsection{Declaração de Atributos}

A declaração de atributos (W3C, 2004a) permite a ocorrência, nos documentos de instância, de atributos com nomes e tipos específicos associando um nome de atributo com um tipo de dado simples. Dentro de uma declaração de atributo, o atributo use especifica a presença (required $\mid$ optional $\mid$ fixed $\mid$ default $\mid$ prohibited); e o atributo value indica um valor fixo ou padrão. O valor padrão do atributo use é optional. O exemplo de declaração de atributo ilustrado nas Listagens 2.5 e 2.6 indica que a ocorrência do atributo gravity é obrigatória. 
Listagem 2.5: Exemplo de definição e declaração de um atributo

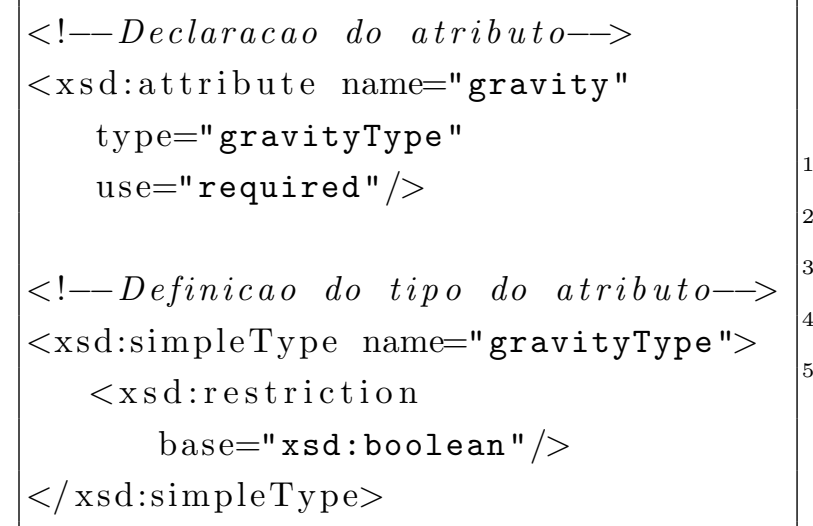

\subsubsection{Definição de Tipos}

A principal alteração introduzida pelo Esquema XML foi a capacidade de não só definir o tipo de dados de um elemento, mas também ser capaz de personalizar um tipo de dados. Existe uma distinção fundamental entre definição de tipos (que cria novos tipos) e declarações. Estas últimas habilitam a ocorrência de elementos e atributos nas instâncias de documentos com nomes e tipos específicos. Definições de tipos definem os componentes internos de um esquema, os quais podem ser usados em outros componentes de esquema, tais como declarações de elementos e atributos ou em outra definição de tipos. As seguintes definições de tipo do Esquema XML são utilizadas neste trabalho (W3C, 2004a):

Definições de tipo simples: não podem ter elementos nem atributos. Elementos e atributos podem ser declarados como sendo do tipo simples (simpleType). O Esquema XML fornece um grande número de tipos simples através de um conjunto de tipos primitivos e de um outro conjunto de tipos derivados dos tipos primitivos (W3C, 2004b,c). Em adição a esses tipos primitivos novos tipos simples podem ser derivados através de restrições, como restriction aplicada a um tipo string (como ilustrado na Listagem 2.7). Além desses tipos simples atômicos, o Esquema XML fornece dois tipos de agregação: lista (list) e união (union).

Listagem 2.7: Exemplo de tipo simples com conjunto específico de valores

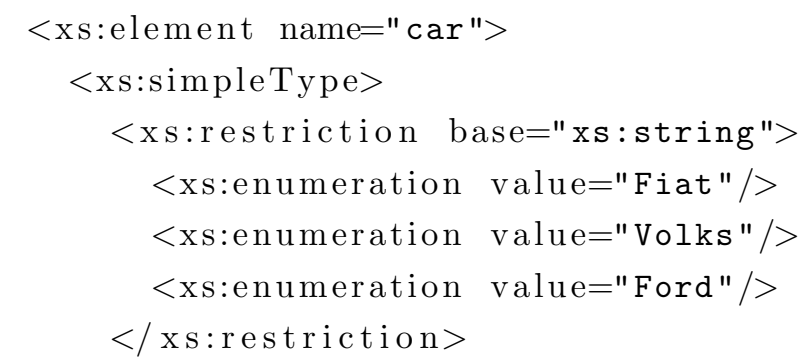


$8</$ xs:simpleType $>$

$9</$ xs:element $>$

Definições de tipo complexo: permitem elementos filhos em seu conteúdo e podem ter atributos. Definições de tipo complexo fornecem (W3C, 2004a):

- Restrições de ocorrência e de conteúdo dos atributos.

- Restrições sobre os elementos filhos e sobre o modelo de conteúdo do tipo.

- Derivação de tipos complexos a partir de outros tipos simples ou complexos através de extensão (extension) ou restrição (restriction).

Ao definir-se um tipo complexo, geralmente pretende-se que um elemento siga uma determinada estrutura. Se o elemento compreender outros elementos, o mesmo pode ser definido como uma sequência específica de outros elementos, por um conjunto de elementos alternativos ou como um grupo de elementos. Nas listagens 2.8 e 2.9 pode-se observar um trecho de um esquema que define um elemento que deve conter um atributo e uma sequencia específica de elementos, e um exemplo de instância para este esquema.

Definições de grupo: os grupos mais utilizados são os grupos não nomeados. Esses grupos aparecem com freqüência na definição de tipos complexos. Eles são formados através de três compositores (W3C, 2004a,c):

- Sequence: restringe os elementos de um grupo para aparecerem na mesma ordem em que foram declarados.

- Choice: apenas um dos elementos do grupo pode aparecer em uma instância.

- All: todos os elementos em um grupo podem aparecer uma ou nenhuma vez e em qualquer ordem. 
Listagem 2.8: Exemplo de definição de elemento complexo

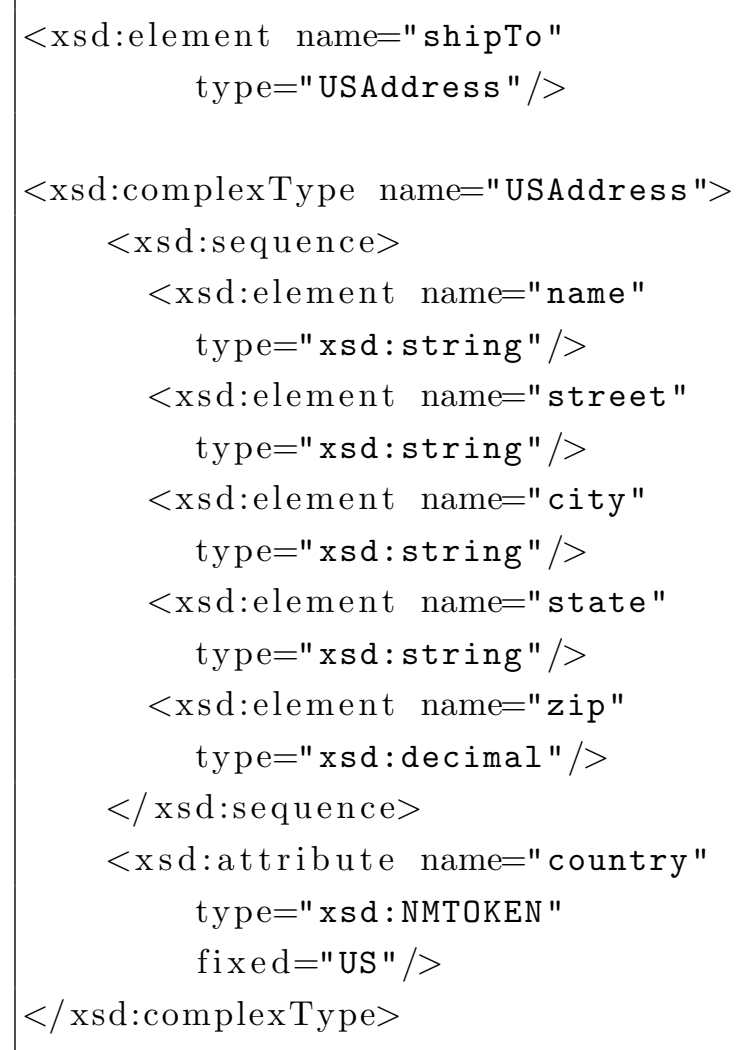

Listagem 2.9: Exemplo de instânciação de elemento complexo

\begin{tabular}{|c|c|}
\cline { 2 - 3 } 2 & $<$ shipTo country="US" $>$ \\
3 & $<$ name $>$ Alice Smith $</$ name $>$ \\
4 & $<$ street $>123$ Maple Street $</$ street $>$ \\
5 & $<$ city $>$ Mill Valley $</$ city $>$ \\
6 & $<$ state $>$ CA $</$ state $>$ \\
6 & $<$ zip $>90952</$ zip $>$ \\
7 & $<$ shipTo $>$ \\
\hline
\end{tabular}

Definições de tipo abstrato: Tipo abstrato é um mecanismo do Esquema XML utilizado para forçar a substituição de um tipo de dados em específico. Quando um tipo é declarado como abstrato, ele não pode ser utilizado diretamente em um documento de instância. Assim, todas as instâncias deste elemento devem utilizar o atributo xsi:type, de modo a indicar que o tipo deste elemento é derivado de um tipo abstrato.

Na Listagem 2.10, o tipo meaning Type do elemento meaning é definido como abstrato. Deste modo, o elemento meaning jamais poderá aparecer em um documento de instância sem que o seu atributo xsi:type referencie um tipo derivado de meaningType.

Listagem 2.10: Exemplo de declaração e definição de elemento e tipo abstrato

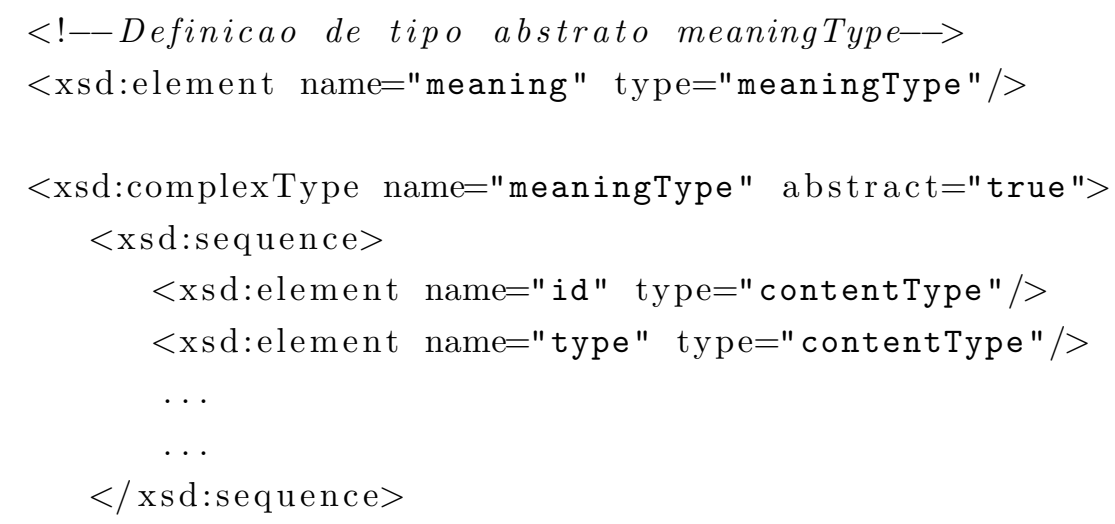




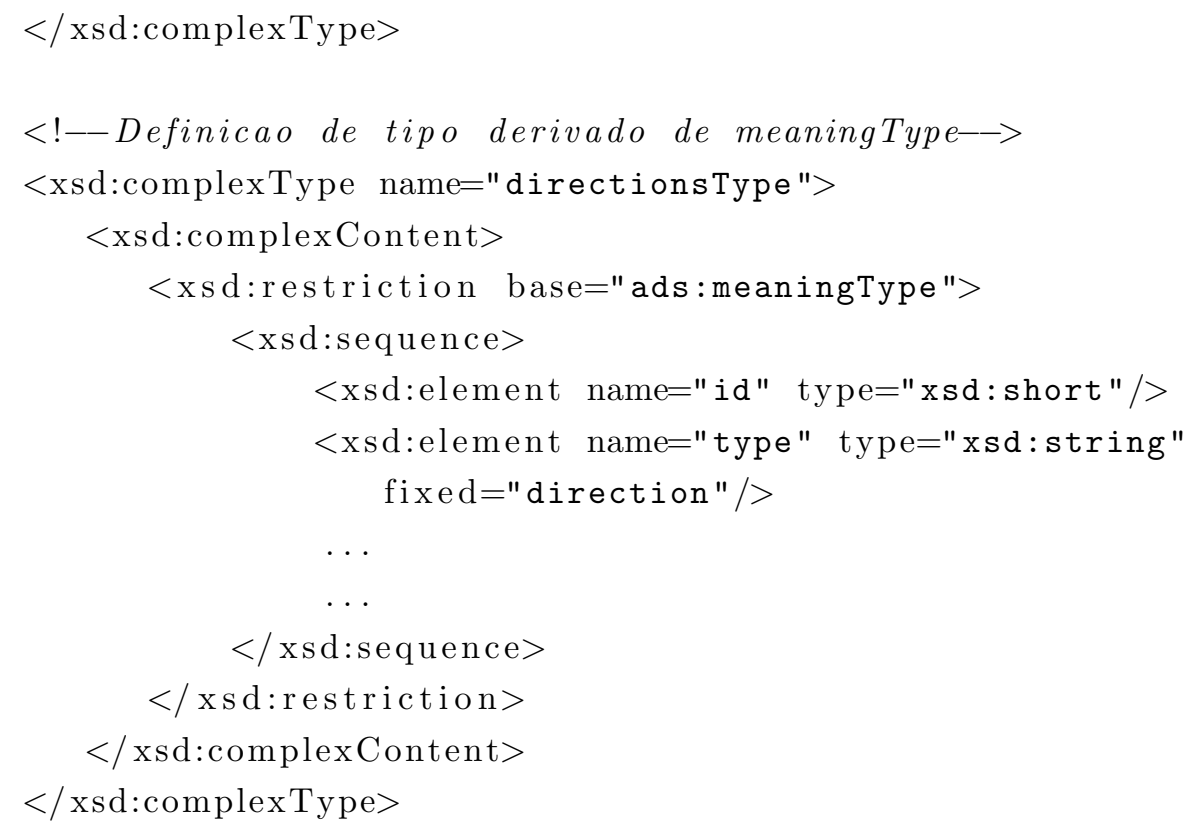

Levando em conta esta restrição, na Listagem 2.11 utilizou-se o tipo não-abstrato directions Type, que por ser derivado de meaningType, pode substituí-lo.

Listagem 2.11: Exemplo de instanciação de elemento com tipo abstrato

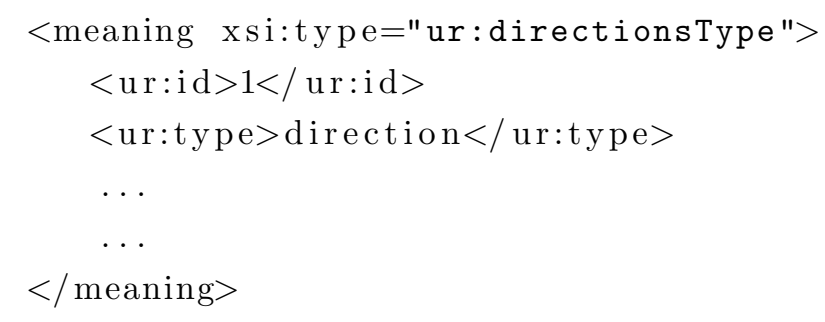

Está fora do escopo deste trabalho discutir todos os recursos presentes na especificação do Esquema XML, assim, para maiores esclarecimentos sobre esta linguagem, este trabalho referencia a documentação oficial no site da W3C (W3C, 2004a,b,c).

Este trabalho, além de fazer uso do XML e dos Esquemas XML, também utiliza outro padrão da W3C para a definição do modelo de documento, discutido na Seção 2.2.2.

\subsubsection{EMMA}

A Linguagem Extensível de Anotação Multimodal (Extensible MultiModal Annotation markup language - EMMA) é uma linguagem de marcação usada para encapsular e anotar a informação extraída da entrada dos usuários que interagem com uma aplicação multimodal (W3C, 2009). Essa linguagem possibilita atribuir significado para diferentes tipos de entrada como: texto, fala, escrita e combinações dessas entradas. A linguagem EMMA considera os seguintes tipos de entradas:

- Entrada por uma única modalidade. 
- Entradas por modalidades seqüenciais.

- Entradas por modalidades simultâneas, ou seja, a entrada pelas diferentes modalidades é interpretada uma após a outra na ordem em que foram recebidas ao invés de serem combinadas antes de ocorrer a interpretação.

- Entradas por modalidades compostas, ou seja, as entradas são recebidas ao mesmo tempo por meio das múltiplas modalidades, e tratadas individualmente.

A linguagem EMMA é utilizada principalmente como um formato padrão para troca de dados entre sistemas multimodais, que idealmente devem ser gerados em sua totalidade automaticamente por componentes de software (e não por desenvolvedores) responsáveis pela interpretação e usados para representar a semântica das entradas dos usuários.

No entanto, a linguagem EMMA não representa uma linguagem de especificação e não contém nenhuma abordagem transformacional para permitir desenvolvimento de aplicações usando modelos diversos. Na Listagem 2.12, pode-se observar um exemplo de documento EMMA representando a entrada de uma aplicação de reserva de vôos.

Listagem 2.12: Exemplo de documento EMMA

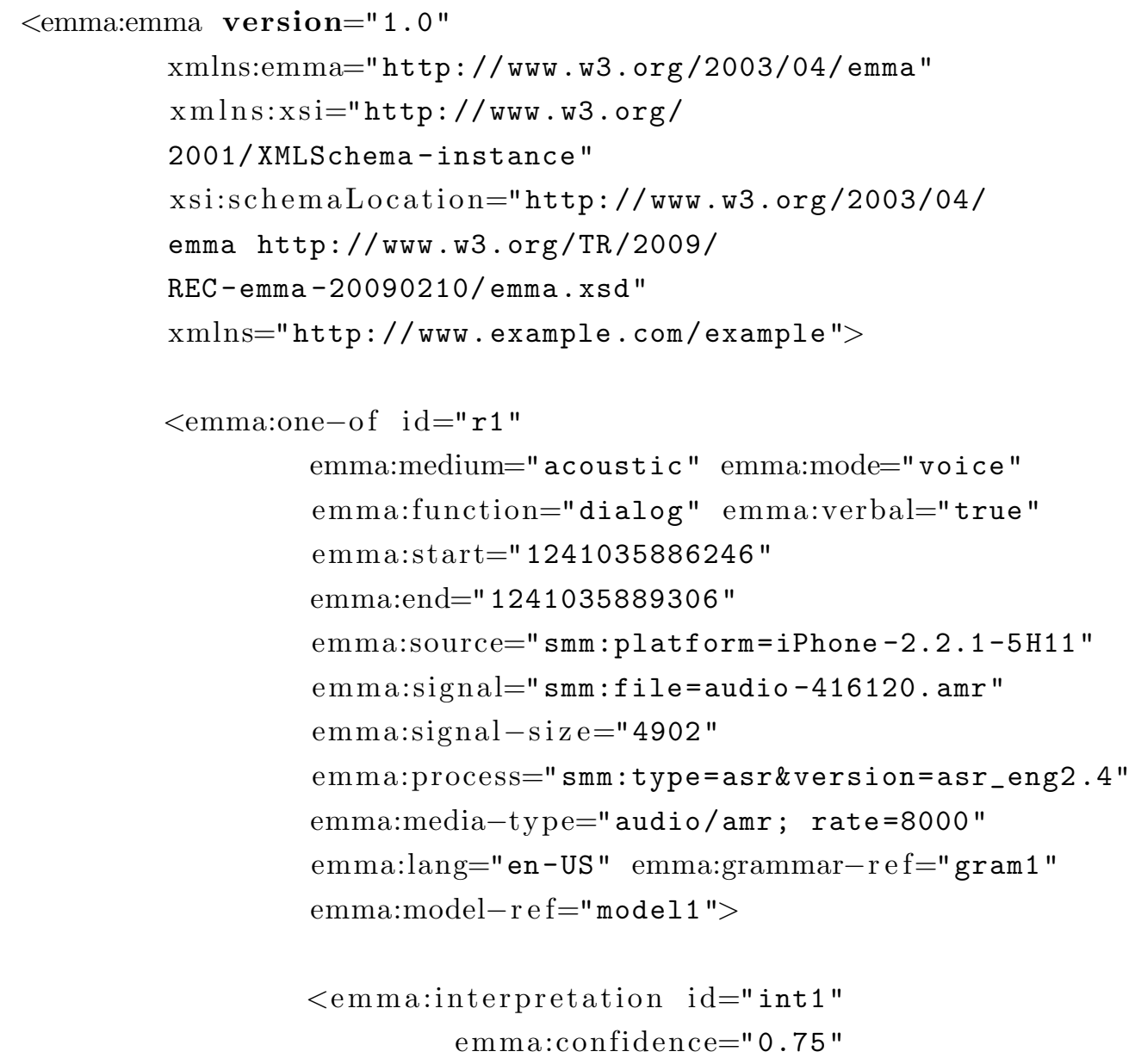




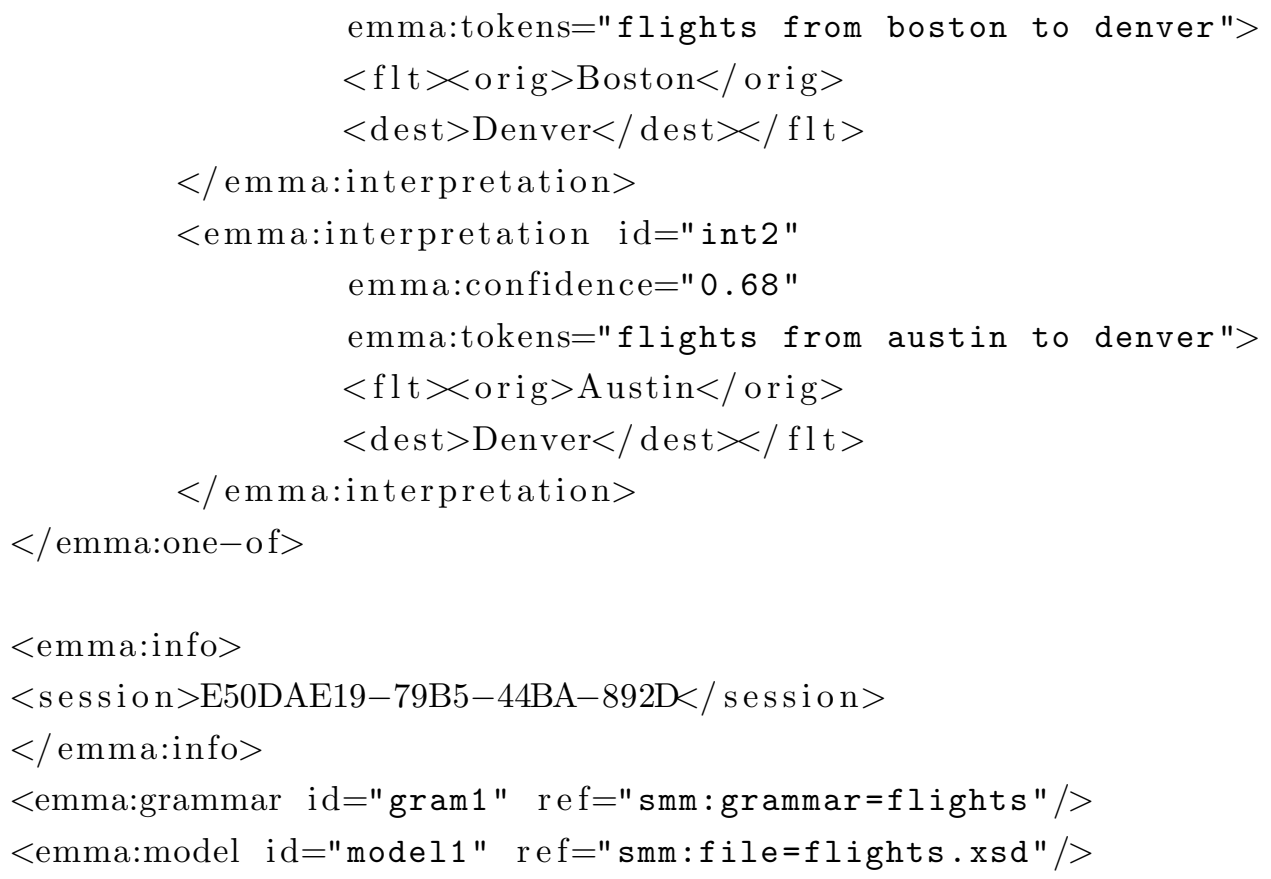

Neste exemplo, extraído de (Johnston, 2009), baseado no exemplo básico provido na página da recomendação ${ }^{7}$, pode-se observar o resultado de dois processos de reconhecimento de voz, juntamente com suas respectivas representações semânticas associadas. O sistema não tem certeza se o usuário disse "flights from Boston to Denver" ou "flights from Austin to Denver". As anotações observadas são indicadores de início e fim da captura da fala do usuário e a medida de confiança que o sistema atribuiu à cada uma das intepretações.

Essencialmente, a função do EMMA é condensar os diversos componentes de um sistema multimodal interativo. Esta linguagem possui dois aspectos fundamentais: uma série de elementos (por exemplo emma:group, emma: one-of, emma:interpretation) que são utilizados como contêineres para as interpretações das entradas dos usuários, e uma série de elementos e atributos de anotação que são utilizados para associar metadados com essas entradas, como timestamps (emma:start, emma:end) e taxas de confiança (emma:confidence). A linguagem também permite que extensões por meio do elemento emma:info, que desempenha a função de contêiner para anotações e entradas específicas da aplicação.

Todos os documentos EMMA devem conter o elemento raiz emma: emma. Este elemento contém atributos que descrevem a versão do EMMA, bem como declarações dos namespaces e esquemas utilizados. A parte principal de um documento EMMA é composta por uma árvore de elementos contêineres (emma:one-of, emma:group e emma:sequence)

\footnotetext{
${ }^{7}$ http://www.w3.org/TR/emma/ - Acessado em 23/jan/2013
} 
terminada por um ou mais elementos emma: interpretation. Este elemento é o contêiner principal para a representação semântica de uma entrada de usuário.

No exemplo da Figura 2.12, a representação semântica é o elemento XML <flt $>$ especificando a origem e o destino de uma busca por vôo em um sistema de reserva de passagens aéreas. Neste caso, o sistema retornou duas interpretações ótimas para a busca do usuário, e o elemento emma: one-of está sendo utilizado como contâiner para as estas duas interpretações possíveis, cada uma encerrada por um contâiner emma:interpretation. Os outros contêineres principais do EMMA são o emma:group para grupos de entradas e o emma: sequence para a representação de entradas sequenciais. Vale notar que as anotações descritas no contêiner one-of se aplicam a todos os elementos emma: interpretation que ele contém.

As anotações emma:medium e emma:mode permitem a classificação da modalidade das entradas fornecidas pelo usuário. Neste caso, a mídia é acústica e a modalidade específica é descrita como voz. A anotação emma:function diferencia o diálogo própriamente dito de outras interações, como gravação e verificação de streams sonoras. O atributo emma:verbal é um booleano que tem por função indicar se a entrada é verbal ou não. Ele é utilizado, por exemplo, quando se deseja diferenciar escrita de desenhos feitos à mão livre, quando a entrada for feita por tinta eletrônica. Os atributos emma:start e emma: end são timestamps absolutos que indicam o início e o fim do sinal de entrada do usuário em milissegundos desde 1/jan/1970. emma:signal é um atributo que comporta URIs que identificam a localização do sinal de entrada, neste caso um arquivo de áudio. O atributo emma:signal-size indica o tamanho deste arquivo em octetos de 8 bits. textttemma-source, ao também comportar URIs, permite a descrição do dispositivo que capturou a entrada do usuário. emma-process é uma descrição da etapa de processamento que resultou na(s) interpretação(ões) atual(ais). No exemplo, é indicado que o processo foi de reconhecimento de fala (asr) e especificada a versão do reconhecedor. O atributo emma: lang indica o idioma utilizado no sinal de entrada, neste caso inglês dos Estados Unidos. O atributo emma:media-type contém o tipo $\mathrm{MIME}^{8}$ do sinal, e fornece um bom local para especificar o codec e a taxa de amostragem (neste caso áudio $\mathrm{AMR}^{9}$ codificado a $8000 \mathrm{~Hz})$.

Se uma gramática for utilizada no processamento do sinal de entrada, ela pode ser especificada em emma:grammar, sob o elemento emma: emma. O atributo emma:grammar-ref nas interpretações ou em emma: one-of apenas indica que gramática foi utilizada naquela interpretação em específico. O uso do elemento emma: gramar combinado com o atributo emma:grammar-ref permite que múltiplas gramáticas sejam especificadas e individual-

\footnotetext{
${ }^{8}$ Extensões Multi-função para Mensagens de Internet (Multipurpose Internet Mail Extensions, em inglês)

${ }^{9}$ Multi-taxa Adaptativa (Adaptive Multi-Rate, em inglês)
} 
mente referenciadas por cada uma das interepretações. De maneira similar, o elemento emma:model é utilizado para a especificação ou referência ao modelo de dados utilizado na representação semântica de determinada interpretação. Mais de um modelo pode ser especificado, e o atributo emma:model-ref é utilizado para associar interpretações com modelos específicos.

Por fim, o elemento emma: info é utilizado neste exemplo para inserir um identificador de sessão específico pelo desenvolvedor do sistema. Nas interpretações, o atributo emma:tokens serve para indicar a sequencia específica de palavras que foram reconhecidas e emma:confidence contém uma taxa de certeza de acerto entre 0 e 1 para cada interpretação.

Levando em consideração a vasta gama de tipos de entrada suportados, uma característica crítica de projeto da linguagem EMMA é que ela não tem por objetivo padronizar a representação semântica das entradas, ao invés disso ela provê uma série de containers para modos e marcações específicas das aplicações, e um conjunto padronizado de anotações para metadados de uso geral. Ou seja, a linguagem descreve como interações multimodais são executadas por meio de algum modo de interação (por exemplo voz, tinta eletrônica, teclado), mas toda a representação de cada mídia é tarefa do desenvolvedor.

Este trabalho pretende, por meio do uso de Esquemas XML, prover uma maneira de lidar com estas representações semânticas, para o caso particular dos sensores de aceleração, e suas diversas aplicações.

\subsection{Considerações Finais}

Este capítulo apresentou os conceitos necessários para o entendimento deste trabalho, cujas contribuições principais encontram-se relatadas no Capítulo 3. Inicialmente, a área de Interfaces Naturais foi discutida, de modo a definir o contexto e possibilitar a compreensão da motivação que levou ao desenvolvimento deste trabalho. Em seguida, foi apresentada a definição formal e são discutidos os usos e vantagens dos três padrões da W3C utilizados neste trabalho: XML, Esquema XML e EMMA, fundamentais para o entendimento do modelo definido por meio de Esquemas XML (Seção 3.2) e das decisões de projeto que levaram à criação da API Meanings API, discutida na Seção 3.3, que faz uso da linguagem EMMA para estruturar os dados mais os significados destes dados no documento XML gerado. 



플

\section{Arquitetura e Modelo Propostos}

Com base nos conceitos discutidos no Capítulo 2, este capítulo tem por objetivo descrever a arquitetura proposta e o modelo de dados desenvolvido neste trabalho, bem como a API criada para dar suporte à sua utilização. Na Seção 3.1 é apresentada uma arquitetura em três camadas, idealizada para organizar, de maneira abrangente os diversos componentes que fazem parte de um sistema de aquisição, processamento e estruturação de sinais obtidos por meio de sensores acelerômetros. A Seção 3.2 discute o modelo de dados em si, com seus elementos e estrutura. Por fim, na Seção 3.3 discute-se a API criada, sua estrutura e maneiras de utilização.

\subsection{Arquitetura}

A arquitetura proposta neste trabalho e ilustrada na Figura 3.1, define o contexto para os problemas tratados pela abordagem proposta, definindo uma separação conceitual entre três camadas, cada uma das quais responsável pelas seguintes tarefas:

1. Aquisição de dados dos acelerômetros.

2. Categorização dos dados obtidos por meio de reconhecimento gestual.

3. Modelagem e adição de significado aos dados obtidos de acordo com um modelo estruturado. 


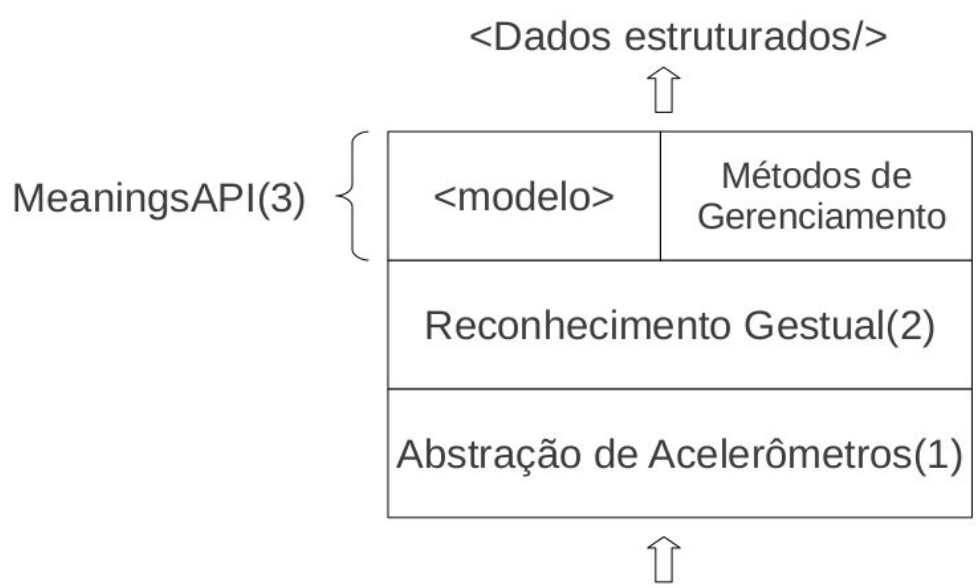

\section{Dados brutos}

Figura 3.1: Arquitetura proposta

Ao definir esta arquitetura, tenciona-se obter um baixo nível de acoplamento entre as camadas, permitindo assim que suas respectivas implementações sejam minimamente dependentes umas das outras. Assim, a API MeaningsAPI, uma das contribuições deste trabalho, foi implementada de modo a ser agnóstica às camadas inferiores, como será demonstrado da Seção 3.3.

Como o foco deste trabalho encontra-se na definição das funcionalidades presentes na terceira camada, para desempenhar as funcionalidades descritas na segunda (Subseção 3.1.2) e primeira camadas (Subseção 3.1.1) fez-se uso de uma solução encontrada na literatura (Seção 1.1), por ser adaptada especialmente para o acelerômetro presente no controle sem-fios Nintendo Wiimote: a API Wiigee (Schlömer et al., 2008). O Wiimote foi projetado para permitir a interação humana com o console Nintendo Wii, e possibilita que reconhecimento gestual básico seja utilizado durante a interação com jogos. Ele foi escolhido para ser utilizado neste trabalho por sua facilidade de obtenção no mercado e seu baixo custo, bem como versatilidade.

A Wiigee disponibiliza interfaces para funções básicas, como obtenção dos dados brutos de aceleração (AccelerationListener), bem como uma interface para funções de reconhecimento (GestureListener). Outras interfaces também são disponibilizadas, como a ButtonListener, que permite a obtenção dos valores emitidos pelos botões do Wiimote quando pressionados. Além das vantagens mencionadas, a Wiigee foi escolhida por ser escrita em Java, livre de custos e de código aberto, bem como compativel com a Requisição de Especificação Java número oitenta e dois (Java Specification Request $n^{\circ}$ 82 - JSR-82), necessária para manipulação de dispositivos bluetooth, como o Wiimote. 


\subsubsection{Abstração de Acelerômetros}

A primeira camada é responsável pela aquisição do fluxo de dados brutos de aceleração e pela conexão com o acelerômetro. Por dados brutos, para os fins deste trabalho, compreende-se a medida da aceleração, em um determinado momento, em cada um dos eixos (X, Y e Z) de um acelerômetro, em unidades de gravidade. Em sua especificação, o acelerômetro utilizado neste trabalho (ADXL330 $)$ é capaz de medir uma aceleração de $3 \mathrm{G}$ até $-3 \mathrm{G}$ (onde $\mathrm{G}$ representa o valor da Gravidade, $-9,8 \mathrm{~m} / \mathrm{s}^{2}$ ). Na Figura 3.2 pode-se observar um exemplo destes dados, da maneira como são obtidos ao se manusear um sensor de aceleração à mão livre.

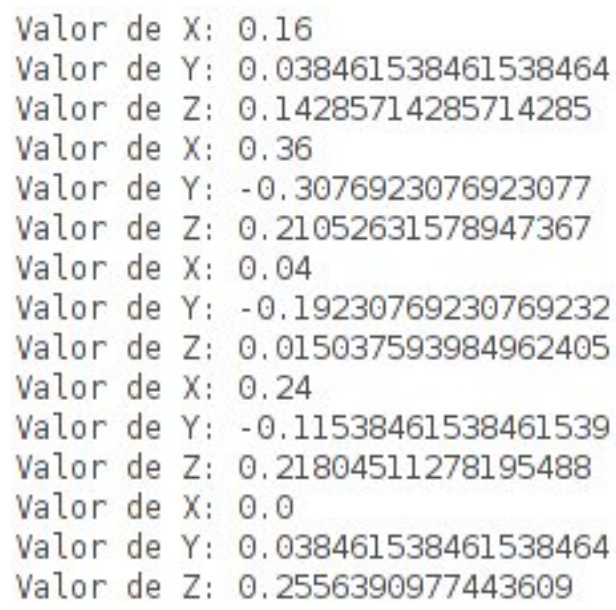

Figura 3.2: Dados brutos de aceleração nos eixos X, Y e Z de um acelerômetro

Ao se medir a aceleração relativa à gravidade, mesmo quando o dispositivo se encontra em repouso, os valores apontados pelo acelerômetro exibem a ação da gravidade da Terra, que continua atuante no dispositivo. Como o valor da aceleração no planeta Terra é constante, o acelerômetro do dispositivo deve apresentar uma aceleração de $1 \mathrm{G}$ em algum de seus eixos, dependendo da posição do dispositivo em relação a gravidade da Terra. No entanto, caso o hardware do sensor seja equipado para descontar a gravidade, em repouso este valor seria zero.

Para implementação dos protótipos descritos neste trabalho (Capítulo 4), escolheu-se o acelerômetro equipado no controle do Nintendo Wii, o Wiimote. O Wiimote vem equipado com o acelerômetro ADXL330, capaz de medir a aceleração em três eixos distintos, sendo eles os eixos X, Y e Z de um plano cartesiano em três dimensões, como ilustrado na Figura 3.3, e enviá-los por meio do padrão de transmissão de dados sem-fio bluetooth.

Como dito anteriormente, a camada de abstração de acelerômetros encontra-se implementada pela API Wiigee. A Wiigee disponibiliza interfaces específicas para obtenção dos

\footnotetext{
${ }^{1}$ http://www.analog.com/en/mems-sensors/inertial-sensors/adxl330/products/product.html. Acessado em $18 /$ nov $/ 2012$
} 


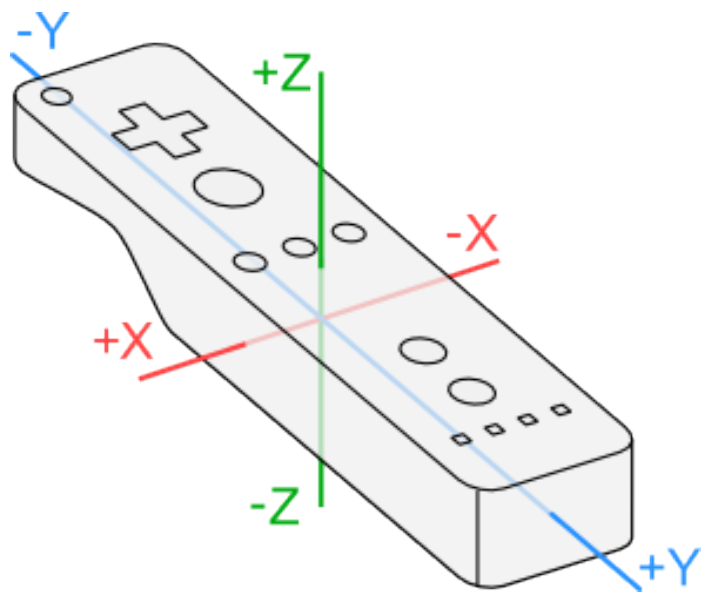

Figura 3.3: Eixos do acelerômetro

dados fornecidos pelo Wiimote. Por meio da interface AccelerationListener é possível implementar o método accelerationReceived, que recebe como parâmetro um evento contendo os dados brutos de aceleração em um determinado momento, como ilustrado na Listagem 3.1. Esta camada é importante pois por meio dela estes dados podem ser acessados a qualquer momento pela terceira camada, podendo então ser encapsulados no documento XML por ela gerado.

Listagem 3.1: Trecho de código exemplificando o uso do método accelerationReceived

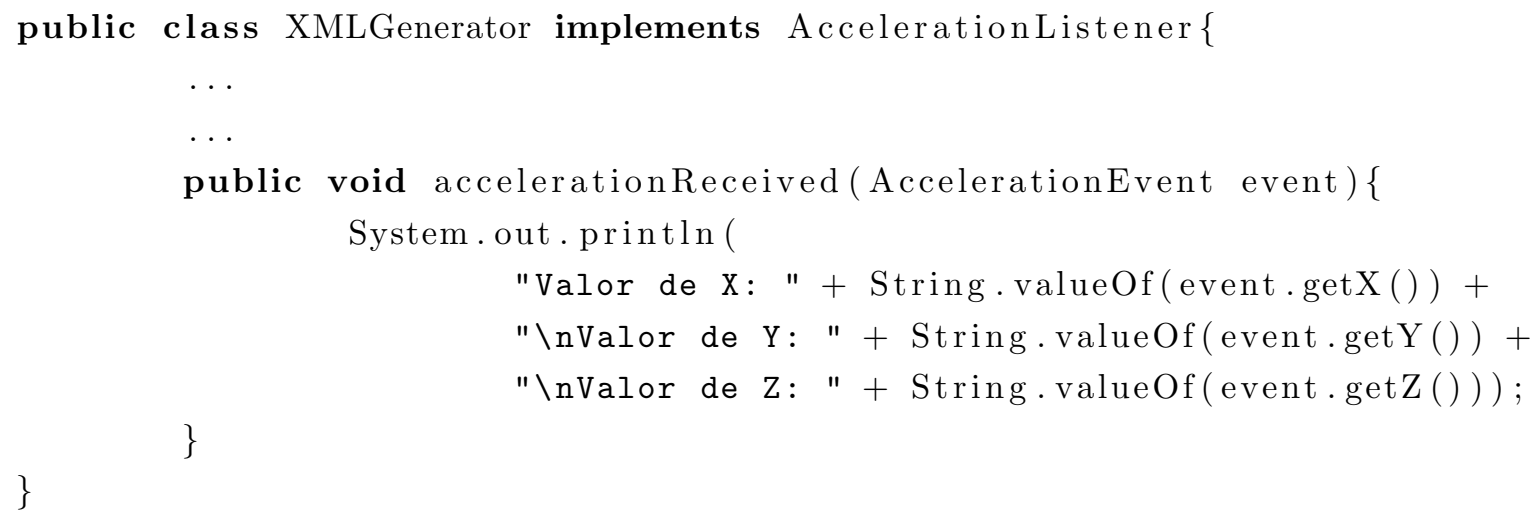

Como especificado por Schlomer et. al. (Schlömer et al., 2008), como a Wiigee é implementada de acordo com o padrão Java de APIs para Tecnologias Sem-Fio Bluetooth (Java APIs for Bluetooth Wireless Technology - JAWT) definida pela especificação JSR-82, para se conseguir fazer uso do Wiimote foi necessário utilizar uma biblioteca bluetooth de terceiros chamada BlueCove ${ }^{2}$. Assim que a conexão é estabalecida por meio do protocolo Bluetooth $\mathrm{HID}^{3}$, é possível obter os dados de auto-descrição do Wiimote. O significado destes dados foram obtidos por meio de engenharia reversa pela comunidade.

\footnotetext{
${ }^{2}$ http://bluecove.org/. Acessado em Acessado em 18/nov/2012

${ }^{3}$ Dispositivo de Interface Humana (Human Interface Device, em inglês)
} 
Baseado nestas descobertas, foi possível estabelecer comunicação com o Wiimote. Desde então, ele vem sendo utilizado pela comunidade open-source e pela comunidade científica, como discutido na seção 1.1 .

Conceitualmente, a camada de abstração de acelerômetros é definida separadamente, para permitir que o modo como os dados dos acelerômetros são obtidos seja flexível, ou seja, possa ser feito de outros modos sem prejuízo para o sistema. Neste trabalho, estes dados são obtidos por meio de eventos gerados por ações executadas com os sensores em tempo real. No entanto, esses dados poderiam ser gerados automaticamente por um programa simulador, ser fornecidos sob demanda por um banco de dados, ou ainda por outro tipo de acelerômetro ou API. Dada a diversidade dos dispositivos disponíveis no mercado, sua implementação é intimamente relacionada com o tipo de sensor utilizado. Nestes casos, a implementação necessária para obtê-los seria diferente, porém enquanto os mesmos forem disponibilizados para outras camadas, do ponto de vista destas, o modo como são obtidos é irrelevante.

\subsubsection{Reconhecimento Gestual}

A segunda camada é responsável pela identificação e categorização dos dados obtidos pela primeira camada, haja vista que somente estes dados brutos são de pouca utilidade para aplicações que visam permitir interação gestual. Ao fim do processo de reconhecimento, uma sequência de caracteres deve ser retornada e encaminhada para a terceira camada, indicando qual ou quais dos gestos definidos na terceira camada foram reconhecidos.

Observando-se que os padrões da maioria dos movimentos executados por usuários mantém-se similares (determinísticos), na literatura é possível encontrar vários algoritmos que possibilitam o seu reconhecimento com alta precisão e baixo custo computacional. Dentre eles, pode-se destacar os Modelos Ocultos de Markov (Hidden Markov Models HMM) (Westeyn et al., 2003), as Redes Neurais Artificiais (Artificial Neural Networks - ANN) (Nissen, 2003) e os de Dobra Dinâmica do Tempo (Dynamic Time Warping DTW) (Sakoe e Chiba, 2005).

Assim como a primeira camada, a camada de reconhecimento gestual, neste trabalho, também encontra-se implementada pela API Wiigee. Como descrito por Schlomer et. al. (Schlömer et al., 2008), o sistema de reconhecimento do Wiigee é composto por três componentes, dispostos em sequência: um quantizador, um modelo e um classificador. Para a quantização, um algoritmo comum de clusterização de dados k-means é utilizado. Devido aos padrões de variação temporal e espacial dos movimentos captados por acelerômetros, um HMM é utilizado devido ao seu extenso uso na literatura com resultados satisfatórios em modelos que seguem estes padrões. Por fim, um tradicional classificador Bayesiano é utilizado. No entanto, antes do fluxo de dados brutos ser tratado pelo sis- 
tema de reconhecimento, ele primeiro passa por dois filtros, um projetado para eliminar todos os sinais que não contribuem para o processo de reconhecimento, como quando o sensor encontra-se em posição estacionária; o outro filtro tem por objetivo eliminar todos os sinais que apresentem repetições, a ponto de pouco contribuir para a caracterização de um gesto.

Por meio da interface GestureListener é possível implementar o método gestureReceived, que recebe como parâmetro um evento contendo os dados relacionados com o resultado do processamento de sinais, como ilustrado na Listagem 3.1.

Listagem 3.2: Trecho de código exemplificando o uso do método gestureReceived

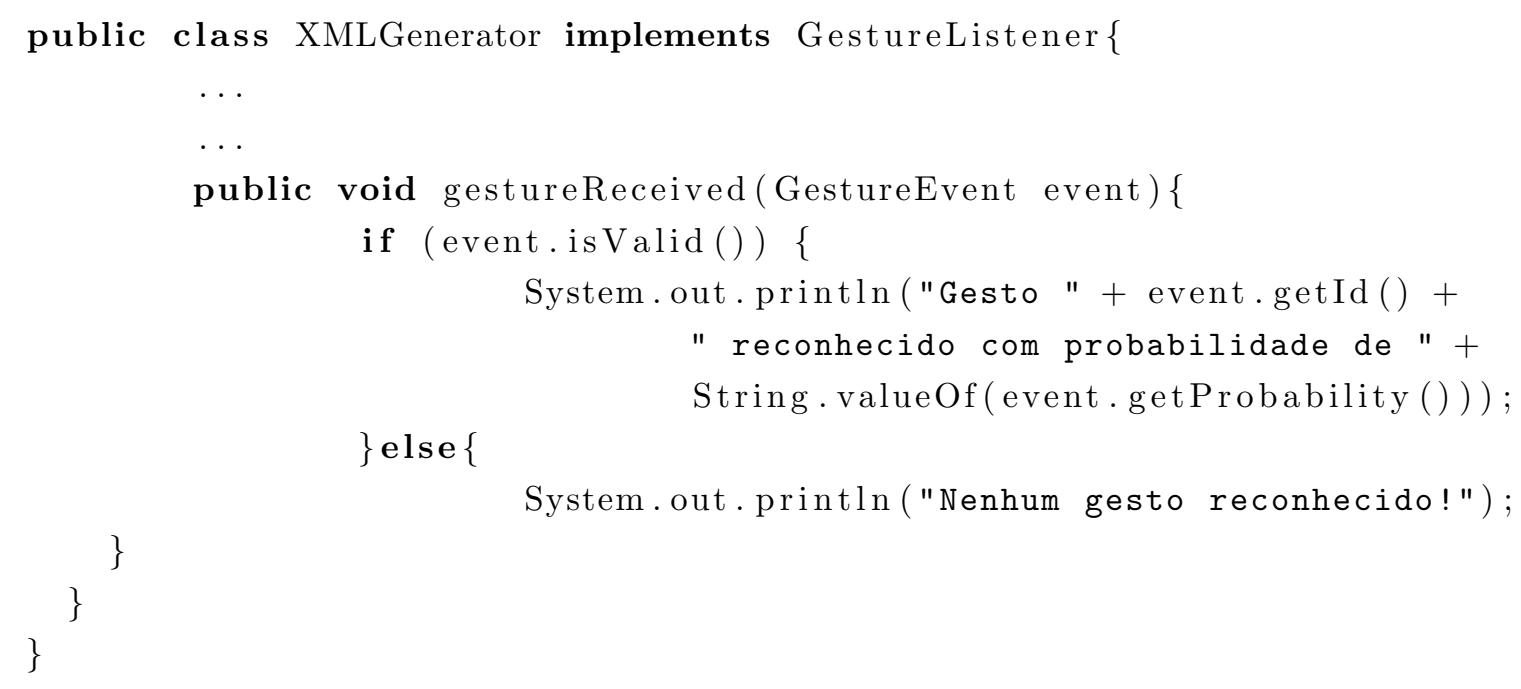

Uma vez identificados e categorizados, os dados brutos agora podem ser associados com seus respectivos significados na terceira camada da arquitetura, responsável por promover o encapsulamento e estruturação destas novas informações no documento XML gerado. Na segunda camada, utiliza-se o processo de reconhecimento de sinais já implementado pela Wiigee, baseado nos modelos ocultos de Markov, no entanto, assim como na primeira camada, este processamento pode ser feito por qualquer algoritmo (por exemplo DTW ou ANN), contanto que por meio dele a terceira camada possa associar um determinado padrão de sinais com os significados definidos pelo desenvolvedor, validando os mesmos por meio do modelo descrito na Seção 3.2.

\subsubsection{API}

Visando implementar a abordagem proposta, uma API chamada MeaningsAPI foi desenvolvida, como pode ser visto na terceira camada da Figura 3.1. Essa API tem como principal objetivo prover os dados da primeira camada juntamente com seus respectivos significados, de acordo com os gestos reconhecidos na segunda camada, por meio da geração de um documento XML para a aplicação requisitante. A API também contém 
métodos de gerenciamento de gestos e de suas categorias, permitindo a edição e a criação de novos gestos de acordo com as necessidades da aplicação. Seu projeto e modos de utilização serão melhor detalhados na Seção 3.3, com base nas características do modelo definidas na Seção 3.2.

\subsection{Modelo}

Como discutido na Seção 1.2, dentre os objetivos deste trabalho está a criação de um formato de dados estruturado e extensível para acelerômetros, juntamente com descritores de significados, de tal modo que a informação seja interoperável. Para atingir este objetivo e possibilitar a interoperabilidade dos dados, este trabalho fez uso da linguagem XML, devido a sua maturidade como especificação e consequente aceitação pela comunidade de desenvolvedores e pelo mercado. Outra característica desejável da XML, é a possibilidade de criação de novas tags, o que na prática permite a definição de novas linguagens a partir desta, por meio dos recursos de descrição de vocabulários e regras delimitadoras definidas pelos Esquemas XML, discutidos na Seção 2.2.1.

Assim, o modelo proposto neste trabalho é composto por dois Esquemas XML, um principal e outro auxiliar, como ilustrado pelo diagrama de classes na Linguagem Unificada de Modelagem (Unified Modeling Language - UML) da Figura 3.4. Embora todo o modelo seja extensível e possa ser adaptado às necessidades de diversas aplicações, neste trabalho foram desenvolvidos dois tipos de esquemas, com o intuito de separar sua estrutura básica (principal) da parte em que os significados dos dados são definidos (auxiliar). Dessa maneira, o modelo auxiliar torna-se um componente intercambiável, podendo ser alterado conforme as demandas da aplicação.

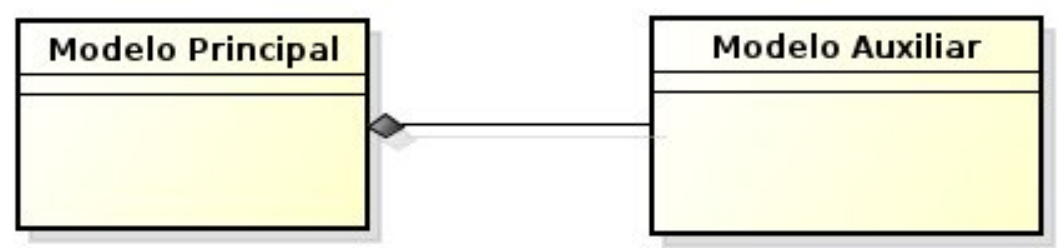

Figura 3.4: Diagrama de classes UML para o relacionamento entre modelos

O esquema principal é responsável pela descrição dos dois elementos que compõem o modelo proposto ("data" e "meaning"), que encapsulam os dados brutos providos pelos acelerômetros (por exemplo aceleração nos eixos X, Y e Z) juntamente com seus respectivos significados. Informações relativas ao significado dos dados brutos são importantes pois, dependendo da aplicação, pode ser muito mais interessante apenas um simples comando (por exemplo "esquerda") do que uma longa sequência de valores de aceleração 
agindo sobre os eixos. Já o esquema auxiliar é responsável pela personalização do elemento "meaning", responsável pelos significados dos dados, definido de maneira abstrata como meio de garantir sua extensibilidade para diversos contextos de aplicações. Para ilustrar esta relação, uma composição é estabelecida entre os modelos na Figura 3.4, pois o modelo principal necessita das definições contidas no modelo auxiliar, não podendo ser instanciado por si só por conter tipos abstratos, como discutido na Subseção 3.2.2.

Na Listagem 3.3 é apresentada a primeira parte do esquema principal, onde pode-se observar a declaração dos dois elementos principais deste modelo: o elemento "meaning" e o elemento "data". O restante do esquema principal, bem como a especificação destes dois elementos, será discutido nas Subseções 3.2.1 e 3.2.2.

Listagem 3.3: Declaração do elementos "data" e "meaning"

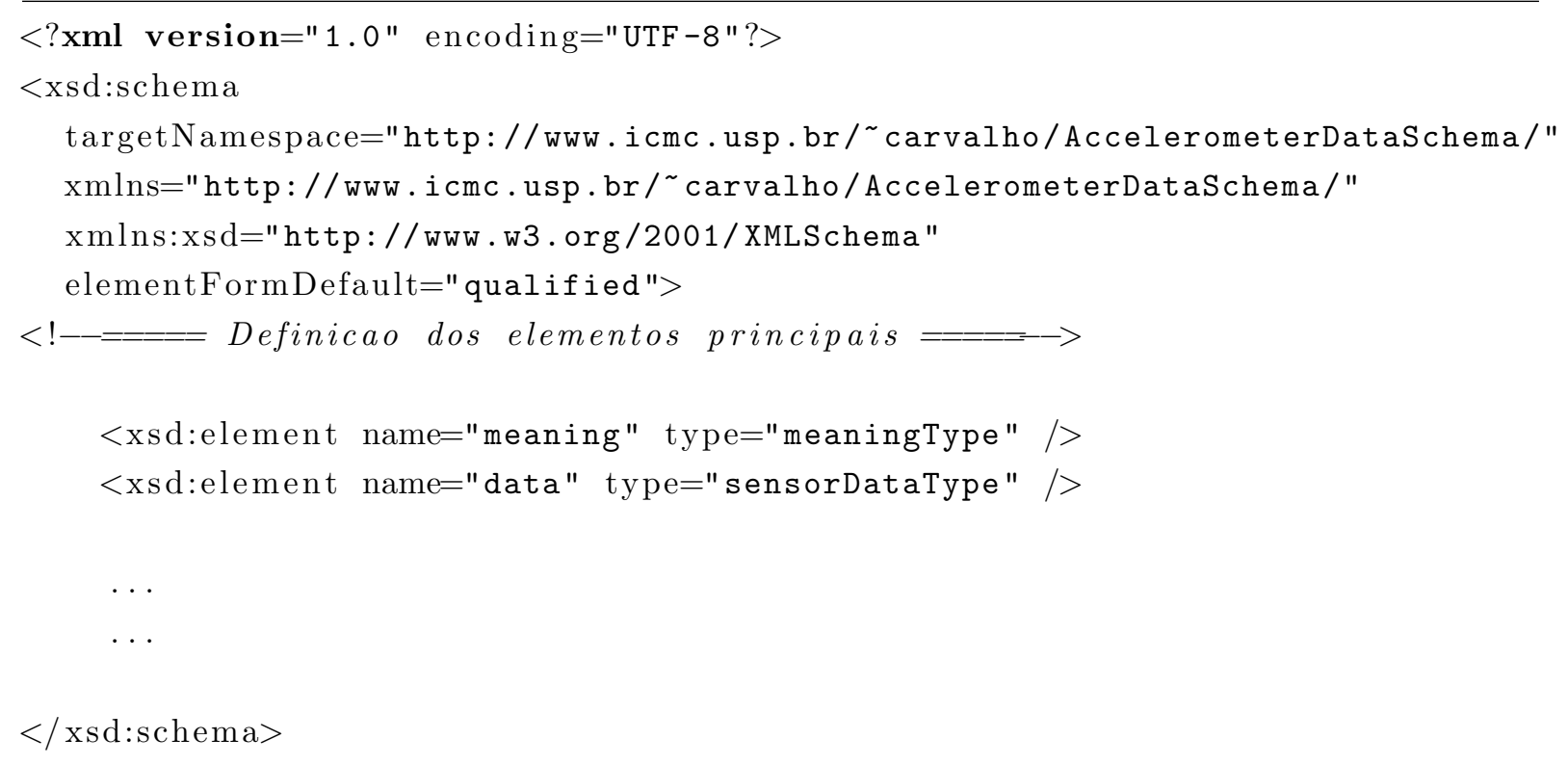

Além dos dados que estes dois elementos encerram, as aplicações necessitam de outras informações para o seu processamento. Essas informações devem vir na forma de metadados que forneçam detalhes técnicos relacionados com o fluxo de dados obtido, bem como seu processo de identificação. O momento inicial e final em que os dados foram capturados (timestamp), qual dos gestos reconhecidos seja o mais provável significado do movimento feito pelo usuário (taxa de confiança) ou ainda qual modelo auxiliar foi utilizado para especificar estes significados, são todos exemplos de possíveis metadados.

Como discutido na Subseção 2.2.2, o padrão W3C EMMA disponibiliza metadados para descrição de dados multimodais, por meio de regras estruturais e várias opções de elementos e atributos. Porém, por definição, a linguagem EMMA não especifica como os dados multimodais que encerra devem ser estruturados. Neste trabalho, preenche-se esta lacuna, para o modo específico de interação provido por sensores de aceleração, por meio da definição de um modelo que descreva tanto os dados brutos quanto os seus respectivos 
significados. Assim como este modelo, EMMA também é descrita por meio da linguagem XML, o que facilitou a sua adoção, objetivando a criação de um modelo completo e abrangente. Na Subseção 3.3.1 mais detalhes sobre esta junção são discutidos.

\subsubsection{O Elemento 'data'}

Ao definir um modelo que encerre e estruture os dados providos por acelerômetros, a primeira necessidade atendida neste trabalho foi a criação de elementos específicos para o fluxo de dados brutos enviados. Estes dados brutos são representados pelo valor da aceleração em um determinado instante para cada um dos eixos do sensor, X, Y e Z. Estas informações, embora desprovidas a priori de significado, são necessárias, pois todo o processamento é realizado com base nelas. Além disso, podem haver situações em que significados não sejam necessários, bastando apenas que, em cada um dos eixos certos valores sejam atingidos, para que uma determinada ação seja executada. Visando atender a estas necessidades, para descrever o elemento "data" o tipo complexo sensorDataType foi projetado.

Como ilustrado na Listagem 3.4, o tipo sensorDataType define uma sequência de seis elementos, criados para encapsular o valor da aceleração dos três eixos do acelerômetro. Isso se deve ao fato de que existem sensores que não dispõem do hardware necessário para descontar a aceleração da gravidade dos valores sendo transmitidos pelos eixos, como discutido na Subseção 3.1.1. Para tratar deste problema, o tipo sensorDataType define dois elementos para representar a aceleração em cada um dos eixos. Assim, para encapsular o valor da aceleração no eixo X, pode-se utilizar tanto o elemento valueX quanto o elemento valueXwithgrav, sendo este último o destinado a conter o valor da aceleração exercida pelo movimento juntamente com valor da gravidade, como é o caso dos sensores que não dispõem de meios para descontá-la. O mesmo ocorre para os eixos Y e Z, com os elementos valueY, valueYwithgrav, valueZ e valueYwithgrav. Desse modo, caso a aplicação necessite dos dados em ambos os casos, com ou sem gravidade, estes são representados pelo modelo. No entanto, como especificado pelo atributo minOccurs="0", os elementos que contém os valores com a gravidade descontada (valueX, valueY e valueZ) são opcionais, haja vista que nem todos os sensores dispõem dessa opção. Por outro lado, o segundo conjunto de elementos (valueXwithgrav, valueYwithgrav e valueZwithgrav) deve aparecer em ambos os casos, devido ao fato de que se o sensor dispõe do hardware necessário para descontar a gravidade, então ele pode fornecer ambos os conjuntos de dados, com e sem os valores descontados.

Listagem 3.4: Definição do tipo complexo sensorDataType

$<!$ $=$ Definicao do tipo sensorDataType 
Objetivando estruturar o modelo de maneira lógica para as aplicações, o elemento data, ao ser declarado no documento de instância, deve conter estes elementos na sequência em que foram definidos, como especificado pelo elemento <xsd:sequence $\rangle$. Assim, se for o caso, os valores de aceleração sem a gravidade devem aparecer primeiro, sempre seguidos pelos valores com a gravidade.

A fim de deixar bem claro para aplicação se o sensor que forneceu os dados encapsulados é capaz ou não de fazê-lo com a aceleração da gravidade descontada, o modelo também especifica um atributo para o elemento data chamado gravity, definido pelo tipo simples gravityType, podendo assumir somente valores booleanos, como true ou false. De modo semelhante, os valores de aceleração são definidos pelo tipo simples accelerationValueType, podendo por sua vez assumir valores numéricos de ponto flutuante do tipo double, definido pela especificação dos Esquemas XML e discutido na Seção 2.2.1. Na Listagem 3.5 ilustra-se os tipos simples especificados pelo tipo sensorDataType.

Listagem 3.5: Definição dos tipos simples accelerationValueType e gravityType

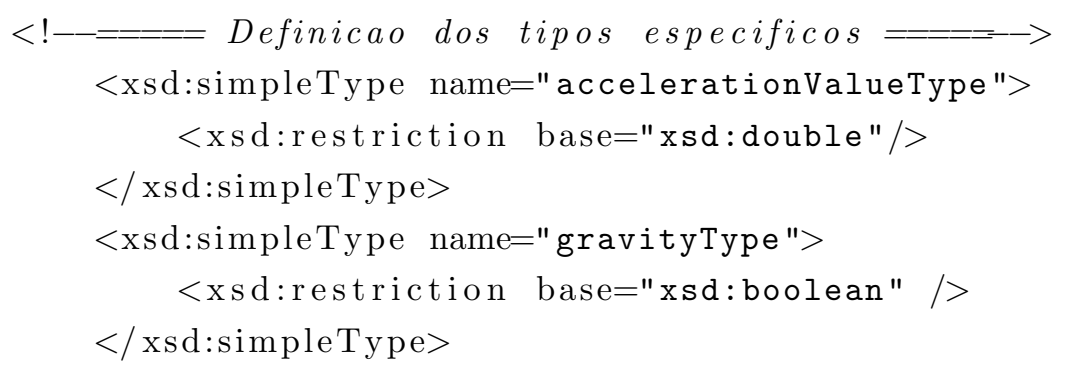




\subsubsection{O Elemento 'meaning'}

Após os dados brutos serem definidos, partiu-se para a definição dos seus respectivos significados. Por "significado", neste trabalho depreende-se uma sequência concisa de caracteres que representem um comando simples e que possa ser interpretada por aplicações de modo não ambíguo. Conceitos únicos, como "frente" e "trás", e comandos como "faça isto" ou "faça aquilo", não geram margem para dúvidas, por tanto podem ser utilizados como significados. Fica a cargo do desenvolvedor a escolha dos significados que irá utilizar, dependendo das demandas da aplicação.

No entanto, além da simples definição de significados (identificados pela segunda camada da arquitetura) relativos ao fluxo de dados brutos(fornecidos pela primeira camada da arquitetura) encapsulados, outras informações sobre este significado, como sua descrição ou algum trecho de código associado, podem ser úteis para as aplicações de um modo geral. Assim, este modelo também define elementos que contextualizam e enriqueçem o significado identificado, de modo genérico. Como pode ser observado na Listagem 3.6, originalmente para o tipo complexo meaningType foram escolhidos sete elementos. Dentre eles, o elemento principal, que contém a sequência de caracteres relativa ao significado identificado associado pela API, é o elemento value, representado por um identificador númerico único contido no elemento id, fornecido pela segunda camada. O valor contido no elemento value deve pertencer à categoria de significados descrita no elemento type.

Como discutido na Subseção 3.2.3, este modelo permite a definição e subsequente incorporação de novos significados e categorias de significados aos dados brutos. Por "categorias de significados" depreende-se um conjunto de valores pertencentes a um certo conceito, por exemplo o conceito de direção, que pode compreender valores como esquerda, direita, cima, baixo, frente e trás, ou o conceito de formas geométricas, como o triângulo, o quadrado e o círculo. Assim, o elemento type foi definido para conter esta categoria de significados a qual pertence o valor do elemento value. Este elemento é importante, pois a aplicação pode estar lidando com vários significados, de modo que fique claro que um mesmo significado pertencente a categorias diferentes não represente o mesmo conceito. O elemento codeSnippet fornece a possibilidade de associar trechos de código relacionados com o significado sendo definido, podendo ser utilizado como parâmetro para a execução da aplicação. Por fim, os elementos creatorName, creationDate devem conter o nome do criador do significado e a data de criação do mesmo, respectivamente. De maneira similar, também há a possibilidade de incluir comentários pertinentes a este significado, por meio do elemento comment. $\mathrm{O}$ atributo min0ccurs $=0$ presente nos elementos comment e codeSnippet indica que não necessariamente precisam estar presentes no XML de instância, no entanto, todos os outros são obrigatórios. 
Listagem 3.6: Definição dos tipos complexo meaningType

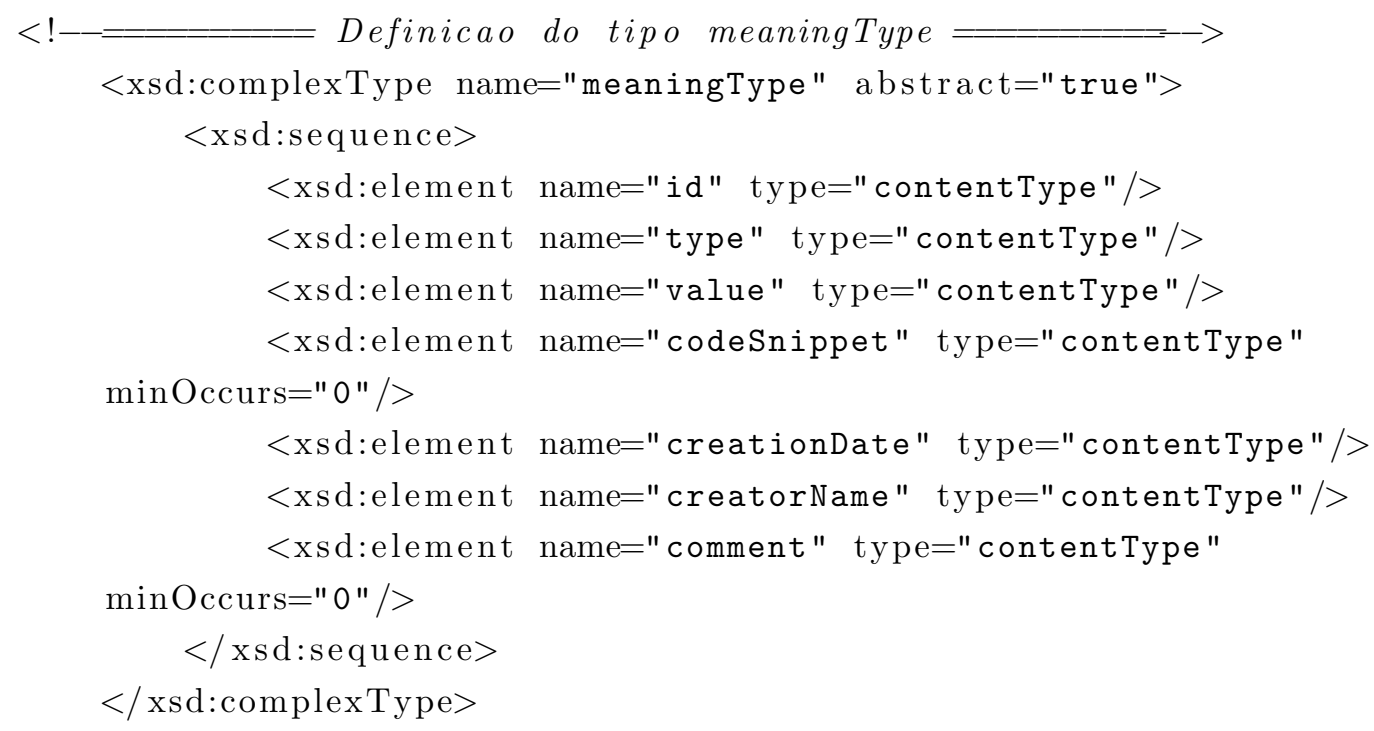

Todos os elementos definidos pelo tipo complexo meaningType são do tipo contentType, o que significa, a priori, que eles podem conter qualquer tipo de dados, como descrito na Listagem 3.7. Isto se deve ao fato de meaningType ser definido como um tipo abstrato, como denotado pelo atributo abstract="true". Devido este elemento ser abstrato, ele não pode ser diretamente instanciado. Primeiramente é necessário que um tipo derivado do mesmo seja definido, seja por meio de uma restrição ou uma extensão (veja Seção 3.2.3). Assim, se obriga o desenvolvedor a personalizar o tipo meaningType de acordo com as necessidades da sua aplicação. Caso apenas os elementos definidos no modelo principal bastem para suas necessidades, então basta que os tipos de dados comportados por cada um destes elementos seja definido. Caso contrário, outros elementos podem ser definidos e os que existem podem ser descartados, bastando que a definição concreta do tipo o especifique, como pode-se observar durante o desenvolvimento dos protótipos do Capítulo 4.

Listagem 3.7: Definição do tipo complexo contentType

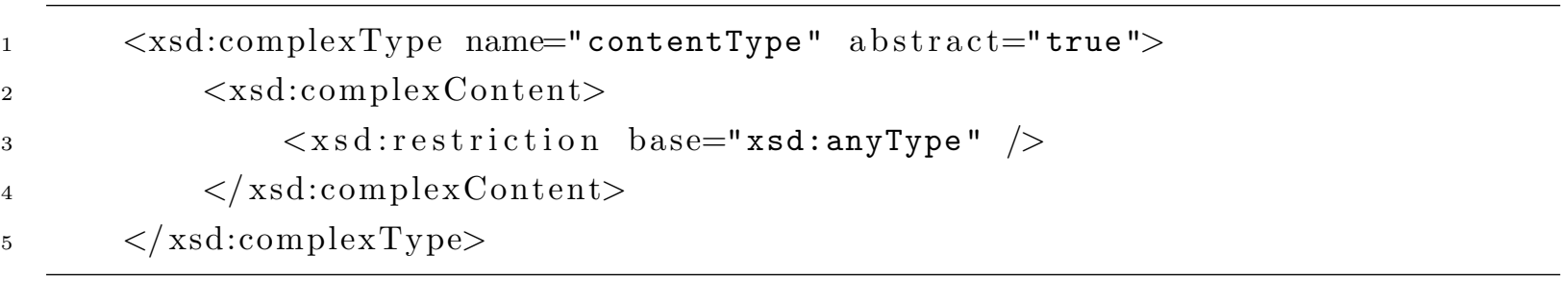

A especificação do tipo tipo concreto meaningType é de responsabilidade do modelo auxiliar, discutido na Subseção 3.2.3. 


\subsubsection{Modelo Auxiliar}

O Esquema XML utilizado para definir o modelo proposto, como visto na subseção 3.2.2, deve ser utilizado com outros espaços de nomes também definidos por Esquemas XML, criados para descrever os tipos concretos derivados do tipo abstrato meaningType. Em outras palavras, um modelo auxiliar deve ser escrito com as categorias de significados a serem utilizadas pela aplicação, juntamente com seus possíveis valores.

Este novo modelo deve ser escrito com base nas demandas da aplicação sendo desenvolvida. Primeiro é necessário identificar os valores de significados utilizados como entrada pela aplicação. Feito isto, deve-se especificar uma categoria de significados para estes valores, com base no conceito lógico que eles representam.

Os protótipos desenvolvidos neste trabalho, e descritos no Cápitulo 4, utilizam como entrada direções e formas expressas através de movimentos, definidas por convenções bem conhecidas, como as noções de esquerda, direita, cima e baixo utilizadas, por exemplo no protótipo de trocas de áreas de trabalho (Seção 4.1), ou o formato de "cruz" utilizado no protótipo Genius, discutido na Seção 4.2. Após identificar-se este valores, cria-se o novo Esquema XML. Este novo esquema, neste trabalho chamado de "UserRepository" (como especificado na linha dois da Listagem 3.8 pelo atributo targetNamespace), deve conter a definição concreta do tipo meaningsType, seus novos elementos (se for o caso) e o tipo de valores que cada um de seus elementos deve conter.

Para atender à demanda de aplicações que necessitem de valores direcionais, na Listagem 3.8 ilustra-se a definição da categoria de significados directionsType. Como pode-se observar, os elementos constantes no tipo abstrato original (Listagem 3.6), bem como sua ordem, foram mantidos, apenas tendo o seus tipos de valores suportados definidos para tipos nativos mais específicos, como string, short e dateTime.

O elemento value, no entanto, aqui tem seus valores limitados pelo tipo simples directionsList. O valores que ele pode assumir são definidos por uma enumeration de string para assumir apenas um destes quatro valores: left, right, up ou down. Aqui são definidos os valores que serão utilizados pela aplicação como entrada para executar suas tarefas. Além disso, o elemento type aqui é definido com um valor fixo, para ilustrar que qualquer elemento meaning do tipo directionsType deve conter em seu elemento type o valor direction, como denotado pelo atributo fixed='direction'.

Antes da definição do tipo concreto, por meio do elemento import o esquema principal é inserido no modelo auxiliar e declarado pelo espaço de nomes "ads", sigla para Accelerometer Data Schema. Assim, o tipo abstrato definido pelo modelo principal meanings Type pode ser utilizado como base para a restrição e sua consequente definição concreta, como denotato pelo trecho de código <xsd:restriction base=' ads:meaningType'>. 


\section{CAPÍTULO 3. ARQUITETURA E MODELO PROPOSTOS}

Listagem 3.8: Definição do tipo concreto directionsType baseado no tipo abstrato meaningType

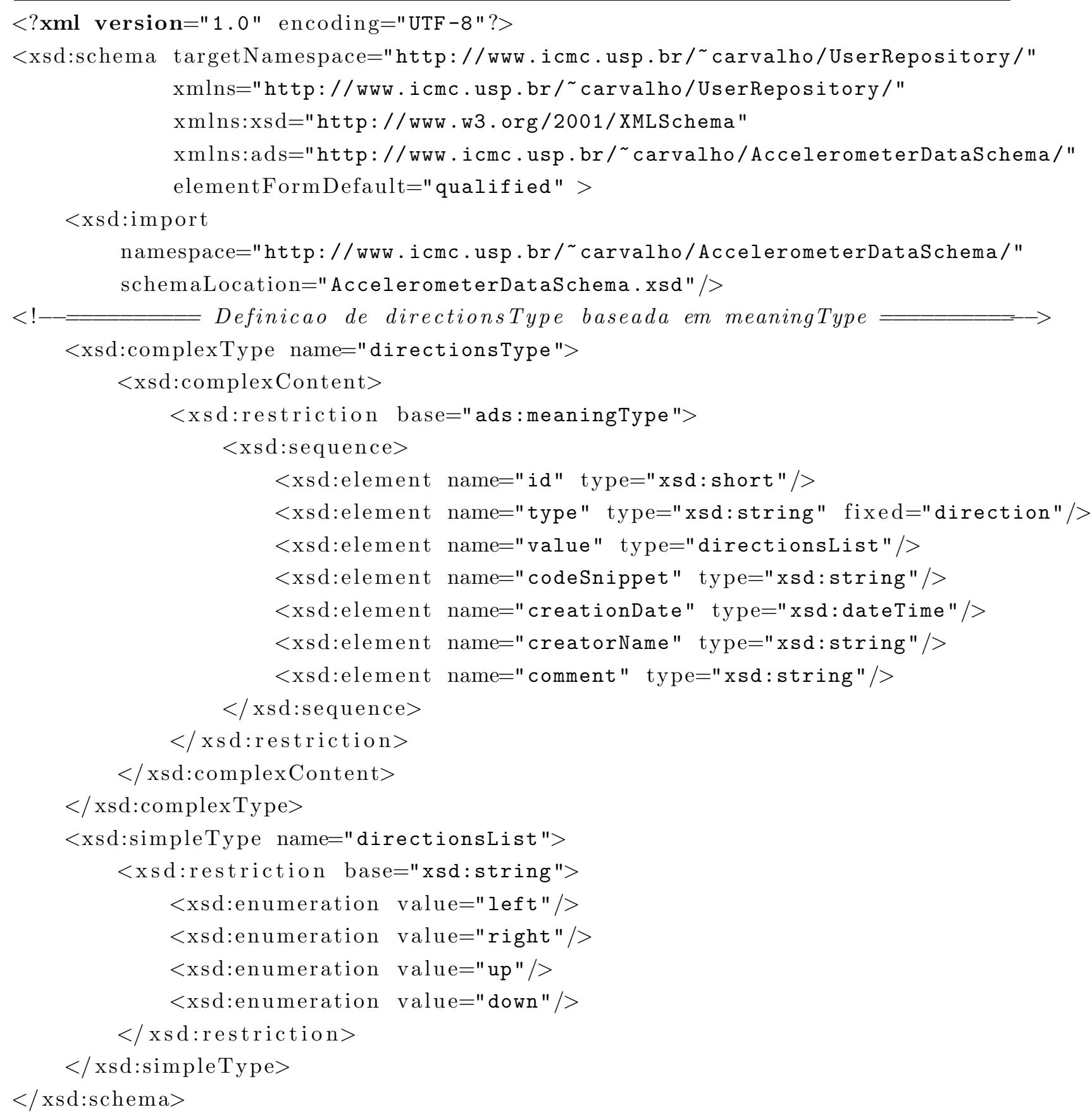

No entanto, outras categorias com outros possíveis valores podem ser definidas, contanto que estas sejam derivadas do tipo abstrato meaningType. Na Listagem 3.9 pode-se observar outro exemplo de categoria de significado e novos valores, baseada no tipo abstrato meaningType.

A presença do trecho de código <xsd:restriction base='ads:meaningType'> denota que este novo tipo concreto tem como base o tipo abstrato meanings Type, porém apresenta algumas mudanças. Este novo tipo, chamado de shapes Type, agora define quatro 
significados relacionados com formas geométricas, como pode-se observar na enumeration de string shapesList, a saber: circle, triangle, square, cross. Outra diferença que pode ser observada é a definição de um novo valor fixo para o elemento type, agora devendo constar no elemento de instância como "shape", como denotado pelo atributo fixed=' shape'.

Listagem 3.9: Definição do tipo concreto shapesType baseado no tipo abstrato meaningType

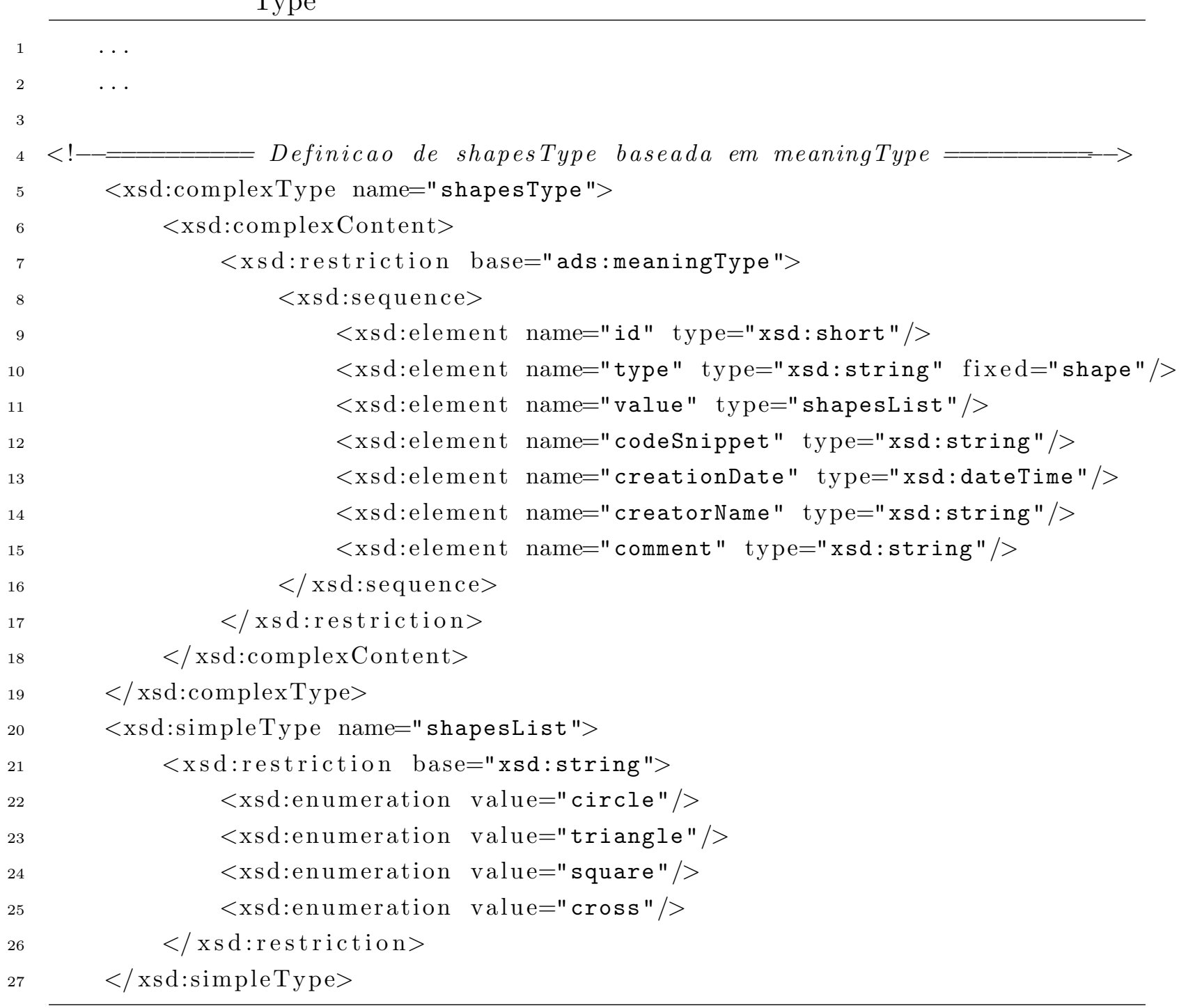

\subsection{MeaningsAPI}

Como discutido na Seção 3.1, uma API que implemente a abordagem proposta deve receber e estruturar os dados provenientes da primeira e da segunda camadas, e então gerar um documento XML contendo os dados estruturados juntamente com seus respectivos significados. Para atender a estas necessidades, neste trabalho desenvolveu-se API " $M e a-$ ningsAPI", ilustrada pelo diagrama de classes UML da Figura 3.5. 
A implementação de uma API que gere documentos de acordo com a abordagem proposta é interessante do ponto de vista dos desenvolvedores, pois ela disponibiliza as ferramentas necessárias para que as regras previstas pelo modelo sejam satisfeitas, permitindo assim que foco da implementação seja voltado para a aplicação que de fato fará uso dos dados.

Para a implementação da Meanings API, a linguagem de programação escolhida foi Java, visando uma melhor integração com a API Wiigee, também desenvolvida nesta linguagem, utilizada neste trabalho por disponibilizar interfaces específicas para obtenção dos dados fornecidos pelo Wiimote e possuir um módulo de reconhecimento gestual, desempenhando assim o papel da primeira e segunda camadas, como discutido na Seção 3.1.

Como ilustrado na Figura 3.5, a MeaningsAPI é composta por três pacotes principais, o core, o pojos e o utils. O pacote core contém a classe "MeaningsAPI", classe principal da API responsável pela implementação das interfaces da Wiigee que contém os eventos gerados pela primeira e segunda camadas. A classe "MeaningsAPI" contém três métodos principais: accelerationReceived(), createGesture() e gestureReceived(). Estes métodos fazem uso de todas as outras classes definidas pela API e ilustradas na Figura 3.5 .

O método accelerationReceived() recebe como parâmetro um evento contendo os valores de aceleração, toda vez que algum movimento for detectado pelos eixos do acelerômetro. Estes valores são então inseridos em uma instância da classe Data, que por sua vez é encapsulada em uma instância da classe AccelerometerData. O método createGesture() é o responsável pelo cadastro de novos significados em instâncias da classe Meaning, e recebe como parâmetros valores correspondentes aos atributos desta classe, como ilustrado na Listagem 3.10. Cada novo significado também é encapsulado em uma instância da classe AccelerometerData. Por fim, sempre que um novo gesto é identificado, um evento é disparado e recebido pelo método gestureReceived(). Este método é responsável por acessar a instância da classe AccelerometerData, recuperar os dados brutos de aceleração contidos em seu atributo Data, comparar o identificador do gesto reconhecido com os identificadores de cada um dos significados cadastrados no atributo meanings e chamar o método generateXML() da classe XMLManager, que por sua vez criará o documento XML com todos os dados encapsulados fazendo uso do método saveFile().

O pacote utils foi criado para conter classes que forneçam serviços para a API, como a classe XMLManager, que possibilita a criação de um documento XML com base nas informações contidas em um objeto AccelerometerData. Neste trabalho, a biblioteca XStream ${ }^{4}$ é utilizada para auxiliar na geração do arquivo XML de saída, como pode ser observado

\footnotetext{
${ }^{4}$ http://xstream.codehaus.org/. Acessado em 18/nov/2012
} 


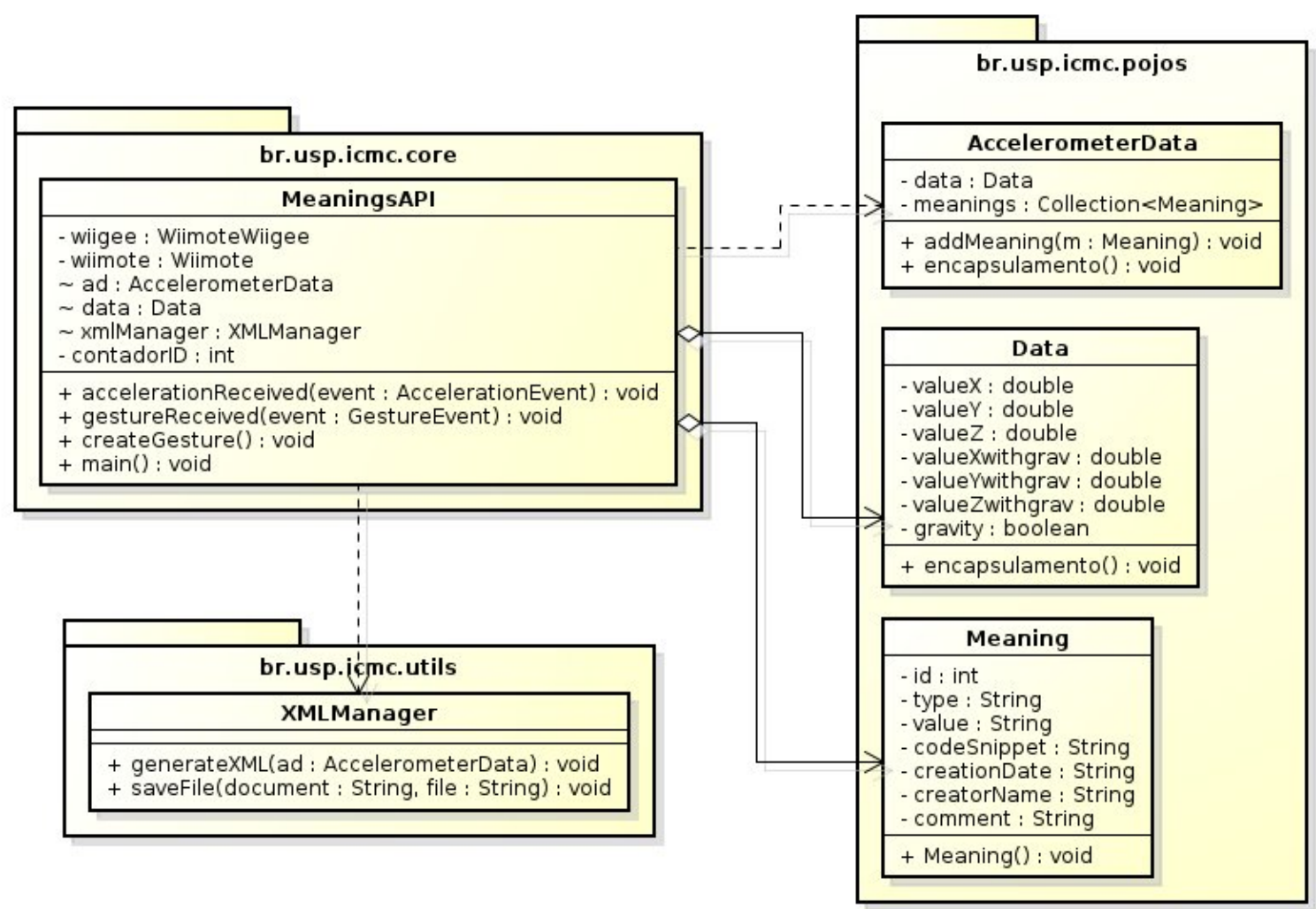

Figura 3.5: Diagrama de Classes UML para o relacionamento entre classes da API $M e-$ anings API

na Listagem 3.10. O pacote pojos, por sua vez, foi projetado para conter simples classes Java (Plain Old Java Objects - POJOs) que servem apenas para armazenar as informações a serem encapsuladas no documento XML gerado pela API.

A API foi projetada para oferecer suas funcionalidades por meio de simples chamadas por métodos. O processo de adição de significados aos dados brutos dos acelerômetros é feito sem a intervenção do usuário, na ocasião da geração do documento XML resultante, com os dados de entrada sendo automaticamente associados com o seu respectivo significado.

Listagem 3.10: Atributos da classe Meaning

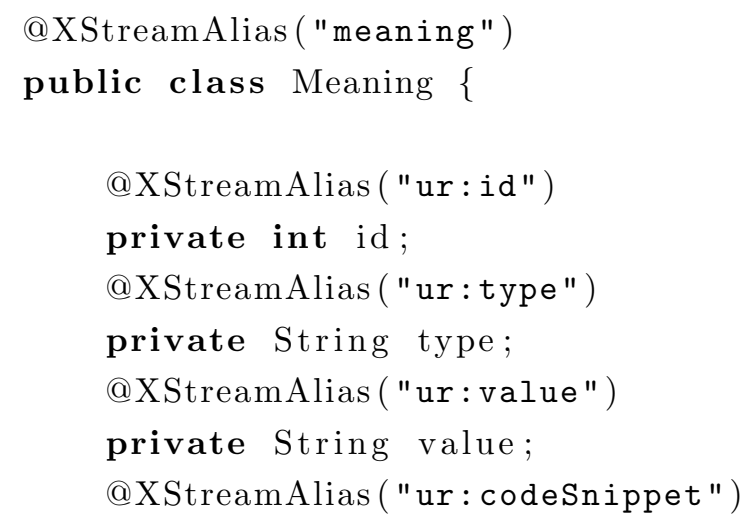




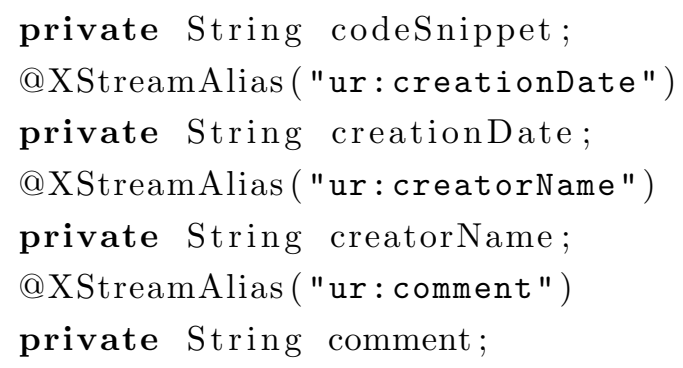

\subsubsection{Documento Gerado e Integração com EMMA}

Como discutido na Seção 3.2, além dos dados brutos e seus respectivos significados, as aplicações necessitam de metadados e regras estruturais que definam melhor os dados e facilitem o processamento das aplicações. Como discutido na Subseção 2.2.2, o padrão W3C EMMA fornece estes metadados, por meio de regras estruturais e várias opções de elementos e atributos.

Contudo, como visto em Carvalho et. al. (Carvalho et al., 2012), a estrutura multimodal provida pelo padrão EMMA não necessariamente precisa ser utilizada. No entanto, a linguagem EMMA é um padrão criado pela W3C para interoperabilidade de dados multimodais, projetada e testada por desenvolvedores do mundo todo ligados tanto à academia quanto à indústria. Assim, visando dar mais alcance a este trabalho, optou-se por fazer uso desta estruturação no documento XML gerado pelo método generateXML() da classe XMLManager.

Como pode ser observado na Listagem 3.11, por meio da utilização do elemento EMMA <emma: group/>, o XML resultante gerado pela API pode conter um ou mais significados associados com os mesmos dados brutos obtidos durante o tempo de captura compreendido por emma:start e emma:end. O atributo emma:medium define todas as entradas descritas como sendo de proveniência tátil. Cada significado no padrão EMMA é definido como uma <emma: interpretation / > . Todas as interpretations são definidas por meio do modelo principal "ADS" referenciado pelo atributo emma:model-ref, embora possam ser definidas individualmente por outros modelos (bastando que os mesmos sejam declarados individualmente por meio do elemento <emma:model/>) e associadas a alguns metadados, como o modo da interação definido pelo atributo emma:mode. A intepretação que contém os dados brutos é aquela definida por meio do emma:mode como sendo "acceleration", podendo vir sozinha no documento XML gerado ou acompanhada de um ou mais significados, identificados pelo emma:mode como sendo "gesture" e descritos pelo namespace "ur" definido no topo do documento, e que faz referência ao esquema auxiliar UserRepository discutido na Subseção 3.2.3, contendo as definições dos significados a serem utilizados pela aplicação. 


\section{CAPÍTULO 3. ARQUITETURA E MODELO PROPOSTOS}

Listagem 3.11: Exemplo de um documento de instância

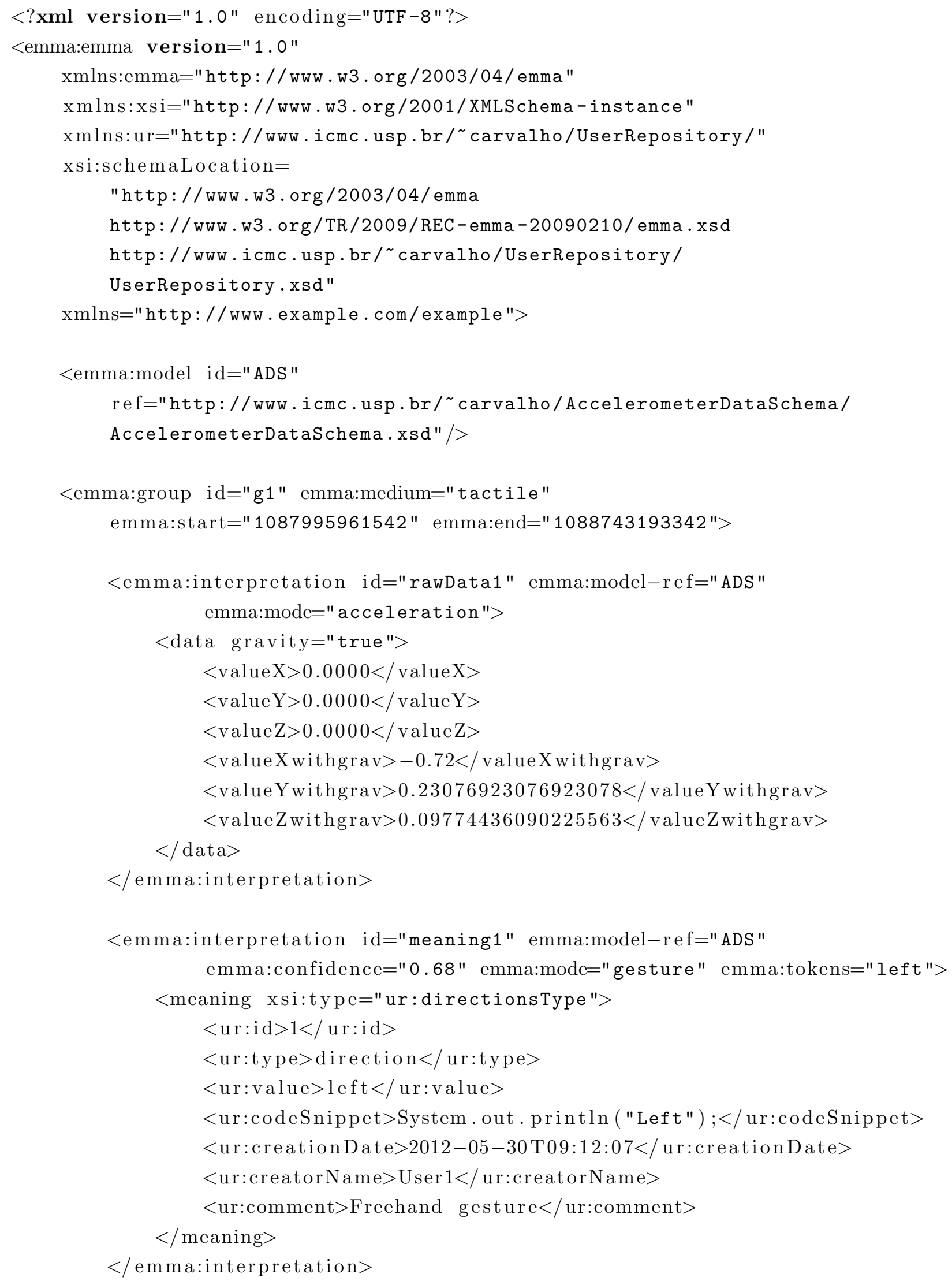




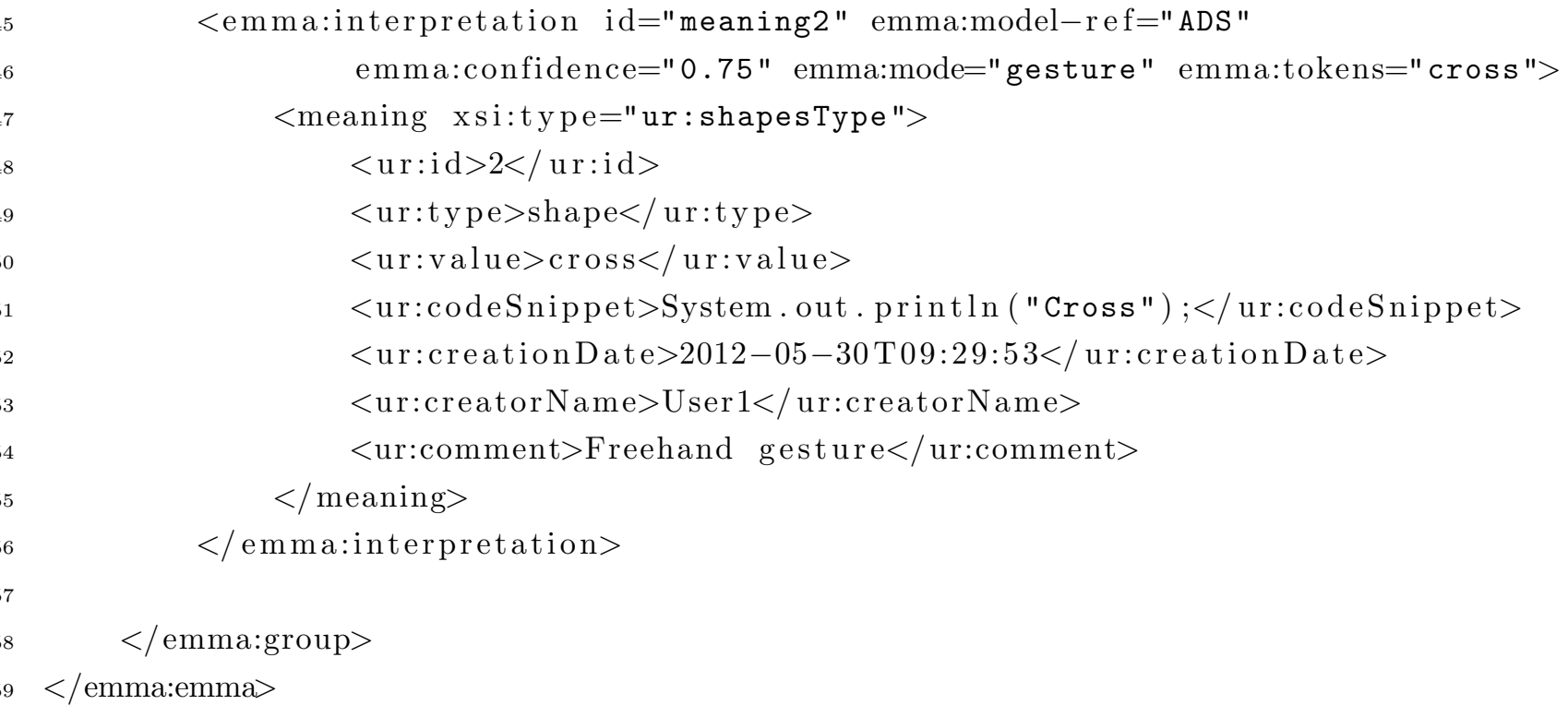

\subsection{Considerações Finais}

Como discutido no Capítulo 1, este trabalho tem por objetivo desenvolver uma abordagem para o tratamento de dados de acelerômetros, permitindo que os mesmos sejam manipulados e intercambiados por diversas aplicações. Neste capítulo, as principais contribuições deste trabalho neste sentido foram detalhadas, por meio da especificação de uma arquitetura que visa um baixo acoplamento entre suas camadas, a definição de um modelo de dados que faz uso da linguagem XML, padronizada pela W3C e adotada por desenvolvedores do mundo todo, tanto na academia quanto na indústria. Para a geração do documento XML especificado pela abordagem proposta, uma API foi desenvolvida, com o intuito de fornecer as ferramentas necessárias para que as regras previstas pelo modelo sejam satisfeitas, permitindo assim que foco da implementação seja voltado para a aplicação que de fato fará uso destes dados.

A fim de exemplificar o uso do modelo e API descritos neste capítulo, no Capítulo 4 alguns cenários que necessitam de diferentes tipos de valores e categorias de significados são descritos, juntamente com três implementações e o modo como foram implementadas por meio das contribuições deste trabalho. 


\section{Cenários e Exemplos de Uso}

Como exposto no Capítulo 3, a abordagem deste trabalho pode ser adaptado para atender a cenários diversos, dependendo das necessidades das aplicações. As tecnologias nas quais este trabalho se baseia, juntamente com o processo descrito na Seção 3.2.3, permitem que o modelo possa ser estendido e reusado para atender às mais diversas situações. Neste capítulo, três protótipos que fazem uso de documentos XML derivados do modelo proposto também são descritos e implementados, para ilustrar características como extensibilidade e interoperabilidade, em três cenários diversos. Estes cenários variam desde aplicações que necessitam de informações de direção para executar suas ações até representações gestuais de formas geométricas associadas com tarefas.

\subsection{Troca de Área de Trabalho}

Em sistemas operacionais Linux, é comum observarmos diferentes tipos de gerenciadores de janelas (por exemplo Gnome, KDE, Fluxbox, etc.). Uma característica marcante destes gerenciadores é a possibilidade de se alternar entre diferentes áreas de trabalho, objetivando uma melhor organização das tarefas, do ponto de vista do usuário. No sistema operacional Ubuntu por exemplo, o Gnome possui quatro áreas de trabalho configuradas por padrão, e que podem ser alternadas facilmente por meio de atalhos de teclado (CTRL+ tecla de direção representando onde a área de trabalho desejada está localizada). 


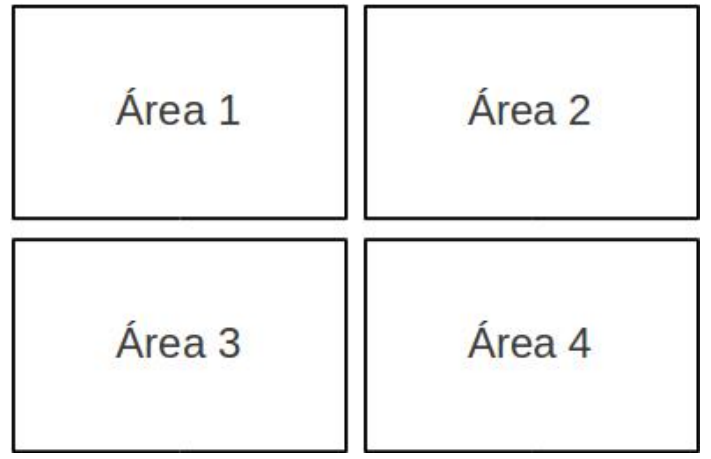

Figura 4.1: Disposição padrão das áreas de trabalho no sistema operacional Ubuntu 12.04 LTS

Estas áreas de trabalho, por padrão, encontram-se dispostas de modo adjacente, formando um quadrilátero composto por duas linhas e duas colunas, como ilustrado na Figura 4.1. Uma vez que se encontre na Área 1, pode-se navegar para a direita, em direção à Área 2, ou para baixo, em direção à Área 3. De modo semelhante, caso o usuário se encontre na Área 4, ele tem como opção navegar para cima, em direção à Área 2, ou para a esquerda, em direção à Área 3. Este conjunto de transições (direita, baixo, cima e esquerda) pode ser associado com direções expressas por meio de movimentos em um sistema que possibilite uma interação mais natural. Assim, por exemplo, caso se deseje fazer uma apresentação que envolva o conteúdo de quatro áreas de trabalho, pode-se fazer uso de gestos que indiquem para qual tela se deseja alternar a fim de dar continuidade à apresentação, ou retornar, caso se deseje recapitular algo. Desse modo, evita-se que o apresentador tenha que dirigir-se a todo momento até o teclado para entrar com um comando de transição, bastando que seu movimento seja captado por um sensor e interpretado como o comando desejado.

Diante da necessidade imposta por tal cenário, este primeiro protótipo tem por tarefa identificar o gesto correspondente a uma das direções pré-estabelecidas (left, right, up or down), e então executar a transição de áreas de trabalho, em um computador de mesa executando o sistema operacional Ubuntu 12.04 com suporte de longa duração (Long-Term Support - LTS), mostrando o nome do movimento reconhecido no centro da tela, como feedback.

Após a criação da aplicação com o código responsável pela transição entre áreas de trabalho (Listagem 4.2), fazendo-se uso da classe java.awt. Robot para simular combinações de teclas, criou-se outro projeto Java com a API MeaningsAPI, juntamente com as bibliotecas BlueCove, XStream e da API Wiigee. O objetivo desta nova aplicação é a criação do documento XML que será consumido pela aplicação que fará a transição. Como discutido no Capítulo 3, BlueCove é uma biblioteca escrita em Java que auxilia no desenvolvimento de aplicações que fazem uso de conexões Bluetooth, que é o modo de transmissão de dados do Wiimote. A biblioteca XStream é utilizada neste trabalho para 


\section{CAPÍTULO 4. CENÁRIOS E EXEMPLOS DE USO}

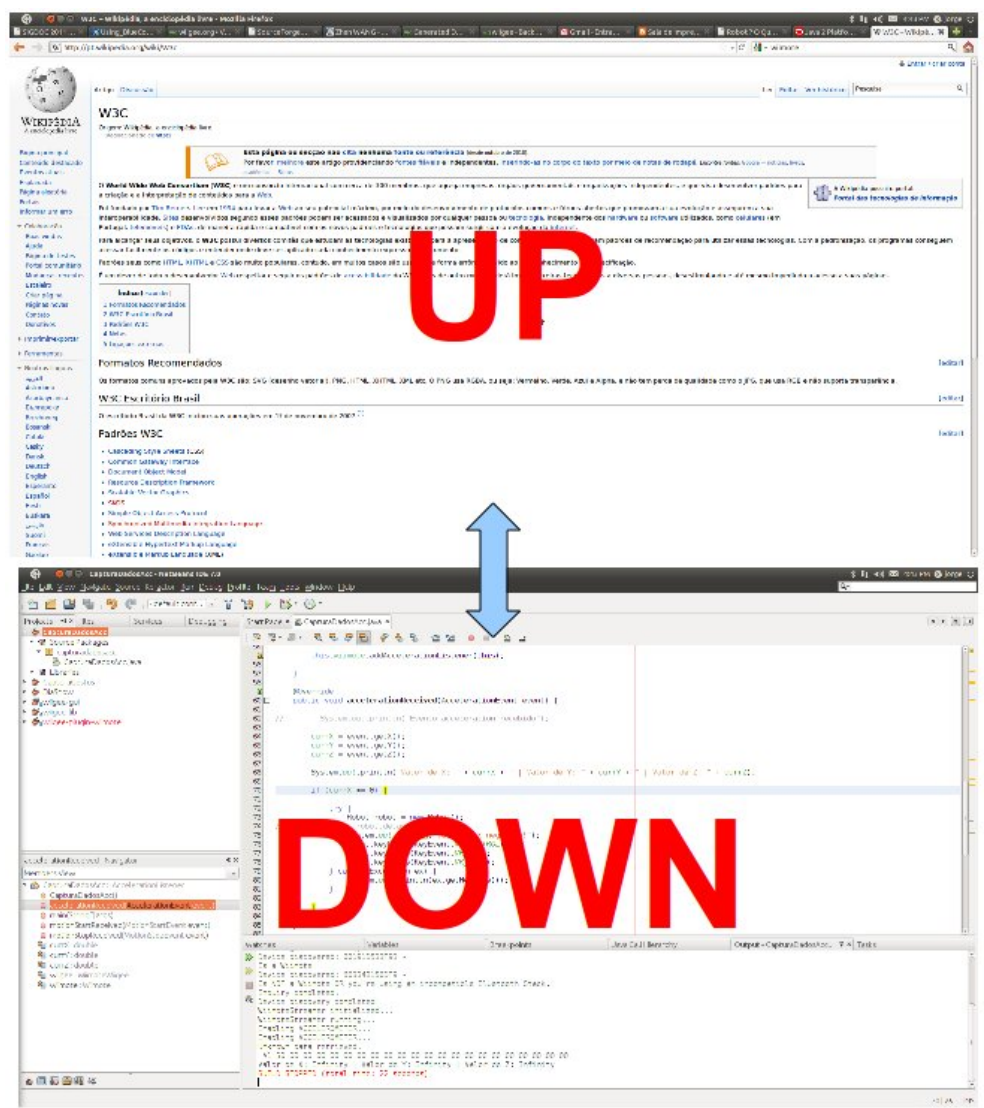

Figura 4.2: Resultado do processo de transição da área de trabalho

a criação e manipulação de documentos XML. Por fim, API Wiigee é responsável pela conexão e aquisição dos dados de aceleração (primeira camada) fornecidos pelo Wiimote e pelo reconhecimento de sinais (segunda camada). Com o projeto Java configurado e as bibliotecas necessárias para o funcionamento da Wiigee e da MeaningsAPI no classpath $^{1}$, pode-se partir para o processo de treinamento de gestos e a definição dos seus respectivos significados.

No entanto, é preciso definir os significados que representam os comandos de que a aplicação necessita. Neste caso, para a interação com a aplicação de transição de área de trabalho, quatro comandos são necessários: left, right, up e down. Primeiramente, estes significados devem ser especificados manualmente no esquema auxiliar responsável por esta aplicação, utilizado posteriormente para validar o documento XML final gerado pela MeaningsAPI. Assim, juntamente com o esquema principal e o Esquema W3C EMMA, este esquema auxiliar pode ser utilizado pela aplicação consumidora de modo a confirmar se o documento contém todos os parâmetros necessários. Na Listagem 3.8 ilustra-se o esquema auxiliar utilizado neste protótipo para especificar estes significados. O esquema

\footnotetext{
${ }^{1} \mathrm{Na}$ linguagem Java, se entende por Classpath uma opção suportada na linha de comando ou através de variável de ambiente que indica à Máquina Virtual Java (Java Virtual Machine - JVM) onde buscar os pacotes e classes necessários para a execução de programas.
} 
principal, contendo as definições estruturais dos dados, não deve ser alterado a menos que se deseje adaptá-lo objetivando atender a alguma necessidade não prevista por este modelo.

Após a especificação do esquema auxiliar, deve-se especificar cada significado por meio do método createGesture() presente na classe MeaningsAPI (Figura 3.5). Este método deve receber como parâmetro cada um dos atributos presentes na classe Meaning, que por sua vez devem corresponder aos elementos definidos no esquema auxiliar, como pode-se observar na Listagem 3.10. Na Listagem 4.1 ilustra-se a definição do significado "left", correspondente ao comando "esquerda" responsável por trocar a tela sendo exibida por outra imediatamente à esquerda. De modo similar, os outros três significados previstos devem ser especificados, cada um com a sua classe de significados, valor, código associado (se houver), data de criação, nome do usuário que o criou e comentário relacionado (se houver), respectivamente, por meio de mais três chamadas do método createGesture(). O $i d$, especificado na classe MeaningsAPI, é definido automaticamente, na ordem que os gestos forem criados. Isto é importante por quê cada gesto treinado pela Wiigee também recebe um identificador, correspondente à ordem em que foi treinado. Assim, caso o movimento "esquerda" seja treinado primeiro, ele receberá da Wiigee o indicador zero, se logo após for treinado o movimento "direita", ele receberá o indicador um, e assim sucessivamente. Desse modo, a MeaningsAPI pode associar cada um dos gestos especificados por meio do seu método createGesture() com os gestos treinados pela Wiigee.

Listagem 4.1: Trecho de código ilustrando o uso do método createGesture

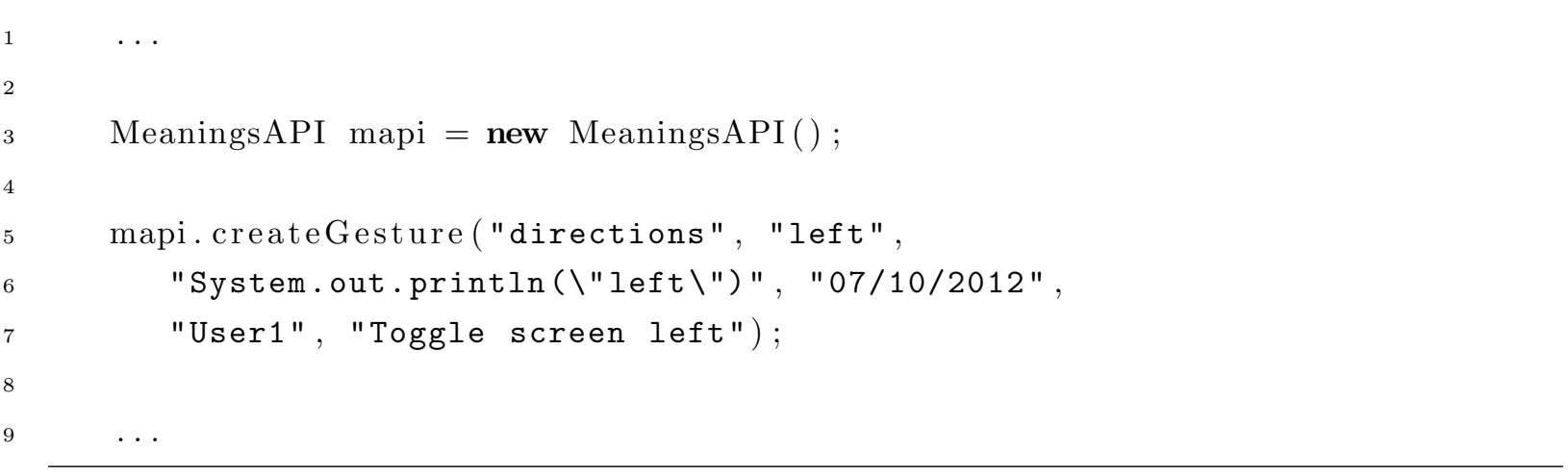

Após estas configurações preliminares, a aplicação que implementa a MeaningsAPI está pronta para ser executada e ter seus gestos treinados. Neste protótipo, a MeaningsAPI é implementada separadamente, com o intuito de separar a aplicação produtora do documento XML, da aplicação que irá consumi-lo, neste caso, a aplicação responsável pela troca da área de trabalho. Assim, todas as etapas do processo podem ser visualizadas mais claramente, como ilustrado na Figura 4.3. 


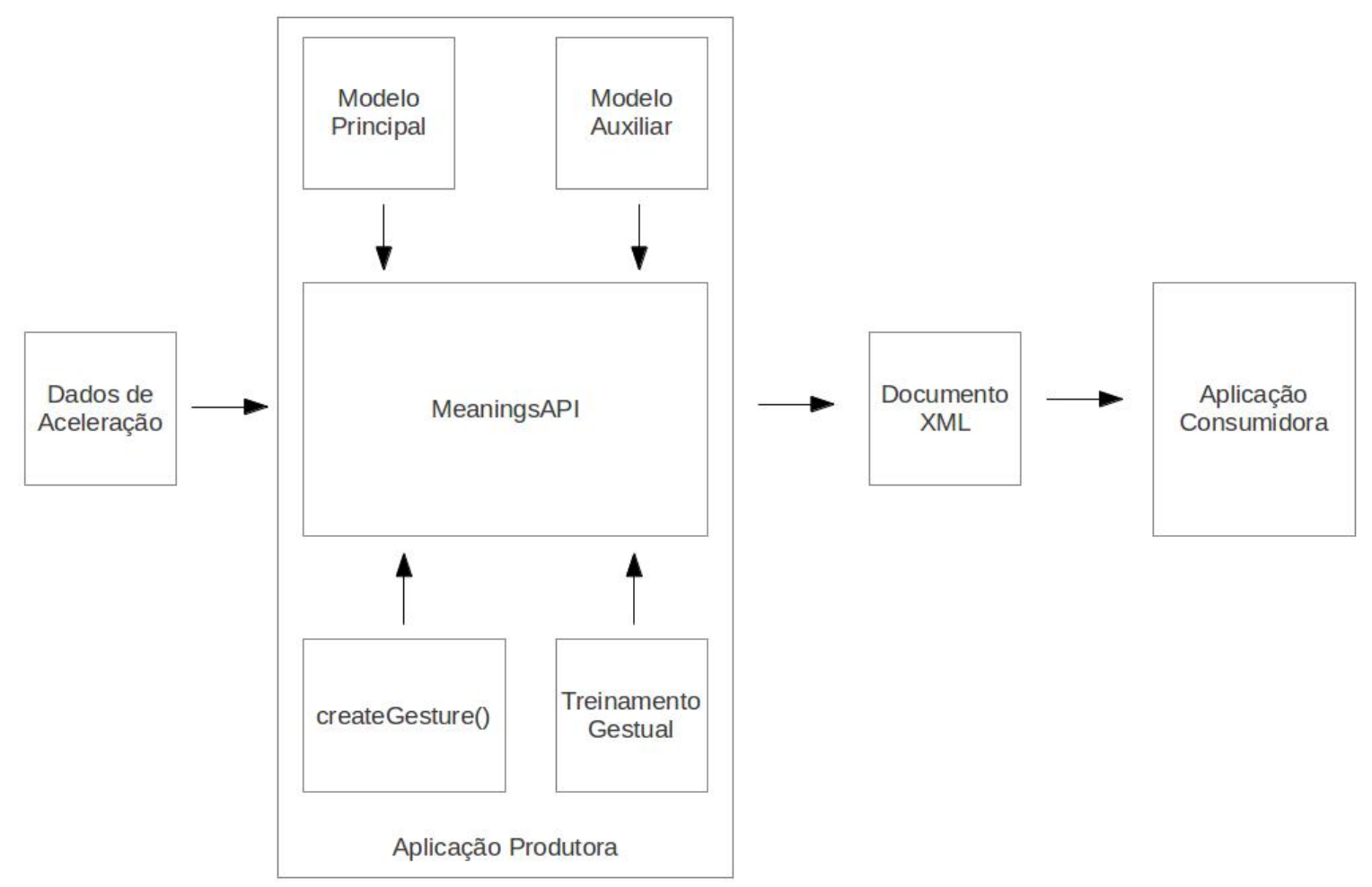

Figura 4.3: Diagrama representando todos os componentes de uma aplicação que faça uso da API MeaningsAPI

O processo de treinamento gestual, intermediado pela Wiigee, exige que cada gesto seja executado algumas vezes, de modo a "ensinar" o algoritmo de processamento de sinais HMM a reconhecê-lo com uma boa taxa de acerto. De acordo com Schlömer et. al. (Schlömer et al., 2008), cinco a dez sessões de treinamento são necessárias para que o reconhecimento seja possível, no entanto, dez a quinze sessões são recomendadas para que os resultados sejam ainda mais confiáveis. Para este protótipo, dez sessões de treinamento foram feitas para cada um dos quatro movimentos (esquerda, direita, cima e baixo), e pôde-se constatar empiricamente que a proporção de erros de reconhecimento para este número de sessões mantém-se em torno de dez porcento.

Após o treinamento gestual, pode-se então iniciar o processo de reconhecimento. Este se inicia com o acionamento do botão "B" do Wiimote e se encerra quando o mesmo é liberado. O timestamp inical e final são guardados nestas duas ocasiões, bem como o valor da aceleração atuante no sensor, no momento em que o botão é liberado. Estas informações são então armazenadas em uma instância da classe Data, que por sua vez é armazenada em uma instância da classe . O processo de reconhecimento ocorre em seguida, com o retorno do identificador do gesto reconhecido, bem como a respectiva taxa 
de confiança, cujo valor pode variar entre zero e um. Este identificador é então comparado com os id's dos gestos cadastrados na instância da classe AccelerometerData, de modo que o mais provável seja selecionado. Com todas as informações necessárias armazenadas na instância da classe AccelerometerData, esta então é utilizada como parâmetro para o método generateXML() da classe XMLManager. Este método é responsável pela criação do documento XML final, fazendo uso dos dados das instâncias contidas na instância da classe AccelerometerData, de acordo com as definições estruturais especificadas pelo padrão W3C EMMA.

Assim, uma vez completo o treinamento gestual, e a associação de cada um destes gestos aos comandos de transição de área de trabalho, é relativamente fácil executar as mesmas tarefas, manuseando de forma natural o Wiimote em qualquer uma das direções previstas. A aplicação de transição de áreas de trabalho executa uma verificação a cada segundo em um diretório específico, por atualizações no documento XML gerado pela MeaningsAPI. Sempre que alguma alteração é encontrada, caso o novo significado especificado no documento indique um novo comando, a aplicação deve executar a transição descrita. Na Figura 4.2 pode-se observar duas telas, e a transição entre elas com o aparecimento das palavras up ou down, dependendo do gesto que foi reconhecido.

Listagem 4.2: Trecho de código com dois casos de combinações de teclas. Para para case 0 a combinação CTRL+ALT+LEFT é simulada. Para case 1 é simulado CTRL+ALT+RIGHT

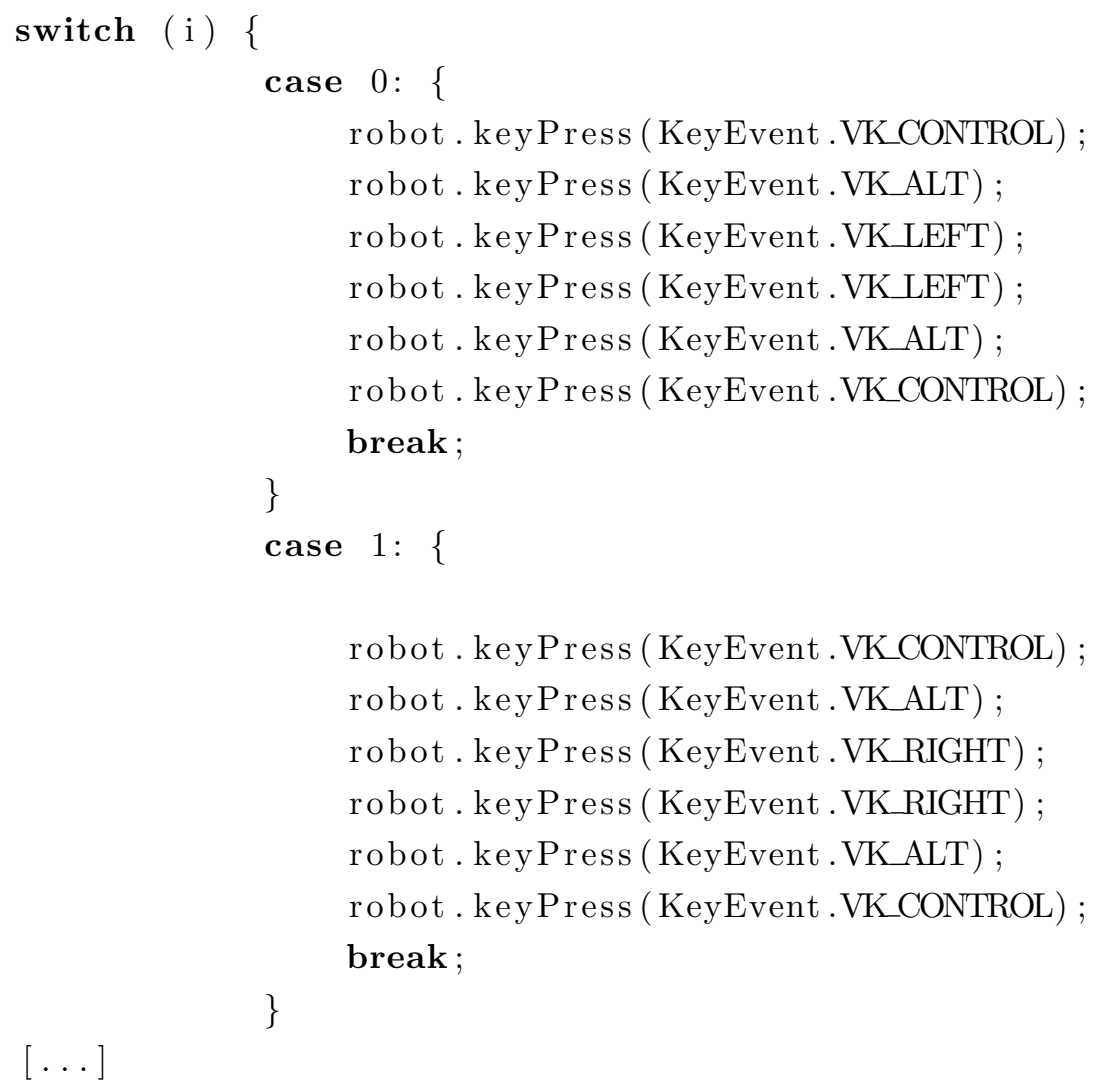


Esta aplicação mostra como o documento XML gerado pela MeaningsAPI pode ser consumido de maneira síncrona (neste caso com um segundo de atraso) por uma aplicação. Os passos relativos à implementação e uso da MeaningsAPI aqui descritos devem ser seguidos por todas as implementações, com apenas algumas alterações, exigidas pela aplicação sendo desenvolvida e/ou contexto em que a mesma se encontra. Na figura 4.4 pode-se observar um usuário interagindo com o prototipo.

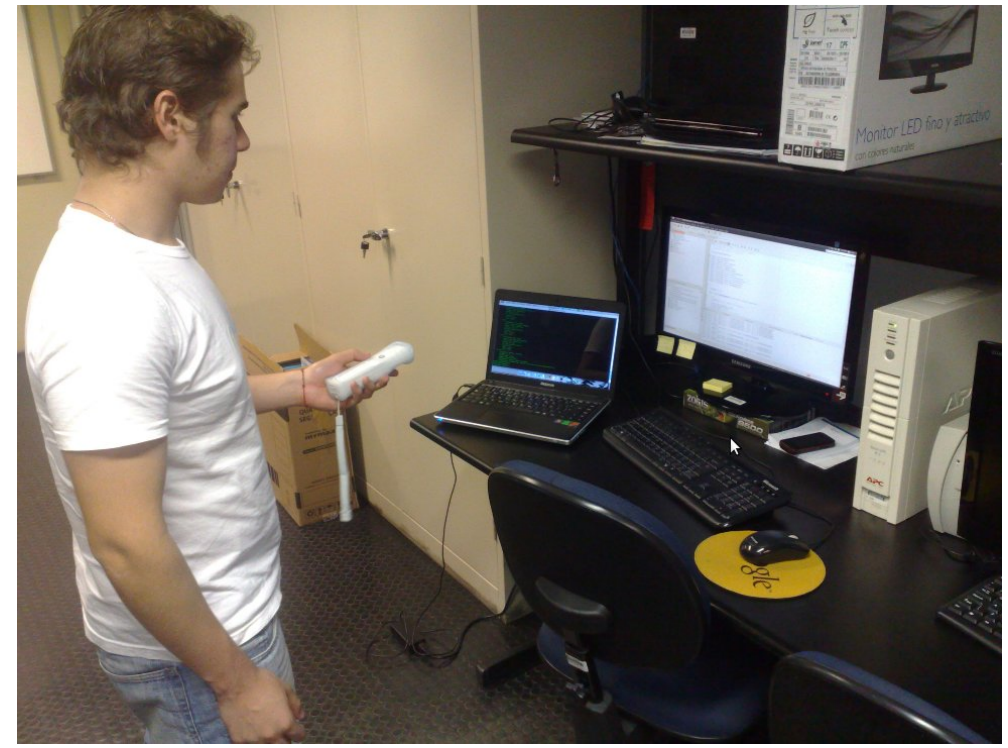

Figura 4.4: Usuário executando reconhecimento gestual

\subsection{Genius}

$\mathrm{Na}$ área de jogos eletrônicos, um aspecto importante são as interfaces com usuários e o modo como a interação é conduzida. A área de interfaces naturais, vertente da computação ubíqua, tem muito a contribuir com a experiência desses usuários, ao permitir que, ao fazer uso de gestos e expressões espontâneas do cotidiano, o jogador se sinta mais à vontade com o jogo, podendo concentrar-se melhor nas tarefas que este último possa exigir que sejam desempenhadas.

O segundo protótipo implementado neste trabalho é baseado em um antigo jogo eletrônico de memória chamado Genius (Simon² na versão americana), cujo objetivo é memorizar uma sequência de cores e seus respectivos sons na ordem exata em que são mostrados, de modo iterativo e incremental. Exemplificando, inicialmente uma determinada cor é fornecida (por exemplo verde), então o jogador deve pressionar o botão verde. Na próxima iteração, verde e azul são escolhidos, e de maneira similar o jogador deve pressionar

\footnotetext{
${ }^{2}$ http://www.hasbro.com/games/en-us/simon/. Acessado em 02/12/2012
} 


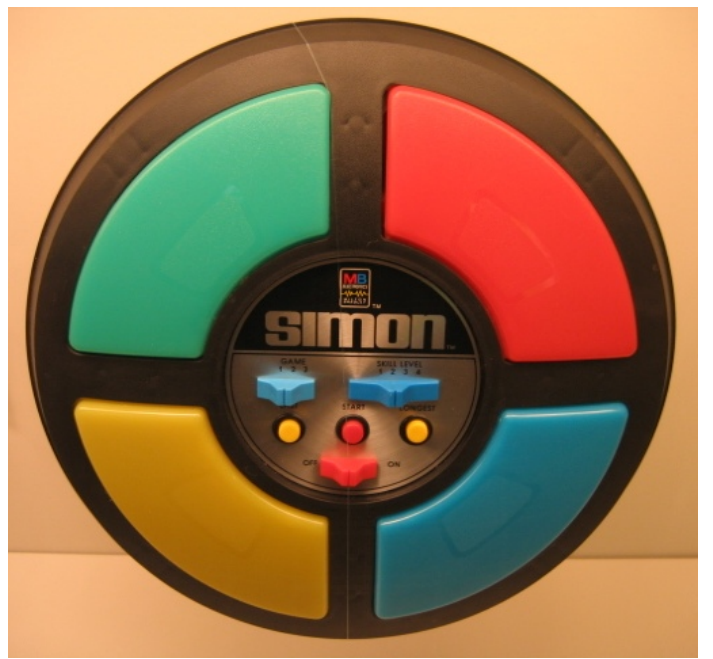

Figura 4.5: Genius, originalmente "Simon" na versão americana

os botões verde e azul, nesta ordem. Em seguida verde, azul e vermelho são escolhidos, ou verde, azul e amarelo, ou ainda uma das cores anteriormente selecionadas, e mais uma vez o jogador deve pressioná-las na ordem em que foram dadas.

À parte a programação do jogo em si, com suas características e funcionalidades, o protótipo foi implementado seguindo as mesmas etapas descritas na Seção 4.1, porém desta vez apenas uma aplicação foi desenvolvida, com a MeaningsAPI sendo diretamente utilizada como um dos módulos do jogo. Desse modo, o documento XML é apenas repassado para ser interpretado pelo módulo responsável pelas interações previstas pelo jogo. Uma vez com este projeto criado, apenas o código do jogo e as alterações devidas na classe Meanings e no método createGesture(), para refletir o novo conjunto de significados necessários, precisam ser acrescentados. Assim, esta implementação pôde ser feita em menos tempo, em comparação com o que seria levado caso a aplicação e toda a interação fosse desenvolvida do zero, sem utilizar a MeaningsAPI. Por fim, o protótipo foi testado sobre o mesmo sistema utilizado anteriormente, em um computador de mesa executando o sistema operacional Ubuntu 12.04 LTS.

Como descrito na Seção 4.1, um novo esquema auxiliar deve ser criado pelo desenvolvedor, para refletir o novo conjunto de significados necessários para o jogo. Sempre que uma nova implementação for desenvolvida, primeiro devem-se identificar os comandos que serão utilizados, e associá-los com seus significados e gestos correspondentes. Para esta implementação, ainda que os comandos tenham mudado, os gestos para representá-los continuaram sendo os mesmos. O treinamento apenas foi necessário para os comandos adicionais que precisavam ser representados. Assim, ao invés dos comandos left, right, up e down, temos os correspondentes yellow, blue, red e green, de modo a refletir os botões principais do jogo (Figura 4.6). A MeaningsAPI possibilita que estes comandos sejam representados pelos movimentos esquerda, direita, cima e baixo, já treinados pelo 


\section{CAPÍTULO 4. CENÁRIOS E EXEMPLOS DE USO}
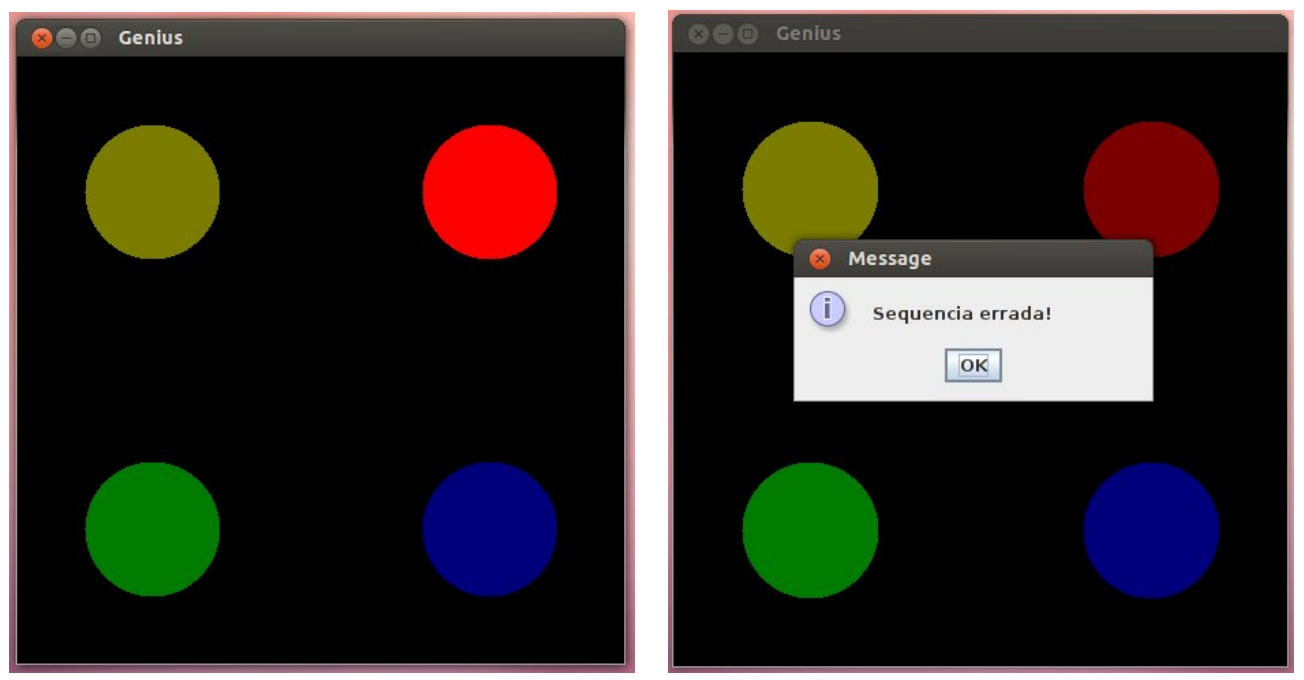

Figura 4.6: Genius sendo executado normalmente com o botão vermelho aceso (esquerda). Uma mensagem indicando um erro na sequencia inserida (direita)

protótipo da Seção 4.1, bastando apenas que os mesmos sejam cadastrados novamente por meio do método createGesture(). Os comandos adicionais necessários para este protótipo são "reiniciar" e "fechar jogo", representados pelos movimentos círculo (circle) e cruz (cross), respectivamente, e também devem ser cadastrados pelo método createGesture().

$\mathrm{Na}$ Listagem 4.3 pode-se observar a definição do esquema auxiliar escrito para armazenar os significados específicos do Genius.

Listagem 4.3: Definição do tipo personalizado simonType

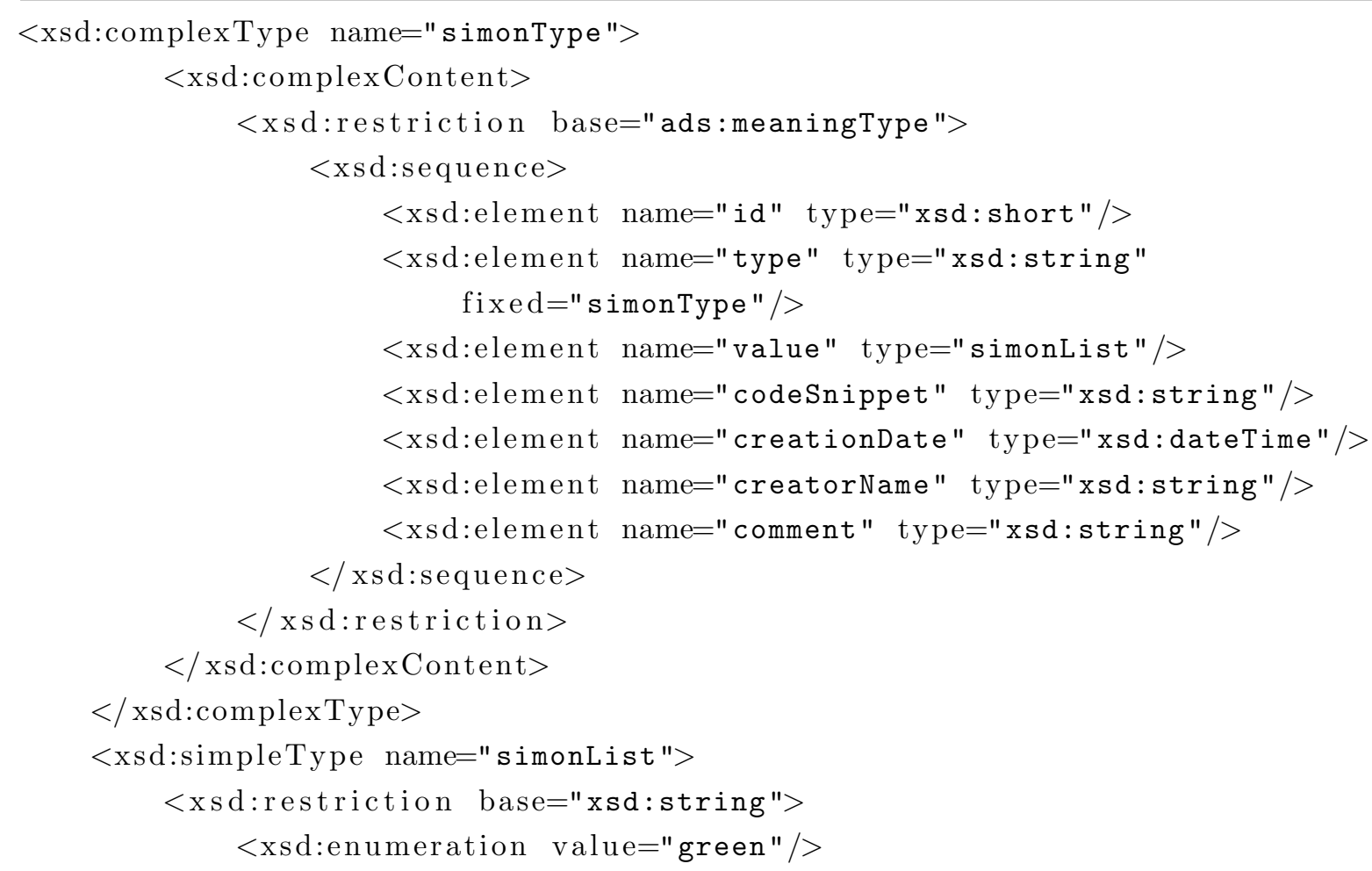




\subsection{Porta-Retratos}

Nos últimos anos, a produção de conteúdo digital como imagens e vídeos, tem aumentando consideravelmente, graças ao barateamento e consequente facilidade de acesso a dispositivos de captura. Uma demanda cada vez maior por dispositivos e sistemas que permitam a reprodução e manipulação deste conteúdo tem se tornado cada vez mais evidente, à medida que a computação se torna pervasiva em nosso cotidiano. Um exemplo desta tendência são os esforços que levaram à criação do middleware do Sistema Brasileiro de Televisão Digital (SBTVD), o Ginga ${ }^{3}$, que permite que aplicações escritas por meio da linguagem de programação de contexto aninhado (Nested-Context Language - NCL ${ }^{4}$ ) sejam executadas em um sistema de televisão, no conforto do lar dos próprios usuários.

Listagem 4.4: Documento HTML responsável pela execução do Porta-Retratos 


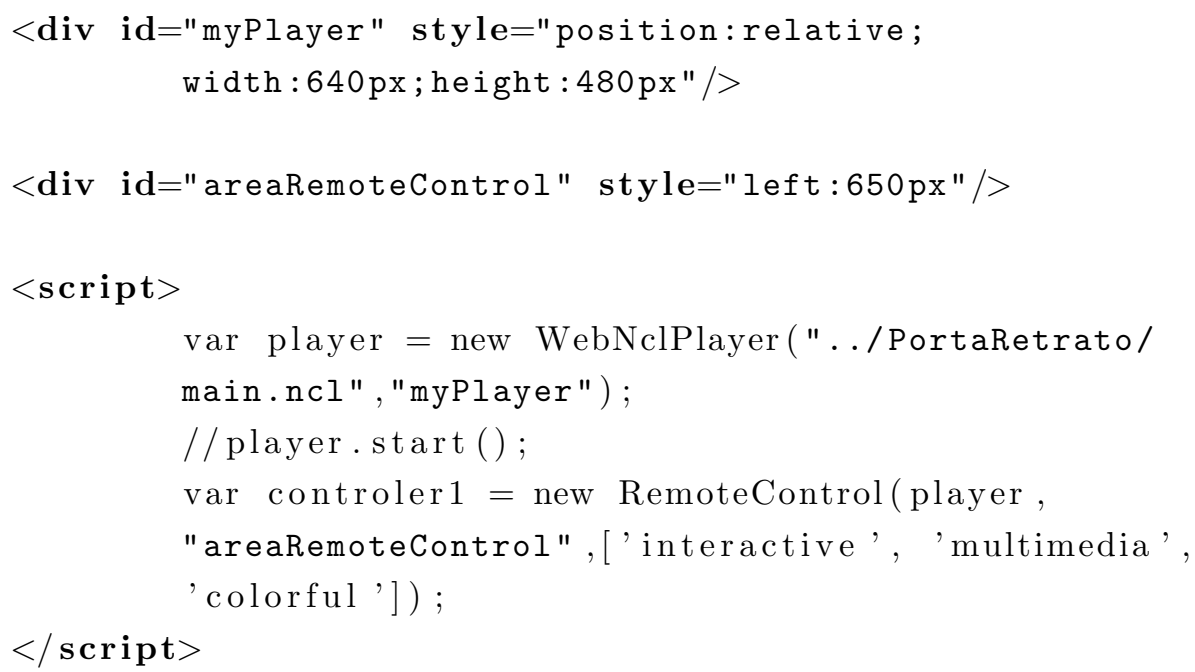

O terceiro protótipo deste trabalho implementa um tocador de mídia escrito em NCL, escrito para ser utilizado na TV digital, capaz de exibir de maneira organizada tanto vídeos quanto imagens. A fim de demonstrar a interoperabilidade dos documentos gerados por meio da abordagem proposta neste trabalho, este protótipo foi desenvolvido para ser executado em navegadores $W e b$, por meio da utilização de uma máquina de apresentação NCL baseada em tecnologias Web chamada WebNCL (Melo et al., 2012). Com o WebNCL, é possível a execução de documentos NCL em qualquer plataforma que possua navegadores compatíveis com a quinta versão da Linguagem de Marcação de Hipertexto (HyperText Markup Language - HTML5), como Personal Computers (PCs), Tablets, Smartphones e SmartTVs.

O Porta-Retratos possui quatro operações básicas, a saber: troca imagem para esquerda, troca imagem para direita, rola lista para esquerda, rola lista para direita. Estas ações estão associadas com os botões de controle remoto seta para esquerda, seta para direita, círculo e quadrado, respectivamente. Assim, como pode-se observar na Listagem 4.5, as ações definidas pelo modelo auxiliar são também respectivamente: left, right, circle e square.

Listagem 4.5: Definição do tipo personalizado showcaseType

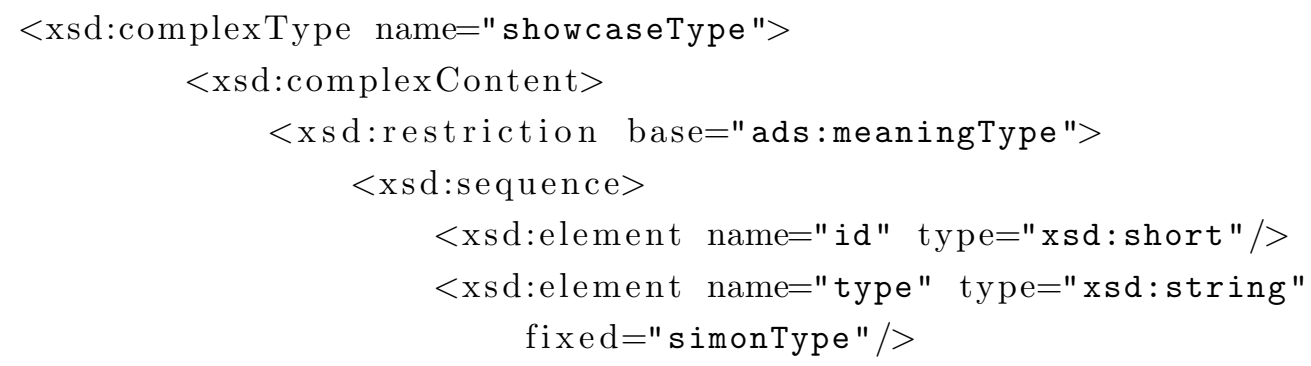




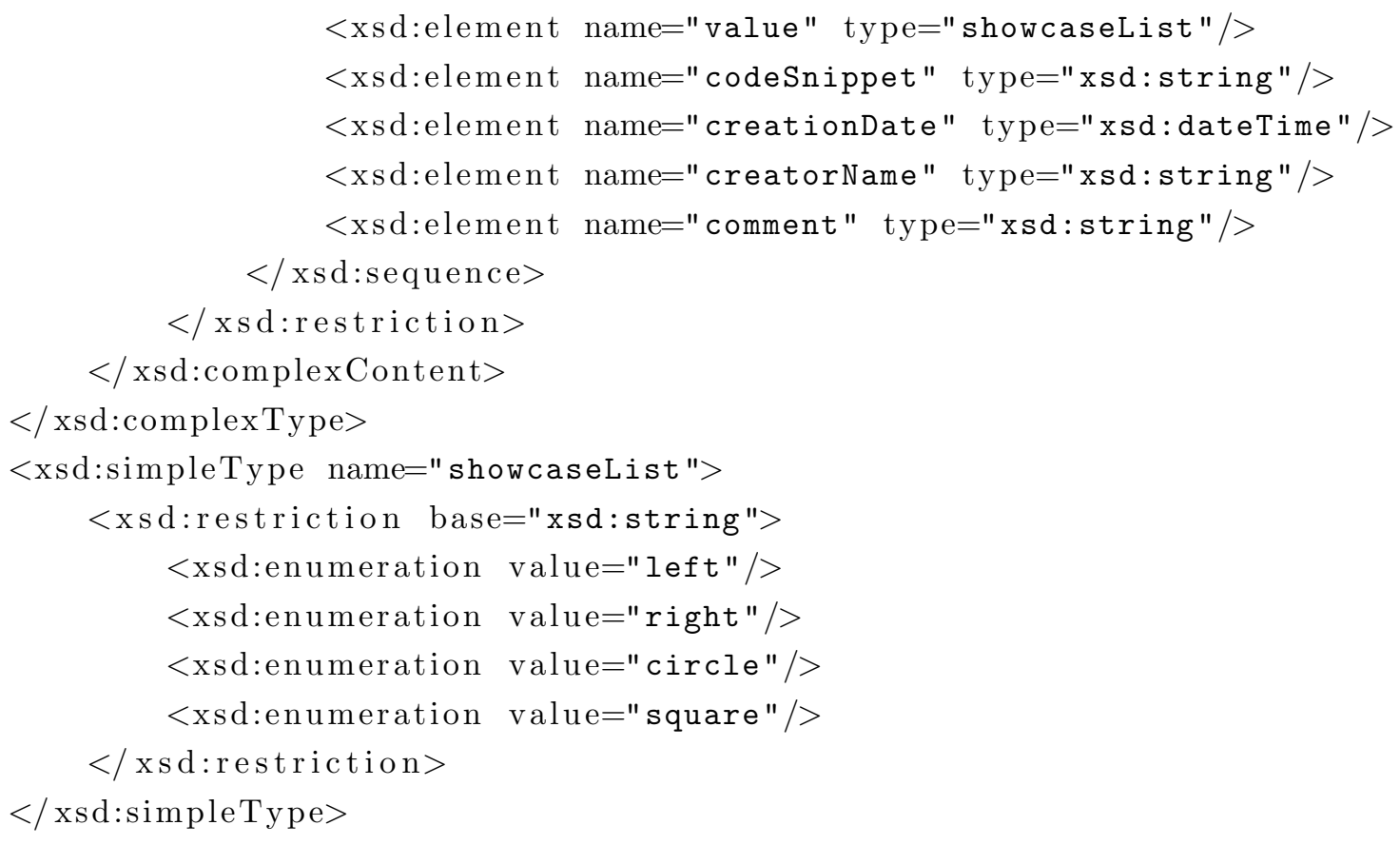

A API do WebNCL, entre outras funcionalidades, possui métodos que permitem que comandos semelhantes aos do controle remoto de uma TV digital convencional sejam emitidos. Como pode-se observar na Listagem 4.4, além da classe responsável pela execução do documento NCL que contém a aplicação porta-retrato (WebNclPlayer), há também o trecho que contém a declaração da classe responsável por comandos de controle remoto, utilizados para interagir com a aplicação NCL sendo executada (RemoteControl). É por meio da chamada dos métodos desta classe que os comandos correspondentes aos botões do controle são enviados. Por padrão, como pode-se observar na representação gráfica do controle remoto (Figuras 4.7 e 4.8), estes métodos são acessíveis apenas por meio de cliques feitos em botões, por intermédio de dispositivos de apontamento, como mouse ou telas touchscreen. Com o uso da MeaningsAPI, uma nova forma de interagir com a aplicação NCL executada pelo WebNCL é possibilitada, desta vez permitindo que a aplicação seja manipulada à distância, de maneira semelhante a observadas em ambientes domésticos. Para isso, a classe RemoteControl da WebNCL precisou ser alterada, de modo que o acesso a estes métodos agora seja feito pelos significados contidos no documento XML gerado pela MeaningsAPI. No entanto, nenhuma alteração na aplicação NCL em si foi necessária.

Assim, como descrito na Seção 4.1, um novo esquema auxiliar deve ser criado pelo desenvolvedor, para refletir o conjunto de significados necessários para a aplicação porta-retratos, como pode ser observado na Listagem 4.5. Mais uma vez, os gestos já treinados podem ser reutilizados, bastanto apenas que seus respectivos significados sejam redefinidos por meio do método createGesture(). Ao fazer uso da WebNCL, os gestos executados com o acelerômetro podem ser reconhecidos e utilizados para desempenhar ações em diver- 


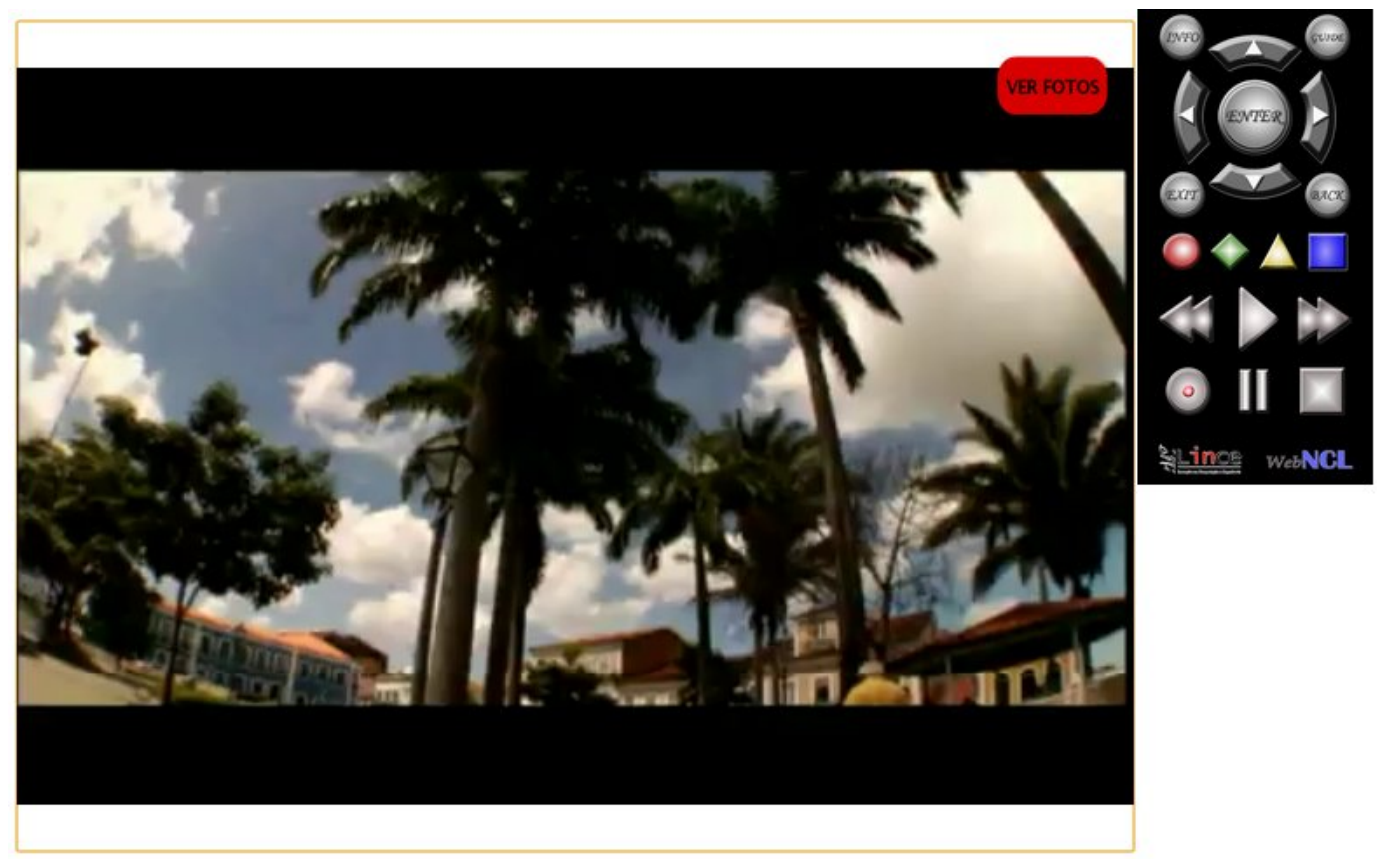

Figura 4.7: Tela de abertura da aplicação Porta-Retratos

sas plataformas, bastando apenas que disponham de um navegador compatível com a linguagem HTML5.
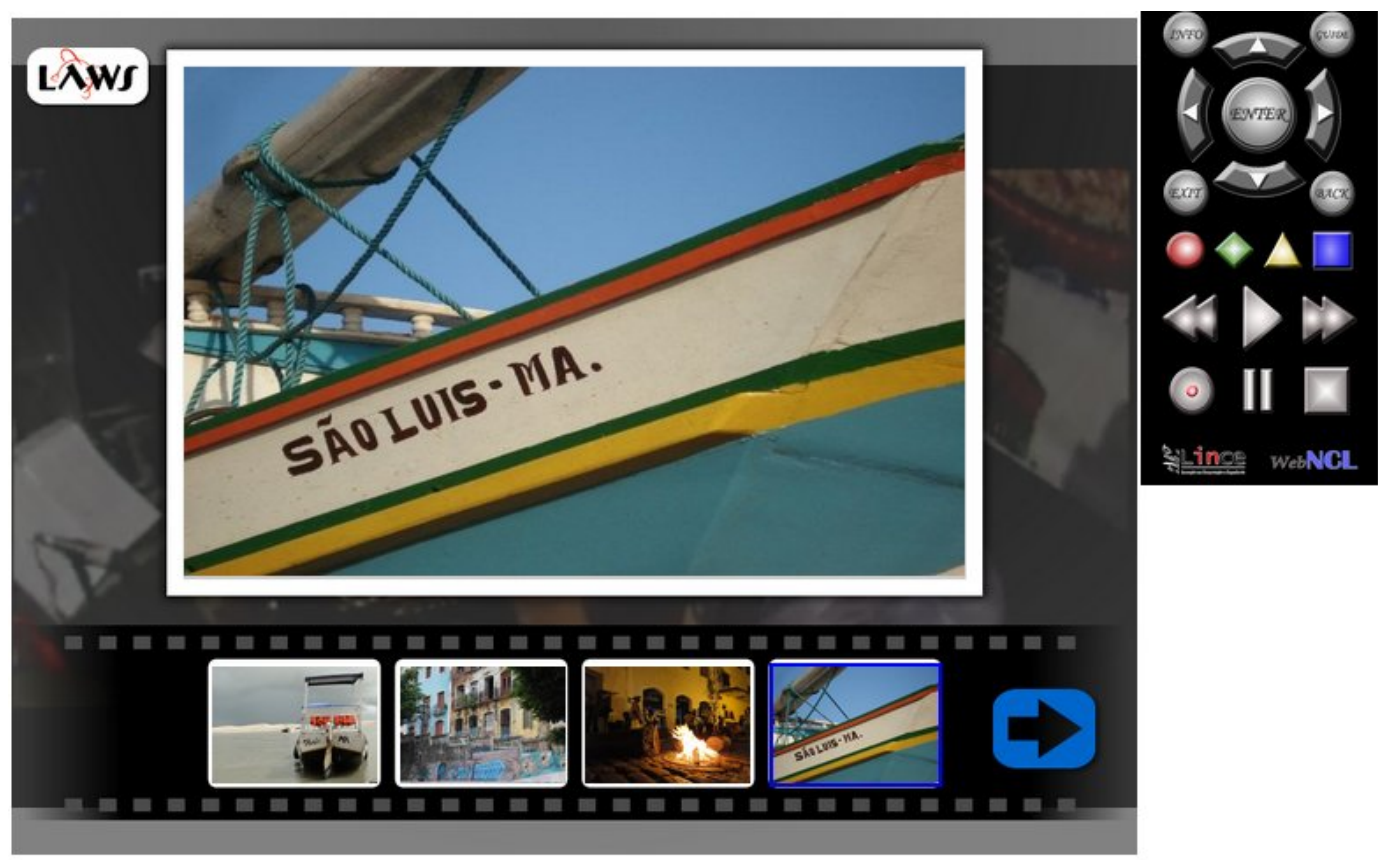

Figura 4.8: Tela principal da aplicação Porta-Retratos

Nas figuras 4.7 e Figura 4.8, pode-se observar uma representação gráfica dos botões de um controle remoto convencional. Na tela de abertura do aplicativo, basta executar o gesto circle ("ver fotos") para entrar na tela principal da aplicação. Já na tela principal (Figura 4.8), pode-se observar na parte inferior uma lista com quatro imagens e uma seta 
indicando que para a próxima parte da lista deve-se executar o gesto square (quadrado azul com seta para a direita), e vice-versa, onde deve-se executar o gesto circle (círculo vermelho com seta para esquerda) para retornar.

\subsection{Considerações Finais}

Tendo em mente a arquitetura conceitual descrita na Seção 3.1 e a abordagem proposta (Seção 3.2) por meio da API implementada (Seção 3.3), nota-se uma simplificação da identificação de cada componente arquitetural dos protótipos, bem como a visualização dos pontos em que estes componentes se interrelacionam. Em todos eles a biblioteca Wiigee obtém os dados brutos dos acelerômetros, fazendo-se uso da biblioteca BlueCove (presente na primeira camada), e promove o reconhecimento gestual ao fazer uso da implementação do algoritmo HMM (segunda camada); por fim, a API MeaningsAPI encapsula e valida os dados de acordo com o modelo, e gera um documento XML para os protótipos. O protótipo descrito na Seção 4.1 é descrito de modo sucinto em todas as suas etapas de implementação, visando o estabelecimento dos passos necessários para o uso da MeaningsAPI. Os pontos que devem ser modificados, tanto no modelo quanto na API, são explicitados, bem como o modo como as alterações devem ser feitas. A maneira como os dados são encapsulados em objetos, e tranferidos de modo tranparente por meio de parâmetros ao longo do processamento, pode ser observada nos protótipos das Seções 4.2 e 4.3, bem como a interoperabilidade proporcionada pelas tecnologias abertas, utilizadas para a descrição da abordagem e sua implementação, podem ser vantajosas em contextos também abertos e padronizados, como a plataforma $W e b$. 


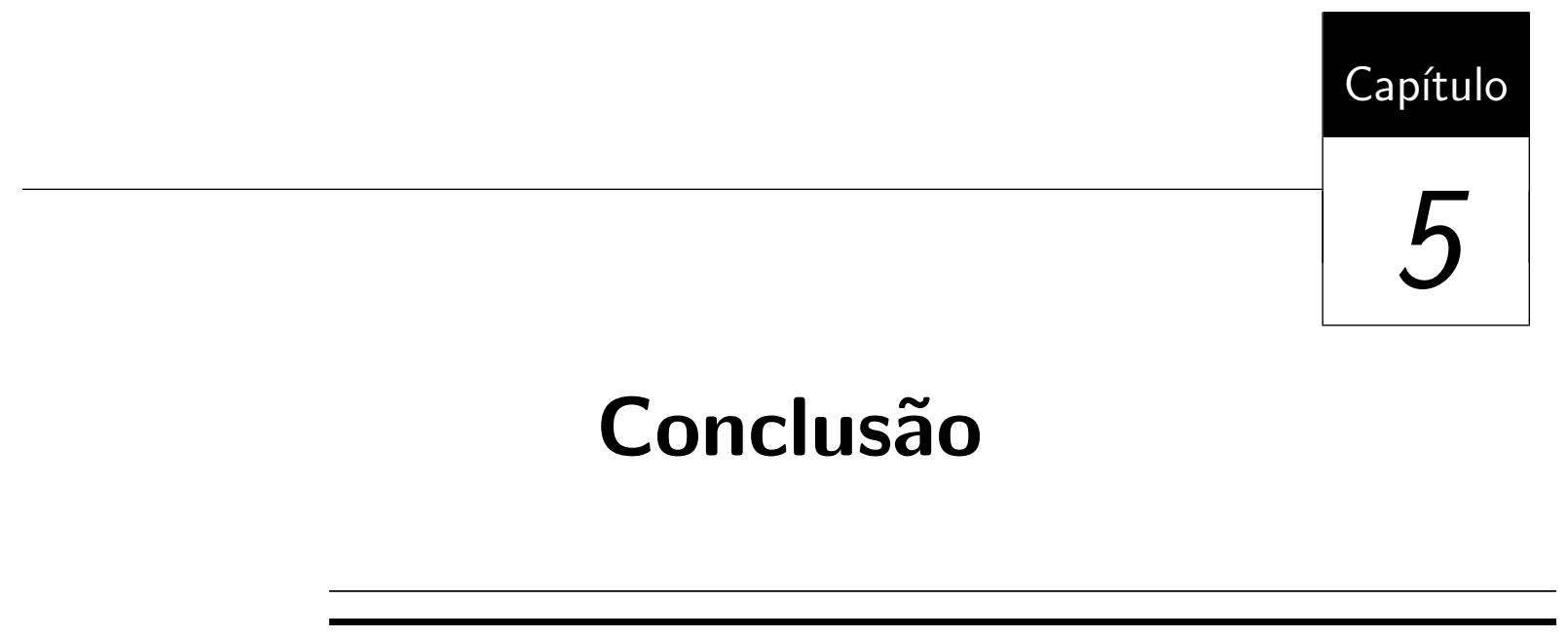

Dispositivos de entrada equipados de sensores como acelerômetros desempenham um papel importante no desenvolvimento de novas formas de interação. Com o baixo custo e subsequente popularização destes dispositivos, o número de aplicações implementadas pela indústria e encontradas na literatura que fazem uso deste tipo de sensor é relevante.

A criação de técnicas e métodos que facilitem o desenvolvimento de aplicações que fazem uso de acelerômetros, bem como a especificação de padrões para os dados compartilhados entre elas, é de grande importância. A literatura até o momento não reporta nenhuma solução específica para este fim, muito menos no que diz respeito à interoperabilização destes dados juntamente com seu respectivo valor semântico. A necessidade de tais padrões é o foco principal deste trabalho de mestrado. Para este fim é proposto um modelo que encapsula todas as informações básicas que os acelerômetros capturam e transmitem, bem como seus significados tais como foram determinados pelo desenvolvedor e, uma vez transformados em instâncias deste modelo, estes dados tornam-se manipuláveis por múltiplas aplicações e dispositivos.

Por meio da arquitetura proposta, é possível visualizar e modelar de maneira simples um ambiente de aquisição, processamento e disponibilização dos dados de aceleração desde o momento em que são capturados pelo sensor até o momento em que são disponibizados de maneira estruturada para as aplicações. Ao fazer-se uso do esquema auxiliar para especificar os tipos de significados aceitos pela aplicação, é possível validar estes dados de maneira que somente sejam utilizados os valores semânticos pertinentes à aplicação 
sendo desenvolvida. Alterando-se o esquema auxiliar, pode-se adaptar estes dados para outros domínios de aplicações, como observado durante a implementação dos protótipos descritos neste trabalho.

\subsection{Resultados Obtidos}

Desse modo, a principal contribuição deste trabalho é o projeto de uma abordagem extensível e genérica o bastante para ser utilizada por diferentes dispositivos (Carvalho et al., 2012). Por fim, haja vista que esta abordagem permite a associação de significados a movimentos específicos (por exemplo reconhecimento gestual), aplicações diversas podem se beneficiar no sentido de não ter que lidar com questões relacionadas com o desenvolvimento no baixo nível.

Assim, podem-se destacar como contribuições deste trabalho:

1. Criação de um modelo de documentos por meio de um Esquema XML que descreve dados básicos de aceleração juntamente com um modelo auxiliar extensível que permite a descrição de significados relacionados com estes dados.

2. Descrição de uma arquitetura em três camadas que tem por objetivo delimitar as etapas de aquisição e processamento dos sinais obtidos por meio dos sensores de aceleração, bem como definir as interfaces necessárias para a utilização da API criada para instanciar o modelo.

3. Desenvolvimento de uma API que produz um documento XML baseado no modelo proposto por este trabalho, recebendo os dados das camadas inferiores e os encapsule para serem utilizados por outras aplicações de modo interoperável.

\subsection{Dificuldades e Limitações}

O presente trabalho apresentou algumas dificuldades e limitações durante seu projeto e implementação, a saber:

A primeira dificuldade encontrada foi durante a especificação do trabalho, pois na ocasião em que a revisão bibliográfica foi feita, notou-se uma falta de técnicas e modelos particulamente projetados para encapsular os dados dos acelerômetros, de modo a torná-los facilmente acessíveis para diferentes aplicações, ou seja, interoperáveis. Assim, embora houvessem modelos gerais para estruturação de dados multimodais, para a descrição de dados de aceleração em específico nada foi encontrado. Espera-se que o modelo criado neste trabalho possa servir como ponto de partida para a criação de novas manei- 
ras de descrever estes dados, não apenas para sensores de aceleração, mas também outros tipos de sensores.

Outra dificuldade encontrada diz respeito à implementação da API Wiigee. Durante os testes iniciais, vários comportamentos aleatórios relacionados à conexão com o Wiimote foram observados, como intermitências durante o processo de identificação do dispositivo e falhas na auto-calibração do sensor, esta última exigindo que o procedimento de conexão com o Wiimote tenha de ser repetido várias vezes para que os valores de aceleração comecem a ser transmitidos. Entrou-se em contato com o desenvolvedor da API e as falhas encontradas foram notificadas. Durante este contato também descobriu-se que o desenvolvimento da API ainda encontra-se em andamento, portanto as contribuições foram bem recebidas.

Como limitação, pode-se citar o fato de a MeaningsAPI e o modelo auxiliar necessitarem ser modificados manualmente pelo desenvolvedor toda vez que uma nova aplicação demandar significados diferentes para a sua utilização.

\subsection{Trabalhos Futuros}

Como trabalhos futuros decorrentes dessa dissertação destacam-se: melhorias na implementação da API MeaninsAPI, no sentido de automatizar configurações que precisam ser feitas de modo manual, como a modifificação da método createGesture() e da classe Meanings, com intuito de refletir as demandas da aplicação que se deseje implementar. A análise de incorporação de outros algoritmos de reconhecimento de sinais, como o DTW ou ANN, bem como a utilização de outros dispositivos sensores além do Wiimote, capazes de medir a aceleração em mais eixos, como no caso dos giroscópios. Um trabalho futuro poderia explorar e estender o modelo deste trabalho para encapsular os dados provenientes de mais de um sensor, permitindo assim a captação de dados fornecidos por vários usuários ao mesmo tempo. Por fim, um estudo mais aprofundado dos usos do modelo em outros contextos além dos citados neste trabalho, principalmente envolvendo Web Services, poderia ser feito, com o intuito de avaliar as suas utilidades em tarefas como o controle de dispositivos eletrônicos à distância, por meio da Internet. 



\section{Referências}

Abowd, G. D. Classroom 2000: An experiment with the instrumentation of a living educational environment. IBM Systems Journal, v. 38, n. 4, p. 508-530, 1999.

Abowd, G. D.; Mynatt, E. D. Charting past, present, and future research in ubiquitous computing. ACM Trans. Comput.-Hum. Interact., v. 7, n. 1, p. 29-58, 2000.

Antle, A.; Wise, A. Getting down to details: Using theories of cognition and learning to inform tangible user interface design. Interacting with Computers, , n. October 2012, 2013.

Disponível em http://iwc.oxfordjournals.org/content/25/1/1. short

Aoki, R.; Maeda, A.; Watanabe, T.; Kobayashi, M.; Abe, M. A new text input method for TV remotes using tilt sensor. IEEE, 1-2 p., 2010.

Azuma, R.; Baillot, Y. Recent advances in augmented reality. IEEE Computer Graphics and Applications, , n. December, p. 34-47, 2001.

Disponível em http://ieeexplore.ieee.org/xpls/abs_all.j.sp?arnumber=963459

Bishop, C. M. Pattern recognition and machine learning (information science and statistics). Secaucus, NJ, USA: Springer-Verlag New York, Inc., 2006.

Blake, J. Natural User Interfaces in .NET. $1 \hat{\mathrm{A}}^{\mathrm{a}}$ ed. Greenwich: Manning Publications Co., 375 p., 2011.

Block, S.; Popescu, A. W3C DeviceOrientation Event Specification - Editor's Draft. 2011.

Disponível em http://dev.w3.org/geo/api/spec-source-orientation.html

Bray, T.; Paoli, J.; Sperberg-McQueen, C.; Maler, E.; Yergeau, F. Extensible markup language (xml). World Wide Web Journal, v. 2, n. 4, p. 27-66, 1997. 
Bulterman, D. C. a.; Cesar, P.; Jansen, a. J. An architecture for viewer-side enrichment of TV content. In: Proceedings of the 14th annual ACM international conference on Multimedia - MULTIMEDIA '06, New York, New York, USA: ACM Press, 2006, p. 651.

Carvalho, J. R.; Manzato, M. G.; Goularte, R. Accelerometers data interoperability: easing interactive applications development. In: Proceedings of the 18th Brazilian symposium on Multimedia and the web, WebMedia '12, New York, NY, USA: ACM, 2012, p. 305-312 (WebMedia '12, ).

Disponível em http://doi.acm.org/10.1145/2382636.2382702

Cattelan, R.; Andrade, A.; Rocha, C.; Pimentel, M. iClass: um sistema para captura e acesso de sessões em ambiente educacional. Revista Eletrônica de Iniciação Científica da Sociedade Brasileira de Computação (REIC-SBC), v. 3, n. 1, p. 10-28, 2003.

Cesar, P.; Bulterman, D.; Obrenovic, Z.; Ducret, J.; Cruz-Lara, S. An architecture for non-intrusive user interfaces for interactive digital television. Interactive TV: a Shared Experience, p. 11-20, 2007.

Chang, K.; Hightower, J.; Kveton, B. Inferring identity using accelerometers in television remote controls. In: Proceedings of the 7th International Conference on Pervasive Computing, Citeseer, 2009, p. 151-167.

Disponível em http://citeseerx.ist.psu.edu/viewdoc/download?doi=10.1.1. 160. 5256\&amp; rep=rep 1\&amp; type $=p d f$

Chin, E.; Felt, A. P.; Greenwood, K.; Wagner, D. Analyzing inter-application communication in android. In: Proceedings of the 9th international conference on Mobile systems, applications, and services, MobiSys '11, New York, NY, USA: ACM, 2011, p. 239-252 (MobiSys '11, ).

Disponível em http://doi.acm.org/10.1145/1999995.2000018

De los Reyes, A. Natural user interface. 2009.

Disponível em http://en.wikipedia.org/wiki/Natural_user_interface (Acessado em 17 de fevereiro de 2013)

Dey, A. K. Understanding and Using Context. Personal and Ubiquitous Computing, v. 5, n. 1, p. 4-7, 2001.

DiMario, M. System of systems interoperability types and characteristics in joint command and control. IEEE/SMC International Conference on System of Systems Engineering, p. 222-227, 2006. 
Disponível em http://ieeexplore.ieee.org/xpl/articleDetails.jsp?arnumber= 1652302http://ieeexplore. ieee.org/xpls/abs_all.jsp?arnumber $=1652302$

Fagá Jr, R.; Furtado, B.; Maximino, F.; Cattelan, R.; Pimentel, M. Context information exchange and sharing in a peer-to-peer community: a video annotation scenario. In: Proceedings of the 27th ACM international conference on Design of communication, ACM, 2009, p. 265-272.

Ferscha, A.; Vogl, S.; Emsenhuber, B.; Wally, B. Physical shortcuts for media remote controls. In: Proceedings of the 2nd international conference on INtelligent TEchnologies for interactive enterTAINment - INTETAIN'08, Cancun, Mexico: ICST (Institute for Computer Sciences, Social-Informatics and Telecommunications Engineering), 2008, p. $1-8$.

Gonçalves, C.; Santos, T.; Santos, M.; Antunes, F.; Moura, R.; Oliveira, M. Implementing Components on the LARIISA, A Homecare Application Using Brazilian DTV. infobrasil.inf.br, p. 7p., 2010.

Gurrin, C.; Lee, H.; Caprani, N.; Zhang, Z.; O'Connor, N.; Carthy, D. Browsing Large Personal Multimedia Archives in a Lean-Back Environment. Advances in Multimedia Modeling, p. 98-109, 2010.

Disponível em http://www. springerlink. com/index/UJ4424284X772HT6.pdf

"Hauptmann, A. Speech recognition in the Informedia Digital Video Library: uses and limitations. In: Tools with Artificial Intelligence, 1995. Proceedings., Seventh International Conference on, IEEE, 1995, p. 288-294.

Hernandez, W. Robust Multivariable Estimation of the Relevant Information Coming from a Wheel Speed Sensor and an Accelerometer Embedded in a Car under Performance Tests. Sensors, v. 5, n. 11, p. 488-508, 2005.

Disponível em http://www.mdpi.com/1424-8220/5/11/488

Hinckley, K.; Zhao, S.; Sarin, R.; Baudisch, P.; Cutrell, E.; Shilman, M.; Tan, D. InkSeine: In Situ search for active note taking. In: Proceedings of the SIGCHI conference on Human factors in computing systems, ACM, 2007, p. 251-260.

Holman, D.; Vertegaal, R. Organic user interfaces: designing computers in any way, shape, or form. Communications of the ACM, v. 51, n. 6, 2008.

Disponível em http://dl .acm.org/citation.cfm?id=1349037 
Ishii, H.; Ullmer, B. Tangible bits: towards seamless interfaces between people, bits and atoms. Proceedings of the SIGCHI conference on Human, , n. March, p. 234-241, 1997.

Johnston, M. Building multimodal applications with EMMA. Proceedings of the 2009 international conference on Multimodal interfaces - ICMI-MLMI '09, p. 47, 2009.

Disponível em http://portal. acm.org/citation. cfm?doid=1647314.1647325

Jones, C. Software assessments, benchmarks, and best practices. Boston, MA, USA: Addison-Wesley Longman Publishing Co., Inc., 2000.

Kela, J.; Korpipää, P.; Mäntyjärvi, J.; Kallio, S.; Savino, G.; Jozzo, L.; Marca, S. Accelerometer-based gesture control for a design environment. Personal and Ubiquitous Computing, v. 10, n. 5, p. 285-299, 2006.

Disponível em http://www.springerlink.com/index/n813460153p6515m.pdf

Khan, A. M.; Lee, Y.-K.; Lee, S. Y.; Kim, T.-S. Human Activity Recognition via an Accelerometer-Enabled-Smartphone Using Kernel Discriminant Analysis. In: 2010 5th International Conference on Future Information Technology, IEEE, 2010, p. 1-6. Disponível em http://ieeexplore.ieee.org/xpls/abs_all.jsp?arnumber= 5482729

Kim, S.; Ok, J.; Kang, H.; Kim, M.; Kim, M. An interaction and product design of gesture based TV remote control. In: $\mathrm{CHI}_{4} \mathrm{O}_{4}$ extended abstracts on Human factors in computing systems, n. 2003, New York, New York, USA: ACM, 2004, p. 1548-1548.

Disponível em http://portal .acm.org/citation. cfm?id=986124

Lee, J. C. Hacking the Nintendo Wii Remote. IEEE Pervasive Computing, v. 7, n. 3, p. $39-45,2008$.

Melo, E. L.; Viel, C. C.; Teixeira, C. A. C.; Rondon, A. C.; Silva, D. d. P.; Rodrigues, D. G.; Silva, E. C. Webncl: a web-based presentation machine for multimedia documents. In: Proceedings of the 18th Brazilian symposium on Multimedia and the web, WebMedia '12, New York, NY, USA: ACM, 2012, p. 403-410 (WebMedia '12, ).

Disponível em http://doi.acm.org/10.1145/2382636.2382719

Mugellini, E.; Sokhn, M.; Carrino, S.; Abou Khaled, O. WiiNote: multimodal application facilitating multi-user photo annotation activity. In: Proceedings of the 2009 international conference on Multimodal interfaces, ACM, 2009, p. 237-238.

Disponível em http://portal.acm.org/citation.cfm?id=1647363 
Nissen, S. Implementation of a fast artificial neural network library (fann). Report, Department of Computer Science University of Copenhagen (DIKU), v. 31, 2003.

Disponível em http://mirror.transact.net.au/sourceforge/f/project/fa/ fann/fann_doc/1.0/fann_doc_complete_1.0.pdf

Oliveira, M.; Cunha, P.; da Silva Santos, M.; Bezerra, J. Implementing home care application in Brazilian Digital TV. In: Information Infrastructure Symposium, 2009. GIIS'09. Global, IEEE, 2009, p. 1-7.

Disponível em http://ieeexplore.ieee.org/xpls/abs_all.jsp?arnumber= 5307042

Oviatt, S. Multimodal interfaces, cáp. 21 Mahwah, NJ, USA: Lawrence Erlbaum Associates, Inc., p. 413-432, 2007.

Pan, G.; Wu, J.; Zhang, D.; Wu, Z.; Yang, Y.; Li, S. GeeAir: a universal multimodal remote control device for home appliances. Personal and Ubiquitous Computing, v. 14, n. 8, p. 723-735, 2010.

Disponível em http://portal.acm.org/citation.cfm?id=1891507

Ravi, N.; Dandekar, N.; Mysore, P.; Littman, M. L. Activity recognition from accelerometer data. In: Proceedings of the national conference on artificial intelligence, Menlo Park, CA; Cambridge, MA; London; AAAI Press; MIT Press; 1999, 2005, p. 1541.

Sakoe, H.; Chiba, S. Introducing speech and language processing. Cambridge, U. K.: Cambridge University Press, 301 p., 2005.

Schilit, B.; Golovchinsky, G.; Price, M. Beyond paper: supporting active reading with free form digital ink annotations. In: Proceedings of the SIGCHI conference on Human factors in computing systems, ACM Press/Addison-Wesley Publishing Co., 1998, p. 249-256.

Schlömer, T.; Poppinga, B.; Henze, N.; Boll, S. Gesture recognition with a Wii controller. In: Proceedings of the 2nd international conference on Tangible and embedded interaction, New York, New York, USA: ACM, 2008, p. 11-14.

Disponível em http://portal . acm.org/citation. cfm?id=1347390.1347395

Schwesig, C.; Poupyrev, I.; Mori, E. Gummi: a bendable computer. In: Proceedings of the SIGCHI Conference on Human Factors in Computing Systems, CHI '04, New York, NY, USA: ACM, 2004, p. 263-270 ( $\mathrm{CHI}$ '04, ).

Disponível em http://doi.acm.org/10.1145/985692.985726 
Truong, K.; Abowd, G.; Brotherton, J. Who, what, when, where, how: Design issues of capture \& access applications. In: Ubicomp 2001: Ubiquitous Computing, Springer, 2001, p. 209-224.

W3C XML Schema Part 0: Primer Second Edition. 2004a.

Disponível em http://www.w3.org/TR/xmlschema-0/

W3C XML Schema Part 1: Structures Second Edition. 2004b.

Disponível em http://www.w3.org/TR/2004/REC-xmlschema-1-20041028/ structures.html

W3C XML Schema Part 2: Datatypes Second Edition. 2004c.

Disponível em http://www.w3.org/TR/2004/REC-xmlschema-2-20041028/ datatypes.html

W3C EMMA: Extensible MultiModal Annotation markup language. 2009.

Disponível em http://www.w3.org/TR/emma/

Want, R.; Hopper, A.; Falcao, V.; Gibbons, J. The active badge location system. ACM Transactions on Information Systems (TOIS), v. 10, n. 1, p. 91-102, 1992.

Weiser, M. The computer for the 21st century (este artigo foi originalmente publicado na scientific american, vol. 265, no. 3 (september 1991), pp. 94-104). SIGMOBILE Mob. Comput. Commun. Rev., v. 3, n. 3, p. 3-11, 1999.

Westeyn, T.; Brashear, H.; Atrash, A.; Starner, T. Georgia tech gesture toolkit: supporting experiments in gesture recognition. In: Proceedings of the 5th international conference on Multimodal interfaces, ACM, 2003, p. 85-92.

Disponível em http://portal.acm.org/citation.cfm?id=958452 